\title{
The development of the Imperfect in Ancient Greek from simple past to imperfective as a blocking phenomenon
}

\author{
Ian Hollenbaugh \\ University of California, Los Angeles, CA, USA \\ ihollenbaugh@humnet.ucla.edu
}

\begin{abstract}
This article seeks to combine the viewpoints of formal semantics and pragmatics, typology, historical linguistics, and philology, in order to give a diachronic overview of the semantic and pragmatic changes observable for the Imperfect indicative within the recorded history Greek. Since its development does not adhere to typologically expected stages of semantic change, I provide a pragmatic account by taking into consideration not only the Imperfect but also the rest of the past-tense system of Greek, namely the Aorist and Perfect. With this holistic approach, I am able to motivate a development that is otherwise typologically anomalous.
\end{abstract}

\section{Keywords}

Ancient Greek verbs - diachronic semantics and pragmatics - tense and aspect - neutral aspect - imperfective/perfective systems - blocking

Let me say straightaway that for all the acute and careful attention that has been paid to the use of the aorist and imperfect, we have yet to achieve a full understanding of them.

WACKERNAGEL 1926-1928 [2009]: 221 


\section{Introduction}

\subsection{Problematization}

The Imperfect (Ipf.) in Ancient Greek is typically described as expressing imperfective aspect (ipfv.) in the past (e.g., Comrie 1976: 17 and passim; Ö. Dahl 1985: 83; Napoli 2006: 64-70), and it is said that it "characterizes the state of affairs as 'not completed"' (Rijksbaron 2002:11). Such descriptions run into trouble, however, when it comes to data like that in (1), which shows the Imperfect in Homer characterizing states of affairs as complete and occurring side by side with Aorists (Aor.) in sequential past narration (cf. Delbrück 1879: 105-106). In all numbered examples of this paper the relevant verb and its translation are in boldface. Underlining is used for other contextual (mostly adverbial) information in the passage that helps motivate the particular interpretation of the verb that I favor, or which is relevant to the reading in some way but is not the primary focus of the example.

(1) Imperfect characterizing a state of affairs as complete

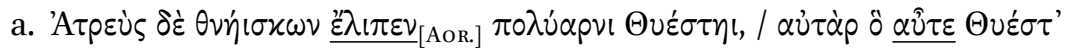

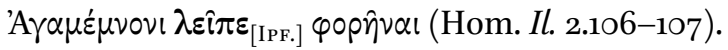

'And Atreus, upon his death, left ${ }_{\text {[AоR.] }}($ the scepter) to Thyestes rich

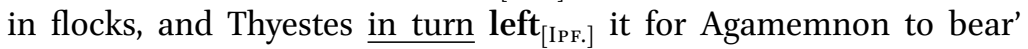
(ex. Wackernagel 1926-1928 [2009]: 235). ${ }^{1}$

1 On this example, cf. Crespo 2014: 74: "The conclusion to be drawn is that the imperfect may refer to an action that is either simultaneous or subsequent to the action denoted by the aorist" (emphasis added). Some have made the (ad hoc) claim that the Imperfect is used here to indicate that the event has lasting effects, since Agamemnon is the one who remains in possession of the scepter at this point in the narrative (Chantraine 1953 [2015]: 224-225; cf. Rijksbaron 2002: 18-19). However, the leaving event is in every sense complete by this time (Thyestes is not in the process of leaving the scepter behind); what is still ongoing is the bearing event expressed by the Present (Pres.) infinitive $\varphi$ op $v$ val. Agamemnon's continued bearing of the scepter is true independent of Thyestes' action of leaving it behind, which is an event located completely in the past. And if the continued effects of the leaving event were at issue, we might, if anything, rather expect an Aorist to be used (as, e.g., at Il. 10.406), signifying 'has left', since the Aorist is the form regularly used in Homer to refer to "result states," or states continuing as a result of a past action (see Appendix § A.1.3 and cf. Chantraine 1953 [2015]: 214; Schwyzer-Debrunner: 281-282; Wackernagel 1926-1928 [2009]: 227; Delbrück 1879: 107108, 1897: 280-281). Cf. also Friedrich 1974: 10: "The imperfect, unlike the present [and] aorist ... may not run into or include the time of the present speech situation." Further, many occurrences of the verb $\lambda \varepsilon i \pi \omega$ 'leave' in the Imperfect do not show continued effects, such as $I l$.

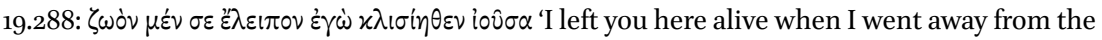
shelter' (to a now dead Patroclus; cf. similarly Od. 4.112), while the Aorist can be used for leav-

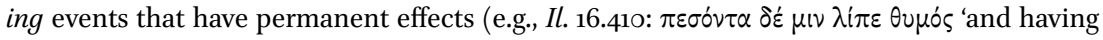
fallen his spirit left him'). 


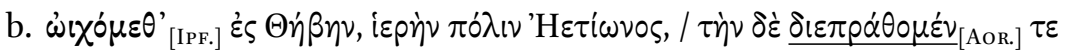

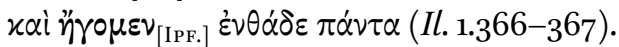

'We went ${ }_{[\mathrm{IPF}]}$ to Thebes, the holy city of Eetion, and then we $\underline{\text { sacked }}_{[\mathrm{AOR} .]}$ it and led ${ }_{[\text {IPF. }}$ hither all (its spoils).' ${ }^{2}$

The use of the Imperfect to characterize states of affairs as complete continues into Classical Greek prose as well (cf. Rijksbaron 2002: 18-19, with examples, as well as (11)-(12) in $\S 5.2$ and Appendix § A.2.6). To explain such uses of the Imperfect, where one might "expect" an Aorist, Delbrück (1879: 105) points out that, from an Indo-European perspective, "Das alte Tempus der Erzählung ist das Imperfectum und nicht der Aorist" ("The old tense of narration is the Imperfect and not the Aorist'), comparing the use of the Greek Imperfect's formal counterparts in Sanskrit and Iranian, which characterize states of affairs as complete almost invariably, very often ordering such events chronologically in sequential narration of the past. Wackernagel (1926-1928 [2009]: 235) concludes likewise, as follows:

Often, particularly in early Greek and later in the most polished prose, to our way of thinking imperfect and aorist are used completely interchangeably in reports about the past ... Homer has in fact many imperfects which serve as straightforward narrative forms, without depicting the action or the process any more than the corresponding aorist. We simply have to recognize, especially in view of comparison with related languages, above all Sanskrit, that the imperfect was often the narrative tense, just as later Herodotus and Thucydides generally use the imperfect in plain narrative. [emphasis added]

The problem, of course, is that perfective aspect (pfv.) is typically defined as characterizing states of affairs as complete (Comrie 1976: 18-20), whereas the imperfective aspect is supposed to depict events as incomplete. So, the Homeric Imperfect is at odds with the typical definitions of both perfective and imperfective aspect, in that it can be used to characterize states of affairs as either complete or incomplete. In view of its commonly supposed association with imperfective aspect, then, the question arises: How can the Imperfect represent an imperfective category if it is so regularly used to characterize states of

2 The linear order of the Aorist and Imperfect in (1a) and ( $1 \mathrm{~b}$ ) is not informative, as some have supposed, given that the opposite order is often attested as well, as in (24a) in Section 6.3.1 below (cf. also Il. 1.446-447). 
affairs as complete? The most recent answer to this question, argued for in Hollenbaugh 2018, is that the Homeric Imperfect simply does not mark imperfective aspect and does not represent what in the typological literature is referred to as an "imperfective gram" (cf. n. 4 below). Rather, the Homeric Imperfect is found to be neutral in aspect-permitting perfective- and imperfective-like interpretations of the verbal predicate - and is best classified as an instance of the cross-linguistic category called "simple past" (similar, for example, to the English Preterite). The Homeric Aorist, meanwhile, marks not perfective aspect simply but is found regularly to have a perfect-like value, especially resultative (i.e., indicating that the state resulting from the completion of the past event referred to by the verb still holds at the moment of utterance). So, the difference between the Imperfect and Aorist to the same verb in Homer, if any, ${ }^{3}$ is typically that the Aorist can be used with a resultative value (cf. $n .53$ and n. 57 below), as in (2a), while the corresponding Imperfect, when it refers to a completed state of affairs, is instead used to sequence events narrated in the past - a context in which the Aorist is also regular-as seen in (2b) (cf. Bianconi 2019: 177-179 on these examples).

(2) Imperfect vs. Aorist to the same verb in Homer

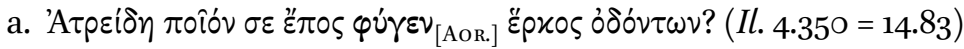

'Son of Atreus, what kind of word has escaped ${ }_{[\mathrm{AOR} .]}$ the fence of your teeth?'.

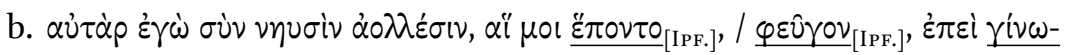

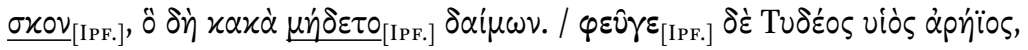

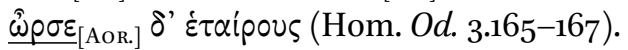

'But I with the crowded ships that were following ${ }_{[\text {[PF.] }}$ me took flight ${ }_{[\text {IPF. }}$ ', when I realized $_{[I P F \cdot]}$ that a divinity was intending ${ }_{[[\mathrm{PF} .]}$ evil. And the warlike son of Tydeus fled ${ }_{[I P F]}$ and $\underline{\text { urged on }}_{[\text {AoR.] }}$ his companions'.

Thus it can be said that $\varphi \dot{\gamma} \varepsilon \varepsilon$ characterizes the action FLEE as complete in the past and occurs in contexts where the result state either persists at speech time ('has fled') or not ('fled'). The Imperfect $\varphi \varepsilon \hat{\gamma} \varepsilon$, on the other hand, characterizes the action FLEE as either complete in the past ('fled') or incomplete in the past ('was fleeing, used to flee, etc.').

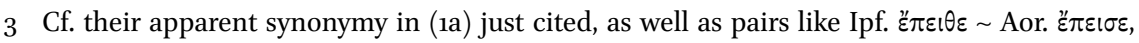
both of which are attested in Homer with the meaning 'persuaded', though the former can also have the conative value 'urged' (Wackernagel 1926-1928 [2009]: 235). 
Assuming the account of the Aorist and Imperfect given in Hollenbaugh 2018 is correct for the Homeric language, the question remains open how these morphological categories are to be understood in the rest of Ancient Greek literature: in particular, What, if any, changes in usage can be observed over time, and how can they be accounted for? Problematically for the account of Hollenbaugh 2018, the Imperfect of the later authors does appear to be more "imperfective-like" (cf. Johanson 200o: 95, 98-99), in that it regularly characterizes states of affairs only as incomplete in the past and becomes less and less regular in contexts where the event is presented as complete in the past, where instead the Aorist is most common (or, in post-Classical Greek, sometimes the Perfect (Pf.)). This amounts to a diachronic change whereby the range of expression available to the Greek Imperfect is reduced over time (often called semantic "strengthening"), such that in Homer (Archaic Greek) the Imperfect regularly characterizes states of affairs as either complete or incomplete, but in the later language it regularly characterizes states of affairs only as incomplete. To account for this change ends up posing some difficulty given the state of typological studies on diachronic aspect shifts. In particular, the change observed for the Greek Imperfect does not conform to well-established paths of change described in the linguistic literature on tense-aspect systems.

Two robustly attested grammaticalization pathways for tense-aspect gram types ${ }^{4}$ are shown in (3) (cf. especially Bybee et al. 1994; Deo 2015b; Condoravdi \& Deo 2014).

(3) Grammaticalization pathways (robustly attested across languages)

a. stative-resultative $>>$ perfect $>>$ emergent perfective $>$ perfective, simple past

b. progressive $>>$ general imperfective, simple present

These cross-linguistic grammaticalization pathways have in common that the range of expression available to a particular form tends to increase over time rather than decrease (or to "weaken" rather than "strengthen," to use a com-

4 "Gram type" refers to a cross-linguistically motivated morphological category. A "gram" is any instantiation of such a category in a language or languages, irrespective of what the form happens to be called in that language's grammatical tradition. On these terms cf. Bybee \& Dahl 1989 and Ö. Dahl 2000: 7. On the notion of cross-linguistic categories vs. comparative concepts cf. n. 12 below. As is conventional (at least since Comrie 1976), I capitalize the names assigned to morphological categories within their own grammatical traditions, while lower case is used for gram types and distributive reference to grams across languages (e.g., "the imperfectives in Romance"). 
mon metaphor). So in (3a), for instance, the perfective gram type has a broader range of contextual applications than does the perfect gram type, since (among other things) perfectives can be used to sequence events in past narration, while perfect grams typically cannot (Condoravdi \& Deo 2014: 266). ${ }^{5}$ At the same time, perfective grams are commonly found in resultative and experiential (i.e., "perfect-like") functions cross-linguistically. Taken together, this means that perfectives uniformly have a wider functional range than perfects, as they can be used in all the contexts that perfects can, plus some other contexts that are unavailable to perfect grams (id.). An example of the change from a perfect to a perfective gram is the French Passé Composé, which originally had only "perfect-like" functions but now is functionally perfective, being used to sequence complete events in past narration, while still retaining its perfect-like uses as well (cf. Bybee et al. 1994).

Likewise, progressive grams ( $3 \mathrm{~b})$ tend to develop into general imperfectives (Deo 2015b): Though both can characterize an event as being in progress (type was doing $X$ ), only the latter can be used in generic-habitual or continuousstate values (respectively of the type used to do $X$ and knew $X$ (NB: *was knowing $X$ ); cf. Deo 2015b:4). The English Progressive may be an example of this change in progress (cf. Comrie 1976: 37-38; see Deo 2015b: 6-8 for examples from other languages). In this way, each gram type in (3) (explained in more detail below) can be seen to always have a wider range of application than the gram type(s) to its left, and the grams belonging to these gram types tend to change in linear order from left to right over time in the languages of the world, with changes in the opposite direction being scarce. So, for example, a general imperfective in a given language is predicted not to become restricted to use only as progressive at a later stage in the development of that language. Accordingly, these paths of change are observed to be "unidirectional" and "uniformly generalizing" by Condoravdi \& Deo (2014: 261-262).

Given these typological facts, the development of the Greek Imperfect from being aspectually neutral in Homer to imperfective later on, if accurate, would pose a serious challenge to the generalizations in (3), in that its meaning seems to become more specific over time rather than more general (cf.Johanson 2000: 95, 98-99). The Greek Imperfect is thus, on the face of it, typologically aberrant and cannot be accounted for in terms of semantic "weakening" of the typical sort. Its development can therefore be better explained by a pragmatic account

5 Concretely, Condoravdi \& Deo (2014: 266) note that one cannot say \#John has iced the cake. He (then) went/has gone shopping but must say instead John iced the cake. He (then) went shopping. 
of the data, with reference to the entire Greek past-tense system, particularly the Imperfect's interaction with the Aorist and Perfect, whose semantic denotations are in flux along the trajectory in (3a). Pressures from these changing categories restrict the usage of the Imperfect in particular ways without affecting its semantic denotation until late in the history of Ancient Greek.

\section{$1.2 \quad$ Structure of the paper}

The rest of this paper is organized as follows: Section 2 restates the research question and proposal in straightforward terms. Section 3 establishes the typological and theoretical groundwork necessary for understanding the analysis put forth in the later sections. Section 4 lays out the assumptions of this paper in terms of linguistic stages of Ancient Greek, my methods of data collection and assessment of evidence, including discussion of the usage labels ascribed to the various functional categories, and an account of which forms are under consideration and which are excluded and why. Section 5 presents all of the readings regularly available to each functional category $(=$ morphological form or "gram") at each stage, according as I have been able to determine on the basis of the procedures and evidence given in the appendix (on which see the next paragraph). Some discussion is given, with relevant examples, insofar as it establishes the overall trend in usage from one stage to the next. Once the facts of the three linguistic stages have been established in Sections 5.1-5.3, the diachronic development of the functional categories is examined in more detail in Sections 5.4-5.5. The analysis is presented in Section 6, which includes a formalization of each denotation for each functional category at each stage of development, such that exactly those readings observed to be available to each form in Section 5 are available under the denotations provided. Also included is discussion of the pragmatic processes that influence the change in usage observed for the Imperfect up to the post-Classical stage (Section 6.2) and its subsequent reinterpretation as an imperfective gram (i.e., semantic change) in the later linguistic stages of Greek (Section 6.1.4). The pragmatic processes at work in Ancient Greek are further explored in Section 6.2 and Section 6.3. Section 7 summarizes and concludes.

I have also created an appendix $(\S \mathrm{A})$ containing information and examples for all readings established in Section 5 (except pluractional and habitual readings), so that the reader can see on what bases the functional ranges assumed for each category rest. This is divided into three subsections, corresponding to Tables 8-10 and the three linguistic stages of Ancient Greek adopted here. It is available online (see p. 141) as an essential supplement to this paper, and the reader is encouraged to consult it wherever questions arise regarding the various readings here discussed. To make such consultation easier, I give references 
to the appendix throughout, where applicable, by section number and example number (which always begin with the letter $A$ ).

\section{$2 \quad$ Proposal}

Following Hollenbaugh 2018, I assume that the Greek Imperfect started off (i.e., in its earliest attestations) as what in the typological literature is called a "simple past tense," which is aspectually neutral, while the Aorist was in Homer a kind of late-stage perfect, which I will call here emergent perfective. ${ }^{6}$ Though descriptions of the Imperfect at later stages of Greek seem to suggest that its meaning strengthens over time (from simple past to imperfective; cf. Goodwin 1889: 7-8, 25), I argue that, in fact, its denotation remains stable, at least until the end of antiquity. Its apparent functional restriction over time is explained as a blocking phenomenon on the part of the Aorist (less so the Perfect and Pluperfect (Plpf.)), which demonstrably becomes more and more grammaticalized as a perfective gram within the attested history of Greek. In addition to accounting for the observed data, this pragmatic account maintains that Ancient Greek is, strictly speaking, not an exception to the typical semantic developments of (3).

\section{3}

\section{Typological and theoretical preliminaries}

There are basically three things one can mean when referring to "an imperfective," which I classify into three Types (capitalized to differentiate these from "gram types"), presented in Table 1 . The pseudo-denotations in Table 1 are deliberately crude and greatly simplified, in order to give a "big picture" overview of the Types. Far more sophisticated formalisms and analyses are available, e.g., in Deo 2015b; Condoravdi \& Deo 2014; Altshuler 2014; Arregui et al. 2014; Grønn 2008a,b.

In Table $1, t_{\mathrm{E}}$ stands for an interval called "eventuality time." "Eventuality" refers to states and events taken together (Bach 1981, 1986), on which cf. n. 18 below. $t_{\mathrm{A}}$ stands for "assertion time." Assertion time (Demirdache \& UribeEtxebarria 2000) is also called "topic time" (Klein 1994: $36-58$ ) or "reference time" (Reichenbach 1947), though precise notions vary (cf. Ramchand 2018:

6 This term is explained and defined in Section 6.1.1 below. On the category, see Laca 2010: 6-7 ("bad perfect") and Bybee et al. 1994: 78-81 ("old anterior"). 

Types:
1. imperfective allows $t_{E} \supset t_{A}$
2. imperfective allows $t_{E}=t_{A} \quad 3$. "imperfective" allows $t_{E} \subset t_{A}$
Denotations:
$\mathrm{t}_{\mathrm{E}} \supset \mathrm{t}_{\mathrm{A}}{ }^{\mathrm{a}}$
$t_{E} \supseteq t_{A}$
$t_{\mathrm{E}} \circ \mathrm{t}_{\mathrm{A}} \mathrm{b}$
Examples:
Central Semitic, Romance ${ }^{c}$
Eastern Slavic ${ }^{\mathrm{d}}$
Sanskrit, Western Slavic ${ }^{\mathrm{e}}$

a Cf., e.g., Klein 1994: 108; Arche 2006: 172-173; Grønn 2008a: 155, 157 (precise implementations vary).

b This is Grønn's (2004) and E. Dahl's (2010: 88) "neutral aspect," based on Smith's (1997: 77-81) "neutral viewpoints." Note, however, that Grønn (2008b: 127) defines the Russian Imperfective with a disjunction: $t_{E} \supseteq t_{A}$ or $t_{E} \subseteq t_{A}$, which he notes amounts to essentially the same thing as $t_{E} \circ t_{A}$.

c Grønn (2008a: 158) claims that the imperfectives in Romance must belong to what I call Type $2\left(t_{\mathrm{B}} \supseteq \mathrm{t}_{\mathrm{A}}\right)$ to allow for the "narrative Imperfect." This usage, however, occurs mostly to achievement predicates (id.: 159-161) and requires specific reference "to a definite point in time" (Arregui et al. 2014: 335).

d The "general-factual" Imperfective is taken to denote the coextension relation, $t_{E}=t_{A}$, which most often corresponds to "complexive" uses, as is clear from examples and discussion in Ö. Dahl 1985: 74-77; Altshuler 2014; Arregui et al. 2014: 330-334; Janda \& Fábregas 2019: 699-708 (though it also has "experiential" perfect uses). Janda's (2019:498) metaphor that the "Imperfective situation can fill whatever time is available" is thus captured quite nicely by this denotation. Note that complexive or "general-factual" uses of the Russian Imperfective "can never move the narration forward" (Grønn 20o8a: 151), though this appears not to be true of the complexive uses in Greek.

e Dickey (2015, 2000, 1997: 90-115) shows that the Eastern Slavic group, including Russian, does not use the Imperfective in sequential narration (similarly Arregui et al. 2014: 335), while the Western Slavic group does. However, the Western Slavic Imperfect is, according to Dickey (1997: 102), "unsuitable to refer to single achievements in the past" (in contrast to the Sanskrit type), while the Eastern Slavic Imperfective allows this (id.: 103).

106-107). Put simply, assertion time is the interval about which some claim is made (i.e., asserted), with respect to which the runtime of the eventuality is said to hold and may be assessed as either true or false. For instance, if I say, "What was your name again?" I do not typically mean to ask what your name was in the past and is no longer; rather, I am asking what it was that you told me your name is. The eventuality BE YOUR NAME in this case holds at the moment of my speech act, but the assertion time interval — the interval that is being asked about - is located in the past relative to my speech act, and so the past tense was your name is used. Tense is therefore defined (following Klein 1994: $4-5,124)$ as a relation between the temporal parameters assertion time $\left(t_{A}\right)$ and speech time $\left(t_{s}\right.$, defined just below). ${ }^{7}$ Counterintuitively, then, it does not matter for tense where the eventuality time interval is located with respect to speech time. Aspect, on the other hand—that is, "grammatical" or "viewpoint"

7 Or, more precisely, tense is defined as a relation between assertion time $\left(t_{A}\right)$ and the time of local evaluation $\left(\mathrm{t}_{0}\right)$, introduced below. 


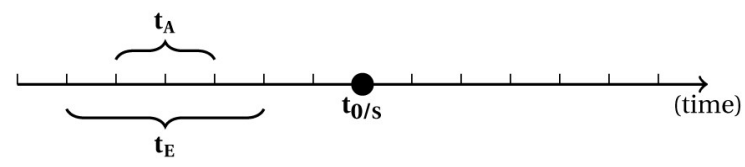

FIGURE 1 Progressive/continuous-state and habitual interpretations, past tense

(available to Type 1, 2, and 3 imperfectives)

aspect (as opposed to "Aktionsart" or "lexical aspect," cf. Smith 1997: 61 ff.) -is defined as a relation of the two temporal parameters eventuality time $\left(t_{\mathrm{E}}\right)$ and assertion time $\left(\mathrm{t}_{\mathrm{A}}\right)$. Various specific aspect types and "readings" can be defined by the several relations that can hold between these two temporal parameters. Thus, $t_{E}$ can include/properly include $(\supset / \supset)$, be included/properly included in $(\subseteq / \subset)$, coextend with $(=)$, or overlap with $(\circ) \mathrm{t}_{\mathrm{A}}$. I will later introduce the precedence $(<)$ and partial precedence $(\leq)$ relations as well (cf. n. 5 o below).

The denotation of Type 1 imperfectives in Table 1 says that eventuality time properly includes assertion time $\left(t_{\mathrm{E}} \supset \mathrm{t}_{\mathrm{A}}\right)$, meaning that the coextension of the two intervals is ruled out. In terms of "readings," Type 1 permits (i.e., may be interpreted in some context as) what are commonly called the progressive/ continuous-state (e.g., I was running/sleeping) and habitual (e.g., I used to run) imperfective uses. I represent this in Figure 1. Here and below, $t_{s}$ stands for "speech time" (also called "utterance time" or "time of utterance"): the point or interval at which the utterance or speech act is made (typically the "now" of the present moment). The speech time may be thought of as a special case of the broader term "evaluation time" $\left(\mathrm{t}_{0}\right)$, which technically does not need to coincide with $\mathrm{t}_{\mathrm{s}}$ (it can be past or future "shifted") but most often does, as a kind of default case. The term evaluation time $\left(t_{0}\right)$ will be more fully introduced in the denotations of Section 6.1 below (see n. 42). The term $t_{0 / s}$ is meant to be read "speech time or time of local evaluation," used to indicate that speech time is to be understood by default but that past or future shifting are not excluded from consideration.

It is sometimes assumed that the coextension relation $t_{E}=t_{A}$ with an event cardinality greater than 1 represents the habitual reading (e.g., E. Dahl 2010: 7172). It is not uncommon, however, to regard the habitual reading as compatible with the proper inclusion relation $\left(t_{\mathrm{E}} \supset \mathrm{t}_{\mathrm{A}}\right)$, which I follow here (cf. Klein 1994: 108; Arche 2006: 173; Grønn 2008a: 155, 157). Others have proposed modal analyses for habitual readings (e.g., Boneh \& Doron 2010: 343, 358-36o, 362-363; Arregui et al. 2014: 317, 343). Such accounts of habituality seem quite attractive, and it is highly likely that more machinery is necessary to adequately account for habituality than I have represented here in my deliberately simplified denotations. I thus treat the habitual reading (artificially) as purely aspectual in 


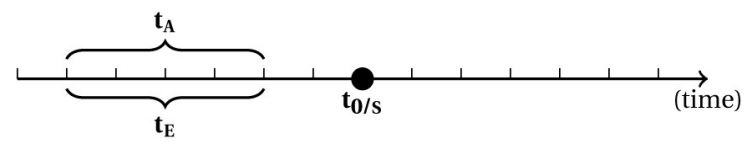

FIGURE 2 Complexive interpretation, past tense (available to Type 2 and 3 imperfectives)

nature, while acknowledging that this is not the whole story. For the purposes of this analysis, however, what matters is that the given denotations be compatible with all readings attested for the form in question. In this capacity, $t_{E} \supset t_{A}$ is sufficient to capture the readings available to Type 1 imperfectives.

The denotation of Type 2 imperfectives in Table 1 , by contrast, says that eventuality time includes assertion time $\left(t_{\mathrm{E}} \supseteq \mathrm{t}_{\mathrm{A}}\right)$, allowing either total inclusion of $t_{A}$ within $t_{E}\left(t_{E} \supset t_{A}\right)$ or coextension of the two intervals $\left(t_{E}=t_{A}\right)$. Type 2 thus permits a reading not permitted by Type 1 , namely the "complexive" reading (e.g., I slept all night), which I take to be captured by the coextension relation $\mathrm{t}_{\mathrm{E}}=\mathrm{t}_{\mathrm{A}}$ and represent in Figure 2, showing how the entire span of $t_{A}$ is saturated by $t_{E}$ (as applied to a non-transformative ${ }^{8}$ eventuality like SLEEP).

As for the Type 3 "imperfective" in Table 1, it requires only that the two intervals overlap $\left(t_{E} \circ t_{A}\right)$, thus permitting the inclusion of either interval within the other $\left(t_{E}\right.$ includes $t_{A}$ or $t_{E}$ is included in $\left.t_{A}\right)$ and the coextension of the two intervals $\left(t_{\mathrm{E}}=\mathrm{t}_{\mathrm{A}}\right)$. The main difference between Type 3 and the other two types is that Type 3 permits a reading that I call "concentrative" $\left(t_{E} \subset t_{A}\right),{ }^{9}$ so called in

8 The term transformative refers to accomplishments and achievements taken together (cf. n. 18 below), in contrast to non-transformative, which groups states and activities together (Ruipérez 1954). This terminology is more precise in referring to natural classes of situation types than the "telic" vs. "atelic" opposition, since telicity operates at the verb phrase (VP) level, including at least internal arguments of the verb (cf., e.g., E. Dahl 2010: $135 \mathrm{ff}$.), whereas the transformative/non-transformative contrast targets just the verb itself without its arguments. When verbal arguments are taken into account, the telic/atelic contrast is used. Telic refers to a predicate (VP) that has an inherent endpoint, such as write a letter or walk to the park (whose verbs are both non-transformative, the activities write and walk). Atelic refers to a predicate (VP) that lacks an inherent endpoint, such as write letters or walk in the park. For the various situation types/predicate types, see n. 18 below (cf. Vendler 1957; Moens \& Steedman 1988; Smith 1997: 27-9o).

9 For the term concentrative (cf. Appendix § A.1.6) see Smyth 1956: 430-431 (though in a sense closer to what is here called "complexive"). The term goes back at least to Krüger (1873: 168) ("konzentrierte Erscheinung"), in reference to the "summarizing" use Aorist to atelic predicates. I use the term in a more restricted way, referring to events (i.e., non-states) and stagelevel states (cf. $n$. 18 below) for which the span of the eventuality time is fully included in the assertion time $\left(t_{E} \subset t_{A}\right)$. Such a relation is not possible for individual-level state predicates (cf. n. 18), which can be terminative only in the inceptive or complexive readings. 


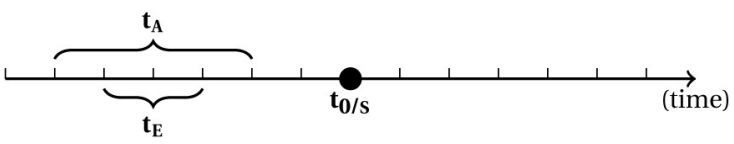

FIGURE 3 Concentrative interpretation, past tense (available to Type 3 "imperfectives" (= simple pasts))

reference to its "concentration" of the event entirely within the bounds of the assertion time. The concentrative reading is regularly found in sequential narration, where eventualities are characterized as complete in the past (of the type Mary ate the cake, then went to bed $).{ }^{10}$ While sequential narration is typically concentrative, the concentrative relation $\left(t_{E} \subset t_{A}\right)$ may in fact hold even in isolated, non-sequential contexts, such as Mary ate the cake (and did nothing else of relevance) while I was away. Accordingly, a form that has concentrative as a use is not automatically preferred in sequential narration (as shown by post-Classical Greek, discussed below). I will therefore specify sequential or concentrative-sequential wherever a form is regularly used in sequential contexts, while concentrative is used where no such specification is necessary or relevant. I represent the concentrative reading in Figure 3.

I thus distinguish in Figures 2 and 3 two main types of what I will call "terminative" readings, which are not a priori restricted to any particular morphosyntactic category. I use the term terminative to mean that the eventuality is 'bounded' by assertion time (cf. E. Dahl 2010: 73-76), designating the total set of readings compatible with the relation $t_{E} \subseteq t_{A}$. Terminative interpretations may be either concentrative $\left(t_{E} \subset t_{A}\right)$ or complexive $\left(t_{E}=t_{A}\right)$, depending on context and situation type of the predicate (activity, achievement, state, etc.). ${ }^{11}$ Other

The concentrative reading is variously known in the literature as "confective," "metaptotic," "completive," "eventive," "perfective," "momentary," “narrative," "resultative," "effective," and "episodic," with little consistency in what these labels actually refer to (cf., among others, Schwyzer-Debrunner: 26o-261 and E. Dahl 2010: 76, 82).

10 Sequential narrative uses "represent the perfective reading par excellence" (E. Dahl 2010: 78).

11 Complexive (cf. Appendix § A.1.9) here refers to a terminative use in which a non-transformative eventuality (cf. n. 8 above) is bounded not by its inherent situation type or telicity but by the limits imposed on it by the morphological form that takes it as an argument (cf. Bary \& Egg 2012; E. Dahl 2010: 73-76, 82), such that $t_{\mathrm{E}}$ is coextensive with (=) $t_{A}$ in the past $\left(t_{A}<t_{0}\right)$. For the term see Smyth 1956: 430-431, though in a broader sense than what I mean by complexive here. The term "komplexiv" was apparently coined by Hermann (1927: 208). It is also called in the literature "constative" (Purdie 1898: 67-68; Jacobsohn 1933: 305-309), "terminative" (E. Dahl 2010: 73-76, 82), "concentrative" (Smyth 1956: 430-431), "factive" ("statement of fact"), "totalitarian" (cf. Schwyzer-Debrunner: 261), 
subcategories of the terminative relation $t_{E} \subseteq t_{A}$ include the inceptive and egressive readings (discussed below).

Typologically speaking, imperfective Types 1 and 2 are taken to constitute the imperfective gram type (cf. Ö. Dahl 1985: 69-79) and may be said to express imperfective aspect $\left(t_{\mathrm{E}} \supseteq t_{A}\right)$. Type 3 , on the other hand, represents not the imperfective but the simple past gram type (Bybee et al. 1994: 84-85, 92-95; Klein 1994: 102; Comrie 1976: 53, 55, 58), which may be said to be neutral in aspect $\left(t_{\mathrm{E}} \circ \mathrm{t}_{\mathrm{A}}\right)$ (following Smith 1997: 77-81; Grønn 2004; E. Dahl 2010: 88). Accordingly, I will hereinafter refer to Type 3 "imperfectives" as simple past grams, since this is a more accurate characterization based on their functional range-i.e., expressing any sort of aspectual relation between $t_{E}$ and $t_{A}$ in the past (where past is defined as the relation $\mathrm{t}_{\mathrm{A}}<\mathrm{t}_{0 / \mathrm{s}}$ (assertion time precedes speech/evaluation time)). The aspect expressed by a simple past tense will be

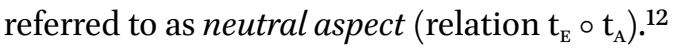

The contrast between imperfective Types 1 and 2 is exemplified by Janda \& Fábregas (2019: 700), showing how Russian (like Eastern Slavic generally) uses its past Imperfective for sentences like I read all night (čital vsju noč) where Spanish, like Romance generally, must use its "Preterite" or past perfective (leyó toda la noche $)$. As is suggested by these examples, the perfective gram type $\left(t_{\mathrm{E}}\right.$ $\subseteq \mathrm{t}_{\mathrm{A}}$ ) must also come in at least two varieties (Types): The "Spanish type" (Type $1, t_{E} \subseteq t_{A}$ ) and the "Russian type" (Type $2, t_{E} \subset t_{A}$ ). Perfective grams characteristically have concentrative as a use (cf. Figure 3 above), but it depends on the language whether a perfective gram is open to complexive interpretation (cf. Figure 2 above) or not. The former will be said to be a Type 1 perfective, such that $\mathrm{t}_{\mathrm{E}} \subseteq \mathrm{t}_{\mathrm{A}}$ (coextension permitted, has the complexive reading, as in Spanish);

and a "phase interpretation" (Bary \& Egg 2012: 113). It is often taken to include the iterativepluractional reading, which I treat separately (cf. Jacobsohn 1933: 306-307; SchwyzerDebrunner: 261). On Purdie's (1898) (broader) use of the term constative, see Appendix § A.1.9, n. 65 .

12 The notions of "imperfective aspect," "perfective aspect," "perfect aspect," "neutral aspect," etc., as specified by their respective denotations, may be taken to correspond roughly to Haspelmath's (2010) notion of "comparative concepts," whereby typological data is classified according to certain pre-defined (idealistic) categories. By contrast, the "gram types" correspond to cross-linguistic categories (as in Bybee \& Dahl 1989) arrived at on the basis of observed cross-linguistic data, whereby "clusters" of (related or unrelated) languages showing similar behavior of their respective morphological forms can be said to possess the same "type" of morphological object (or "gram"). For each gram type thus identified, every gram belonging to it (i.e., across languages) will display a similar functional range (restricted to some observable threshold). I thus take an inclusive, "middle-way" approach to the ongoing debate about the validity of cross-linguistic categories vs. comparative concepts. 
TABLE 2 Aspectual systems differing by complexive use

\section{Imperfective Perfective}

\begin{tabular}{llll} 
Type 1: & Spanish & $\mathrm{t}_{\mathrm{E}} \supset \mathrm{t}_{\mathrm{A}}$ & $\mathrm{t}_{\mathrm{E}} \subseteq \mathrm{t}_{\mathrm{A}}$ \\
Type 2: & Russian & $\mathrm{t}_{\mathrm{E}} \supseteq \mathrm{t}_{\mathrm{A}}$ & $\mathrm{t}_{\mathrm{E}} \subset \mathrm{t}_{\mathrm{A}}$ \\
\hline
\end{tabular}

TABLE 3 Western Slavic aspect

$$
\begin{array}{ll}
\text { “Imperfective" } & \text { Perfective } \\
\text { (= simple past) } & \text { (Type 1) }
\end{array}
$$

Western Slavic $\mathrm{t}_{\mathrm{E}} \circ \mathrm{t}_{\mathrm{A}} \quad \mathrm{t}_{\mathrm{E}} \subseteq \mathrm{t}_{\mathrm{A}}$

the latter will be said to be a Type 2 perfective, such that $t_{E} \subset t_{A}$ (coextension not permitted, lacks the complexive reading, as in Russian).

Putting the two Types of imperfectives together with the two Types of perfectives just discussed, we can observe a systematic difference across languages, as shown in Table 2.

In other words, the Russian Imperfective is semantically slightly "weaker" (i.e., permits a broader range of interpretations) than the Spanish Imperfective, while the Spanish Perfective is slightly "weaker" than the Russian Perfective. Accordingly, Spanish encodes complexive readings by means of its Perfective morphology, while Russian does so with its Imperfective. Whichever form has the "stronger" denotation blocks the application of the semantically "weaker" form in just those contexts where the "stronger" form can apply.

This is also true in languages that have a simple past tense standing in contrast to a perfective, where the complexive use falls to the perfective (Dickey 2015: 30), which is the semantically stronger form, as shown in Table 3.

Similarly, as shown in Hollenbaugh 2018, Homeric Greek has an aspectual contrast of the type in Table $4 .{ }^{13}$ As the Homeric Aorist does not appear to regularly permit the coextension relation, the complexive reading (i.e., coextension of $t_{E}$ and $t_{A}$ in the past) is regularly expressed only by the Imperfect in Homer, as

13 The denotation of the Aorist is more complicated than what is relevant to show in Table 4. See (17) and accompanying discussion below for a more detailed account and full denotation of this "emergent perfective" gram. 


\begin{tabular}{lll}
\hline & $\begin{array}{ll}\text { “Imperfect" } \\
(=\text { simple past })\end{array}$ & $\begin{array}{l}\text { Aorist } \\
(=\text { emergent pfv. })\end{array}$ \\
\hline Homeric Greek & $\mathrm{t}_{\mathrm{E}} \circ \mathrm{t}_{\mathrm{A}}$ & $\mathrm{t}_{\mathrm{E}} \subset \mathrm{t}_{\mathrm{A}}$ \\
\hline
\end{tabular}

(4) demonstrates. ${ }^{14}$ Here, $\pi \alpha v v u ́ \chi 10 \varsigma$ 'all night long' overtly indicates the bounds of the assertion time interval $\left(t_{\mathrm{A}}\right)$, and the actions of the verbal predicates $\left(\mathrm{t}_{\mathrm{E}}\right)$ are asserted to last for exactly that long. Hence, the two intervals are coextensive, yielding the complexive reading.

(4) Complexive Imperfect in Homer

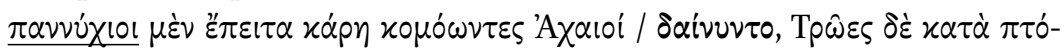

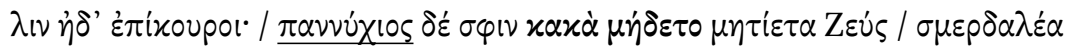

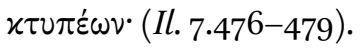

'Then, all night long the long-haired Achaeans feasted, and the Trojans likewise throughout the city, and their allies; and all night long Zeus, the counsellor, plotted harm against them, thundering terribly'.

Homeric Greek thus resembles the "Western Slavic type" system (cf. Table 1 above), in that it shows a simple past tense gram (= Type 3 "imperfective"), namely the Imperfect, rather than an imperfective gram (of Types 1 or 2 ). As mentioned earlier, despite the fact that the relation $t_{E} \supseteq t_{A}$ is compatible with the coextension relation and so with the complexive reading, the Imperfect of Homer cannot represent a Type 2 imperfective, since it is also compatible with use in sequential narration (unavailable under the relation $t_{E} \supseteq t_{A}$, as Russian shows (cf. Table 1 note e)).

By the time of Classical Greek, however, the Aorist (i.e., past perfective) competes with the Imperfect in the complexive use ( where $t_{E}=t_{A}$ ), as exemplified by (5).

(5) Complexive Aorist and Imperfect in Classical Greek

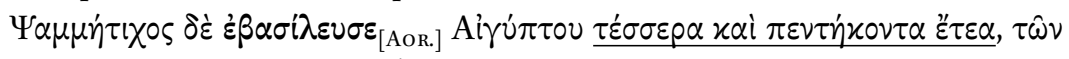

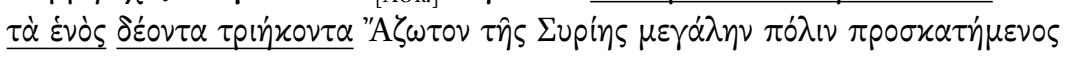

14 So conclude Purdie (1898: 70 "constative") and Jacobsohn (1933: 307-309), with very few possible exceptions discussed in Appendix § A.1.9. 


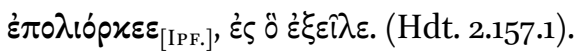

'Then Psammetichus ruled ${ }_{[\mathrm{AoR} .]}$ Egypt for fifty-four years, for twenty-nine

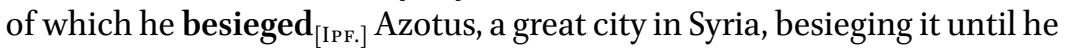
took it out' (ex. Basset 2009: 213-214). ${ }^{15}$

In addition, by the end of the Classical period and the beginning of the postClassical period, the Imperfect is no longer regular in sequential narration, where the Aorist or Perfect are employed almost exclusively (cf. discussion in $\S 5.3$ ), and is much more restricted in concentrative function generally. The complexive function of the post-Classical Imperfect is also greatly restricted, again in favor of the Aorist. The Greek of later antiquity thus comes to resemble the "Eastern Slavic type" system (with differences of detail), in that it shows an imperfective gram (of Type 2), namely the Imperfect, standing in contrast to a perfective gram (in this case of Type 1), namely the Aorist, as shown in Table 5 .

The basic claim of this paper is that, in terms of usage, the "Western Slavic type" Imperfect found in Homeric Greek (Type 3 in Table 1) develops into an "Eastern Slavic type" (Type 2) at least by the end of the Classical period. This ends up as a "Romance/Semitic type" (Type 1) Imperfective in Medieval and Modern Greek, as shown in Table 6. These developments are indicated by the Imperfect's gradual dispreference for (STAG ES II-III) and eventual loss of (STAGE IV) of its concentrative and complexive functions. Meanwhile, the Aorist undergoes semantic change along the typical grammaticalization pathway shown in (3a) above. Starting from an emergent perfective of Type 2 in Homeric $\left(t_{E} \subset t_{A}\right)$, it develops into a Type 1 perfective thereafter $\left(t_{E} \subseteq t_{A}\right)$, indicated by its gaining of regular complexive usage and significant decrease in "perfect-like" usage. In addition, by the time of Polybius (Plb.), the inceptive and egressive readings of the Aorist are restricted to prefixed forms of the verb (Purdie 1898). Table 6 has brief labels under each "mini-denotation," as a mnemonic to indicate, in practical, usage-based terms, how each semantic development is reflected in the functional rage of each category. Only the most important points are represented here, with the actual details being much more complicated and discussed in depth in the subsequent sections.

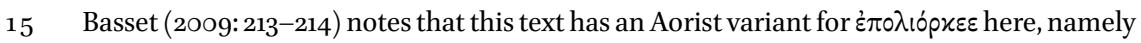
$\varepsilon \pi \circ \lambda$ ı́o $x \eta \sigma \varepsilon v$. The fact that the Imperfect precedes an 'until'-clause may be relevant as

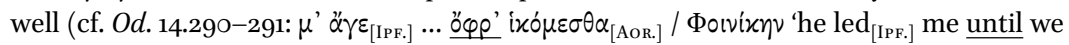
reached $_{\text {[Аов.] }}$ Phoenicia'). Cf. Janda \& Fábregas's (2019: 705-707) treatment of the Russian Imperfective as licensed by "time until," where Spanish has the Perfective. 
TABLE 5 post-Classical Greek aspect

\begin{tabular}{lll}
\hline & $\begin{array}{l}\text { “Imperfect” } \\
(=\text { Type 2 ipfv. })\end{array}$ & $\begin{array}{l}\text { Aorist } \\
(=\text { Type 1 pfv. })\end{array}$ \\
\hline post-Classical Greek & $\mathrm{t}_{\mathrm{E}} \supseteq \mathrm{t}_{\mathrm{A}}$ & $\mathrm{t}_{\mathrm{E}} \subseteq \mathrm{t}_{\mathrm{A}}$ \\
\hline
\end{tabular}

\begin{tabular}{|c|c|c|c|c|c|c|c|}
\hline & $\begin{array}{l}\text { Stage I: } \\
\text { Homeric }\end{array}$ & $>>$ & $\begin{array}{l}\text { Stage II: } \\
\text { Classical }\end{array}$ & $>>$ & $\begin{array}{l}\text { Stage III: } \\
\text { post-Classical }\end{array}$ & $>>$ & $\begin{array}{l}\text { Stage IV: } \\
\text { Medieval/Modern }\end{array}$ \\
\hline Imperfect & $\mathrm{t}_{\mathrm{E}} \circ \mathrm{t}_{\mathrm{A}}$ & $>>$ & $\mathrm{t}_{\mathrm{E}} \circ \mathrm{t}_{\mathrm{A}}$ & $>>$ & $\mathrm{t}_{\mathrm{E}} \supseteq \mathrm{t}_{\mathrm{A}}$ & $>>$ & $\mathrm{t}_{\mathrm{E}} \supset \mathrm{t}_{\mathrm{A}}$ \\
\hline Aorist & $\begin{array}{l}\mathrm{t}_{\mathrm{E}} \subset \mathrm{t}_{\mathrm{A}} \\
\text { (Ipf. sequ./cplxv., } \\
\text { frequ. pf. Aor. })^{\mathrm{b}}\end{array}$ & $>>$ & $\begin{array}{l}\mathrm{t}_{\mathrm{E}} \subseteq \mathrm{t}_{\mathrm{A}} \\
\text { (reg. cplxv. Aor.) }\end{array}$ & $>>$ & $\begin{array}{l}\mathrm{t}_{\mathrm{E}} \subseteq \mathrm{t}_{\mathrm{A}} \\
\text { (losing sequ./ } \\
\text { cplxv. Ipf.) }\end{array}$ & $>>$ & $\begin{array}{l}\mathrm{t}_{\mathrm{E}} \subseteq \mathrm{t}_{\mathrm{A}}^{\mathrm{a}} \\
\text { (lost conc./ } \\
\text { cplxv. Ipf.) }\end{array}$ \\
\hline
\end{tabular}

a Despite Hedin 200o: 227-228, cf. discussion in \$6.1.1.

b Abbreviations: sequ. = sequential, cplxv. = complexive, frequ. = frequent, reg. = regular, pf. = "perfect-like" readings (viz. resultative, experiential, stative), conc. = concentrative.

c See Hedin 200o: 229, 232-233.

Table 7 substitutes the denotations of Table 6 with their associated grams at each stage of development. For completion, I include here the (synthetic) Perfect as well, which is lost after antiquity (cf. BDF: 176). The "Types" (1 or 2 ) of each perfective and imperfective gram refer to those in Tables 1 and 2 above.

The change in usage of the Imperfect summarized in Tables 6-7 does not, however, entail a change in its denotation during the Ancient Greek period, since at Stages 1-3 the Imperfect is never incompatible with terminative (i.e., concentrative and complexive) uses, permitting interpretations such that $\mathrm{t}_{\mathrm{E}} \subseteq$ $t_{A}$ (i.e., "perfective-like" aspectual relations). Yet the application of the Imperfect in complexive or concentrative-sequential contexts becomes highly restricted in the Koine, being regularly blocked by the Aorist and Perfect in these functions. Thus, the Koine/post-Classical Imperfect may be understood as semantically identical to the Homeric/Archaic and Classical Imperfect $\left(t_{E} \circ t_{A}\right)$, even if its range of application has been pragmatically restricted in the manner shown in Tables 6-7 (discussed in detail below). When, however, the blocking of the Imperfect by the Aorist in complexive and concentrative-sequential contexts 
TABLE 7 Typological categories (i.e., "grams") in the diachrony of Greek aspect

\begin{tabular}{|c|c|c|c|c|c|c|c|}
\hline & $\begin{array}{l}\text { Stage I: } \\
\text { Homeric }\end{array}$ & $>>$ & $\begin{array}{l}\text { Stage II: } \\
\text { Classical }\end{array}$ & $>>$ & $\begin{array}{l}\text { Stage III: } \\
\text { post-Classical }\end{array}$ & $>>$ & $\begin{array}{l}\text { Stage IV: } \\
\text { Medieval/Modern }\end{array}$ \\
\hline Imperfect & simple past & $>>$ & simple past & $>>$ & $\begin{array}{l}\text { imperfective }^{\mathrm{a}} \\
\text { (Type } 2 \text { ) }\end{array}$ & $>>$ & $\begin{array}{l}\text { imperfective }^{b} \\
\text { (Type } 1 \text { ) }\end{array}$ \\
\hline Aorist & emergent perfective & $>>$ & $\begin{array}{l}\text { perfective } \\
\text { (Type } 1 \text { ) }\end{array}$ & $>>$ & $\begin{array}{l}\text { perfective } \\
\text { (Type } 1 \text { ) }\end{array}$ & $>>$ & $\begin{array}{l}\text { perfective } \\
\text { (Type } 1 \text { ) }\end{array}$ \\
\hline Perfect $^{\mathrm{c}}$ & stative-resultative & $>>$ & perfect & $>>$ & perfective & $>>$ & $x$ \\
\hline
\end{tabular}

Browning $(1983: 29,34)$ says that by the time of the Koine the Greek aspectual system had become a genuine perfective/imperfective system, contrasting "polar opposites."

b Browning $(1983: 64,78,124,135)$ says that early (and late) Medieval Greek opposed "continuous and momentary actions," expressed by the Imperfective and Perfective (= Aorist) respectively, which continues into Modern Greek, with some variation according to dialect.

c For the diachronic stages presented here, see Gerö \& von Stechow 2003. The form is moribund in Hellenistic Greek (Browning 1983: 30, 34), vestigial by the early medieval period (id.: 64), and completely gone $(\boldsymbol{x})$

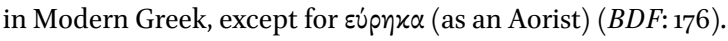

becomes categorical at the Medieval stage, such that the Imperfect's compatibility with these interpretations is no longer recoverable to learners, then I consider it most straightforward to assume that the denotation of the Imperfect was reinterpreted to exclude its grammaticality in such contexts altogether. This last step amounts to genuine semantic change and yields the "Type 1" imperfective found in Modern Greek. The changes observed for the Aorist and Perfect (i.e., along the typical grammaticalization path of (3a) above) also constitute semantic change, which establishes the pre-conditions driving the pragmatic restrictions on the usage of the Imperfect over time, ultimately leading to its own semantic change. Thus, while the Aorist and Perfect display semantic change in the form of grammaticalization of a well-known sort, the Imperfect shows pragmatically driven semantic change that, while cross-linguistically atypical, is nonetheless entirely systematic in its development and explainable in these terms. 


\subsection{Linguistic stages of Greek}

As just discussed, this paper makes use of three main "stages" of Ancient Greek: Archaic (or "Homeric"), Classical, and post-Classical (or "Hellenistic"). These stages are, as all linguistic stages, a somewhat arbitrary means of tracking a particular change over time. As will be clear in what follows, both the stages and the observed changes should not be regarded as abrupt and absolute, nor entirely discrete and uniform across all dialects or even individual authors. It is simply the case that without defining stages of some kind, one cannot clearly track a linguistic change. I have therefore adopted stages that have been used in other scholarship to track similar changes (e.g., Gerö \& von Stechow 2003) and which can be defined by a set of independent linguistic criteria not directly related to tense and aspect. In addition to a thorough examination of the Ancient Greek stages, I provide more cursory remarks about the Medieval and Modern stages of the language for the sake of completeness, so that one may get a full picture of the trajectory of the relevant morphological categories in terms of their usage over time. These latter remarks are accordingly almost entirely based on observations of others found in the philological and semantic literature. I exclude Mycenaean Greek from consideration here because the nature of the documents, particularly as regards verbal usage, is far too uncertain to be adduced as evidence of historical change.

The first stage, Archaic/Homeric Greek, covers roughly 700 to 50o BCE and encompasses the epics of Homer (Iliad (IL.) and Odyssey (Od.)), the fragments of the Epic Cycle, the Homeric Hymns (HH), Hesiod (Hes.) (Theogony (Th.), Works and Days $(W D)$ ), the Shield of Heracles (SH) (Pseudo-Hesiod (Ps.-Hes.)), and archaic lyric (up to Pindar (Pind.)). However, given the nature and limitations of the lyrical genre, as well as the relatively small corpus size of Hesiod and the Homeric fragments, the epics of Homer have generally been found to be most informative in regards to the usage of the functional categories of this period. Wherever they are informative, though, I include discussion of the nonHomeric witnesses of the Archaic period in the appendix ( $\$$ A.1). It should be noted, nonetheless, that remarkable differences in usage-especially of the Aorist - are observed between the Homeric epics and Hymns and the nonHomeric authors of the Archaic period (cf. discussion and Figures 4-6 in § 5.4). Partly for this reason and partly for other considerations, I subgroup the nonHomeric authors of the Archaic period as "late Archaic" (i.e., all except the Homeric epics/fragments, Hymns, and the works of Hesiod/Pseudo-Hesiod), though for the purposes of tracking the changes in usage of the Imperfect this distinction is non-essential. 
The second stage is Classical Greek, spanning approximately 500 to $300 \mathrm{BCE}$ and including many Classical authors and a variety of genres (Attic drama (tragedy and comedy), history, dialogue, oration, etc.). Since the authors, genres, and dialects are inevitably more varied at this period than at the Archaic stage, I include discussion of the variety met with in the data wherever it is relevant to the present investigation (see especially Appendix § A.2). For instance, we find numerous occurrences of the so-called "tragic Aorist" in drama but few in prose. On the other hand, we find many examples of Imperfects used in sequential narration (i.e., concentrative use) in the histories of Herodotus and Thucydides but relatively few in (e.g.) the dialogues of Plato. Such differences are generally to be attributed primarily to stylistic influences based on genre. It should thus not be expected that every reading be attested in every author with equal frequency, nor is such uniformity required for piecing together the functional range of the morphological categories under investigation. Crucially, such variation has more to do with the relative frequencies of the occurrences of readings than with their presence or absence from the grammar outright. To the extent that "Classical Greek grammar" refers to a particular sphere of usage within a particular period of time, I therefore take readings like the "tragic aorist" (i.e., performative/reportive use) or concentrative-sequential Imperfect to belong to the general grammar of Classical Greek, despite their partial (but crucially not total) distribution by genre. To do otherwise would be to construct a separate grammar for each genre (or even for each author), which would fail to yield a coherent picture of the general diachronic developments of interest here. Hence, I consider all data available and regard a usage as marginal or absent from the grammar only when it is wanting in general, rather than in this or that roughly contemporaneous author or genre.

The third stage I refer to as "post-Classical" and take to include the Hellenistic Koine and the Greek of the Roman Empire (cf. Browning 1983:19-52), spanning roughly $300 \mathrm{BCE}$ to $400 \mathrm{CE}$. Due in part to its considerably longer time span (700 years as opposed to 200), I have relied extensively on discussions in grammatical treatments and their citations of the primary texts for my supposition of the readings available to the functional categories at this stage, somewhat more so than was necessary for the readings of the prior stages. However, as with the previous two stages, there is no reading here supposed for which the relevant section of the appendix ( A.3) does not contain either a textual citation or reference to a handbook treatment containing such citations (or both). Key witnesses to the grammar of this period come from early Judeo-Christian literature (the New Testament (NT) and Septuagint (LXX), the Greek translation of the Hebrew scriptures), as well as scholarly and literary writings, such 
as the works of Polybius (Plb.) and Plutarch (Plut.). Of course, caveats similar to those given for the Classical period apply here as well. What emerges quite clearly, however, is that many uses attested marginally already in the Classical period are more firmly established in the post-Classical period. For example, though the Perfect is used in Classical Greek to refer to complete past events (i.e., concentrative) in a manner similar to the Aorist or Imperfect, the Aorist and Imperfect are strongly preferred to the Perfect in sequential narrative contexts. By the time of the Koine, however, the Perfect in sequential narration occurs quite regularly alongside Aorists in the same function (Browning 1983: 30 ), while the Imperfect is rarely so used. This is yet another testament to how gradual and gradient the changes observed here are-emergence at one stage leading to regularity at a later stage - though they necessarily appear abrupt when one looks only at the data for each stage separately $(\S 5)$. Whether gradual or abrupt, however, the point here is that a clear and definable change can be observed between the usage of Classical authors and that of post-Classical authors. This paper aims only to track such developments, to assert that some change has taken place within the history of Ancient Greek, without making any firm claims about its rate of change or precisely how and when the first stirrings of the change arose or at what threshold they can be considered to have been fully grammaticalized. What is important is the mere fact of change, keeping in mind that this paper seeks to explain what developments gave rise to the palpable difference in usage of the Imperfect from the Archaic to the post-Classical stage.

So, though the generalizations made here cannot be hoped to be exceptionless at any stage, nevertheless their value will be clear in that they explain major changes in the regular functional range of the categories in question, helping to address the question at hand: Why does the Imperfect in Homer differ so markedly in its usage from that of later Greek, and how did this change come about?

\subsection{Forms under consideration}

I have chosen to consider only the Aorist, Imperfect, and Perfect/Pluperfect indicative in this investigation. There are several reasons for this. First and most important, these are the functional categories for which aspectual contrasts are most readily observable. It is a well documented fact that, across languages, aspectual contrasts are most robust in the past tenses of the indicative (see Comrie 1976: 71; Ö. Dahl 1985: 81-84; Napoli 20o6: 25-26; inter alios). This is partly because perfective aspect does not typically operate in the present time (though there are exceptions to this, such as the performative/reportive and stative uses, discussed below) and therefore does not stand in direct contrast to 
the imperfective aspect in the indicative except in the past tense. ${ }^{16}$ Moreover, it seems that present tenses tend to be somewhat "biased" toward imperfectivelike meaning, regardless of whether they are built to what might be termed an imperfective gram or not, due largely to the fact that the present typically requires an event to be ongoing at the time of speech $\left(t_{A} \supseteq t_{0 / s}\right) \cdot{ }^{17}$ In this way, whether a morphological stem expresses imperfective or, say, neutral aspect is somewhat obscured in the present indicative. This, coupled with the fact that the perfective aspect contrasts with the imperfective aspect most prominently in the past, points to the Imperfect in Greek as the form maximally informative of the functional range of the Present stem in Greek, standing in clear contrast to the Aorist indicative in its various aspectual uses in the past time.

The Perfect is considered here as well, for reasons similar to those just described for the Imperfect and Aorist. In the oldest documented language, it represents a "stative-resultative" gram type, which shares at least two uses

16 The resultative, experiential, and universal readings of the perfective aspect are indeed presential. However, the first two are not common readings of the present (though the Greek Present can have such interpretations on occasion: e.g., resultative $\hat{\eta} \mu \varepsilon ́ \gamma \alpha \pi \dot{\varepsilon} v \theta 0 \varsigma$

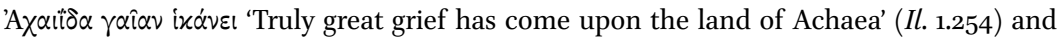

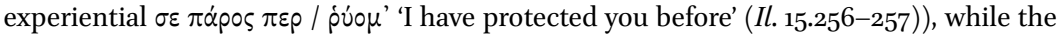

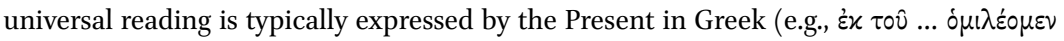
$\Delta \alpha \nu \alpha o i \sigma l v ~ ' s i n c e$ that (time) we have been fighting the Danaans' (Il. 13.779)). In addition, the Present can, like the Imperfect, be used to sequence events in past narration (after Homer (Chantraine 1953 [2015]: 191)) and, like the Perfect, regularly has continuous-state interpretations in the present time (cf. Appendix § A.1.1). So, while the functional range of the Present does overlap with the functional ranges of the three "past tenses" to some extent, it nevertheless does not do so to nearly the same degree as the Imperfect, Aorist, and Perfect/Pluperfect among themselves.

17 Present tenses tend to have progressive or continuous-state uses even where their pasttense counterparts do not, as in Early Modern English, which regularly uses its simple Present form in progressive contexts (e.g., "What do you read, my lord?" (Hamlet II.ii)) (Rissanen 1999: 221), while the Preterite tense, built to the same stem, most often refers to a complete or "bounded" (concentrative) past action in sequential narration (id.: 224). Similarly, the indicative Present in Sanskrit regularly has progressive or continuous-state interpretations (E. Dahl 2010: 163-165), despite the fact that its corresponding past tense, the Imperfect, which is built to the same morphological stem, does not (Whitney 1889: 201, 278). In some languages present tenses to stems that are distinctly not imperfective grams can be used to indicate imperfective aspect in the past in narrative contexts, as was probably the case in Middle English, where the simple Present tense was used to fill a functional gap of "past imperfective," since the periphrastic Progressive construction (BE + -ing) had yet to fully grammaticalize (Fischer 1992: 244-245). If non-imperfective presenttense forms can be put into service to designate imperfective aspect, then there must be something about the tense meaning of the present (rather than aspect) that is functionally "close enough" to the imperfective aspect so as to allow it to substitute for a genuine imperfective gram when a language lacks a better alternative. 
(stative and resultative) with the Aorist. Further, the Pluperfect, in its expression of states ongoing in the past, shares at least one reading in common with the Imperfect (in fact it shares many). As time goes on, the Perfect and Aorist come to overlap more and more in terms of their functional ranges, until the Perfect can be used in sequential narration alongside the Aorist in the postClassical period (Browning 1983: 30). So, even though the Perfect is not properly past referring until at least the Classical stage, and is not regularly used in sequential narration until the post-Classical stage, it is included in this investigation because it shows clear interaction with the aspectual system of the other past-referring categories of Ancient Greek, namely the Imperfect and Aoristcompeting with these in some uses, but also having several uses for which it is the preferred means of expression (e.g., experiential perfect). Moreover, all three of these functional categories in Greek belong to the same cross-linguistic grammaticalization pathway (see (3a) above), whereby stative-resultatives may become perfects, and perfects may become perfectives or simple pasts (sometimes called "aoristic drift"; cf. Willi 2018: 411-412). Note that, even though the Aorist and Perfect are, strictly speaking, not past tenses but respectively a perfect(ive) and a stative-resultative (later perfect, then perfective) gram, I will sometimes use the cover term "past tenses" to refer to the Imperfect, Aorist, and Perfect/Pluperfect together, simply as a shorthand for their more precise labels. These are also referred to throughout as "functional" or "morphological" categories.

As for the non-indicative forms of the verb (i.e., modal, participial, and infinitival forms), these are set aside for the purposes of the present investigation not because they do not show aspectual contrasts, but because these contrasts are far more difficult to form reliable philological judgments about. In the imperative mood, for instance, it is often impossible to feel confident in one's understanding of why an author has chosen to use the Aorist or the Present stem on any given occasion, such that any claims that might be made about them would be unreliable at best and virtually unfalsifiable. Moreover, the inclusion of such forms would stray too far afield from this paper's stated subject: the Imperfect, which is necessarily indicative, just as it is necessarily past in tense. Hence, I limit myself here to the three indicative "past tenses."

It remains only to be explained why, in a paper purportedly about the Imperfect, I bother discussing the Aorist and Perfect/Pluperfect at all. This is because much of what I observe in the development of the usage of the Imperfect is detectable only insofar as it contrasts with the other past-referring aspectual categories in the verbal system. For example, the shift in preference from the Imperfect (in Homer) to the Aorist (in Classical and post-Classical) for the expression of complexive readings (see below) would be impossible to dis- 
cover without recourse to the Aorist. In this way, observing a functional change belonging to the Imperfect crucially depends on consideration of morphological categories other than the Imperfect. Similarly, it requires looking at the entire past-tense system to observe the regular competition in sequential narration (concentrative use) that exists, on the one hand, between the Imperfect and Aorist at the Homeric and Classical stages, but between the Aorist and Perfect at the post-Classical stage. It is, therefore, a basic methodological assumption of this paper that aspectual forms are best understood as operating within a system. Accordingly, to understand the role of a single member of the aspectual system of a language, particularly in diachrony, it is essential to understand the roles of all other forms that stand in contrast to it within that system, in this case the Imperfect versus the other past-referring indicative forms of Ancient Greek, namely the Aorist and Perfect/Pluperfect.

\subsection{Evidence and its assessment: a usage-based approach}

The evidence for the claims of this paper is taken to be all the readings available to each of the tenses under investigation (Imperfect, Aorist, and Perfect/Pluperfect) at a given historical stage of Ancient Greek. In the next section ( $\$ 5)$, I present this evidence in tabular form, with discussion of points relevant to the overall trajectory of observed functional shifts, highlighting how each subsequent stage differs from prior stages in terms of readings. The aim of collecting and presenting the readings in this way is as follows: I assume that changes in usage can be detected by taking the complete set of readings available to a given morphological category at STAGE A of a language and comparing it to the complete set of readings available to the descendant of that morphological form (assuming it survives as such) at STAGE B of the same language. Whatever differences are observed at STAGE $B$ as compared to STAGE A with regard to losses or gains of individual readings for a particular form are taken to be innovations of usage at STAGE B. Whether changes in usage correspond to semantic change requires consideration of the rest of the verbal system (Is the change pragmatically motivated?), as well as typological considerations (Is the change likely when considering cross-linguistic tendencies or parallels?). Thus, while an addition, subtraction, or modification to the set of readings for a given gram entails a diachronic change in usage, it does not necessarily indicate a change to the semantic denotation of that gram. Given this set of assumptions, I adopt the following procedure for tracing semantic/pragmatic change in diachrony: I first seek (in §5) to determine the changes in usage at each stage of Greek (as designated in $\S 3$ ). Then, in Sections $5^{-6}$, I seek to determine what may be attributed to pragmatic and what to semantic change, with a corresponding analysis for how these two types of change work and interact. 
The readings are based, of course, on attestations in the primary Greek texts, as well as on reliable grammatical treatments (such as Kühner-Gerth or Schwyzer-Debrunner), which can be followed up by interested readers for further examples and discussion of particular usages. In order to maintain focus on the shift in general usage of these categories over time, however, I have elected to put the majority of the primary data and philological discussion in an appendix (§A) published as a supplementary document online (see p. 141). I emphasize that this is not done in order to downplay the importance of the primary texts. On the contrary, my claims fundamentally depend on the validity of the readings supposed at any given stage, for which primary attestation is indispensable. I have therefore included careful discussion of such attestations in the appendix, with references to standard handbooks and linguistic treatments where relevant.

In the appendix the reader will find examples of each reading assumed for each functional category at each stage of Ancient Greek, or else references to grammatical treatments containing such examples. In the first section of the appendix (§ A.1), each reading is introduced and discussed with reference to semantic and typological literature, as well as each reading's status within the Greek grammatical tradition, including discussion of the often bewildering variation in terminology. The division of usage into readings is necessarily somewhat arbitrary, of course, but I have aimed to give all the major readings that are commonly found in handbook treatments of Greek grammar, supplemented and refined by treatments in the linguistic literature. I have tried to make note of any significant departures from prior research (such as treating the recent past as a special case of the resultative reading, or the conative as a special case of the progressive). I have also had to make some decisions about what to call certain readings, which have a wide variety of labels in the literature, most especially what I call "complexive" and "concentrative." I aim in my choice of labels for transparency of meaning, insofar as this is possible, though I yield to the standard labels wherever they are firmly established, even if these are not particularly transparent (e.g., "experiential" or "intensivefrequentative"). In all cases, I explain my reasoning for adopting non-standard terminology in footnotes and/or the appendix, and define each reading in terms of temporal relations between assertion time and eventuality time (see Appendix $\S$ A.1), such that the precise meaning can be understood, even if the chosen label is found to be deficient.

In all sections of the appendix I try my best to give an accurate sense of how well or poorly attested each reading is at a particular stage of development (as near as can be determined) and whether any regular variation or deviation from an observed tendency occurs from author to author or genre 
to genre within that stage. Where there is a possible but unlikely example of a given use of some form, I present it with discussion of why its validity is in doubt. Throughout $\S$ A.3, besides detailed discussion of post-Classical usage, I indicate the status of each reading within the Medieval and Modern stages of Greek, to the extent that I have been able to determine from reference to available grammatical treatments alone. The focus of this paper being Ancient Greek, I have not conducted first-hand research to verify the assertions of the grammatical treatments regarding Medieval and Modern usage as I have done for the Ancient stages. Still, my cursory treatment of the non-Ancient periods should suffice to give a reasonably accurate sense of the later trajectory of the usage of the forms here considered.

It should be made clear that this is not a corpus study. There is no particular text sample that I have exhaustively investigated and prioritize as representative of a given stage of the language (though certain texts have, for various reasons, contributed more than others). This is because, for present purposes, what matters fundamentally is whether a particular reading is attested regularly, marginally, or never for a given form at a given stage. The exact frequencies of each reading are not of primary importance, nor could such information be acquired without careful reading of the whole of Greek literature, tracking each instance of, say, experiential uses of the Perfect or complexive uses of the Aorist. To my knowledge such an enterprise has not been carried out on a large scale. I have therefore pieced together what the results of this kind of investigation might yield, namely what readings are available to a particular form at a given stage. Though this approach cannot provide exact counts or frequencies, the grammatical treatments that we have are quite thorough in their descriptions and presentation of the data. These treatments are coupled with my own investigation of various Greek texts-for example, I have exhaustively charted the readings of these functional categories in the first book of the Iliad for Hollenbaugh 2018 -in order to present what I believe is a reasonably thorough and complete characterization of the functional range of the three morphological categories here considered (viz. Imperfect, Aorist, and Perfect/Pluperfect) at each stage of their development.

To this end, I have made extensive use of various reference materials, including not only grammatical treatments but also dictionaries, concordances, digitized and searchable corpora, and, above all, Perseus under PhiloLogic (last accessed November 2, 2019). This has allowed me to search for various sequences of forms within range of some adverbial or other contextual element that tends to elicit a particular reading. For example, to confirm claims that the complexive use of the Aorist is lacking in Homer and Hesiod (cf.Jacobsohn 1933: 307-309), I searched for the Aorist indicative (ind.) alongside various 


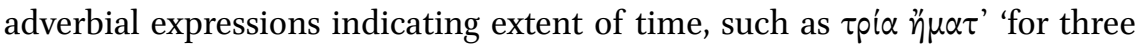
days' or $\pi \alpha v v \dot{x}$ los 'all night'. This returned few and mostly doubtful results (enumerated and discussed in the appendix, § A.1.9). In contrast, a series of searches for the Imperfect with these same adverbials returned a remarkable number of examples in Homer and Hesiod (discussed with many textual citations in the appendix, § A.1.9). Though of course these had to be read carefully to verify their complexive meaning, and though only a subset of the items returned by the search turned out to be genuinely complexive, there are nonetheless dozens upon dozens of complexive Imperfects that can be readily cited for this stage, beside just a few probable complexive uses of the Aorist. Conducting such searches - with the returned passages always checked manually to verify that they represent the reading under investigation-has thus helped me to confirm or deny the existence of a particular usage for a form at a given stage without reading through the entire set of corpora that each stage comprises. Further, this has served as an additional check on the assertions and denials of various readings as reported in the grammatical literature.

It bears emphasizing that readings are fundamentally sensitive to context and actionality (also called "Aktionsart" or "lexical aspect") ${ }^{18}$ of the lexical item or predicate combined with a particular functional category. To clarify, "reading" (also "use," "function," "interpretation," or "(functional) value") is defined as follows: some interpretation within the semantic range of a particular morphological form that is available in certain contexts and/or with certain types of predicates (or situation types). In other words, the semantic contribution (or "notional content") of a particular functional category (for our purposes, the Imperfect, Aorist, or Perfect/Pluperfect) determines what sorts of contexts that form will be felicitous in and, therefore, what sorts of readings it can have. Accordingly, not only should one not expect every reading to be possible for every morphological category, but one should also not expect to find every reading available in all contexts or to all predicate types. Certain con-

18 I operate here with the basic "Vendlerian" situation types (or "predicate types"), namely states (e.g., know, be happy, sleep), activities (e.g., run, write, eat), accomplishments (e.g., write a letter, eat up, strip down), and achievements (e.g., die, finish, fall asleep). "States" are contrasted with the other situation types, which are collectively referred to as "events." The reader is referred to Vendler 1957; Moens \& Steedman 1988; Smith 1997: 27-9o for fuller explanation of these categories. There is sometimes need to distinguish "stage-level states" from "individual-level states" (cf. Kratzer 1995). The former refers to impermanent states like BE HAPPY or SLEEP, which tend to behave similarly to events. The latter refers to permanent states like BE TALL or KNOW, which often behave quite differently from other kinds of eventualities (e.g., they cannot be combined with the Progressive in English: *was being tall, "was knowing). 
texts license certain readings. For example, a verb meaning 'they ran away' in the context after a participle meaning 'having gotten scared' is likely to receive an inceptive interpretation: 'having gotten scared, they ran away (i.e., took off running)' (cf. Thuc. 2.12.3 in Appendix § A.2.8). This is a contextually determined reading of a form whose semantic range is sufficiently broad to allow it to occur in such contexts (viz. inceptive). If its semantics did not allow inceptive as a use, we would expect it to be ungrammatical in such contexts and therefore not to occur in them, or else to be coerced into some special interpretation in order to render the utterance grammatical. Similarly, many readings are sensitive to situation/predicate type, such that only certain types of verbs or predicates can yield certain readings in combination with a given morphological form. For example, the stative use of the Aorist at the Archaic stage (see (6) below) arises when the Aorist morphology is combined with a verbal predicate that is a state, such as $\varphi$ i $\lambda \varepsilon \omega^{\prime}$ 'love'. This is also true of the complexive and inceptive readings of the Aorist. It is not true, however, for some of the analogous readings of the Imperfect: While the continuous-state reading of the Imperfect does require a state predicate (type 'he was sleeping'), just like the stative use of the Aorist, in its complexive and inceptive uses the Imperfect attests predicates of all types (mainly activities, accomplishments, and states, in Vendlerian terms), in contrast to the Aorist usage. Restriction of a certain reading to a certain situation/predicate type is thus in part a property of the morphological category that the lexical verb or verbal predicate combines with and, in this way, reveals something about the semantic range of that category. This kind of evidence has been indispensable in determining the denotations of the various functional categories at each stage of Greek. I therefore include information about the Vendlerian categories that license particular readings of functional categories in the summary tables of $\S 5$ enclosed in curly braces.

The total set of uses regularly available to a particular functional category indicates its functional range, which must be permissible under the semantic denotation associated with that form (as formalized in $\S 6$ ). The functional range for a given form is thus discerned on the basis of what readings we find actually attested for that form. Any sufficient formalization of the denotation of a given form must capture exactly this functional range (i.e., how broad or narrow its semantics must be) and be neither too "weak" nor too "strong" as to permit more or fewer readings for that form than are actually available to it.

This paper is structured so as to develop a synchronic analysis of functional categories at each stage of their development, then observe the changes from one stage to the next, thereby achieving a diachronic analysis. The synchronic component proceeds in the following way: First, the functional range of each 
form at each stage is determined on the basis of attested usage $(\S 5)$. Once its functional range has been determined, a denotation for each form is formulated in Section 6 in such a way that it permits exactly the functional range observed for that form, and so is compatible with just those readings regularly attested for the form in question. Additionally, pragmatic matters are discussed and explained, involving the interaction of the various functional categories with one another, which limits their usage in predictable ways and depends on the synchronic grammar operative at a given stage of development.

Because it is the total set of regularly attested readings that determines a form's functional range at a given stage, no particular function is regarded as more important or "central" to establishing the form's denotation than any other. This approach contrasts strongly with the assumptions of many standard grammatical treatments and even prior theoretical treatments down to the present day: See, e.g., Chantraine's (1953 [2015]: 220) notion that the Imperfect (and Present) expresses basically "duration," or Smyth's (1956:423) generalization that it "represents an action as still going on ... in the past". More recently, Bary \& Egg (2012) take an extreme approach of this kind in assuming that there is one particular reading that is essential to the Aorist (viz. concentrative, of the type 'received in that moment'), and one that is essential to the Imperfect (viz. past continuous state, of the type 'was king at that time'), and that all others must be explained by means of various "coercion operators." These "coerced" readings include, remarkably, the inceptive ("ingressive") and complexive ("phase interpretation") uses of the Aorist and the progressive, iterative, and habitual uses of the Imperfect. ${ }^{19}$ By contrast to these approaches, I assume instead that all regular uses of a form operate essentially on the same "footing," so to speak. Accordingly, a form's denotation must be formulated in such a way as to accommodate all of its regular functions, rather than just one or another reading that receives some special status in the (inevitably arbitrary) view of the analyst.

However, that is not to say that there are not certain readings that help us home in on a particular diachronic change more than others. In this analysis, the complexive and concentrative readings may appear to have some special status over and above the other readings for determining the aspectual value of a functional category at a given stage. Yet this is only because it is precisely

19 Napoli's (2006: 64) conclusion that the Imperfect (and Present stem generally) "views the internal structure of the situation" is much closer in spirit to the approach of this paper, though I think her identification of this functional category with imperfective aspect assigns to it a semantics too narrow (or "strong") to account for all the uses of the imperfect that we find attested, especially in Homer. 
with respect to these readings that the most significant changes have been observed - and can thus be tracked over time-for the Imperfect and Aorist. So, while it is not the case that the complexive use is more "essential" to the Aorist's denotation than any other reading available to it at the post-Classical stage, it can be truly said that the functional range of the Aorist at this stage differs most notably from that of the Homeric Aorist precisely with respect to this reading, and so its post-Classical denotation is formulated as permitting the coextension relation $\left(t_{\mathrm{E}} \subseteq \mathrm{t}_{\mathrm{A}}\right)$ that its denotation at the Archaic stage had excluded $\left(t_{E} \subset t_{A}\right)$. In this way, a particular reading may emerge as especially important to the diachronic analysis in a non-arbitrary (and non-circular) way, simply from examination of the data, without having been artificially endowed with this privileged status by the analyst. In conducting my analysis in this way, I hope to have avoided undue confirmation bias and, above all, to have hit as near the mark as possible in understanding the full functional range of these forms at each stage in terms of their attested usage.

\subsection{The notion of regularity}

In the tables of Section 5 below, I have summarized the readings available to each of the three functional categories at each stage of development, based on my investigation of the data detailed in the appendix. The point is to determine the regular functional range of each category at each stage, so that I can then assign to it a semantics (or denotation) that accounts for this functional range in Section 6 and, finally, explain the observed shifts from one stage to the next in these terms, taking into account both semantic and pragmatic factors.

I distinguish in this treatment the notion of regularity of usage from that of commonality or frequency of usage. Crucially, just because a usage is regular does not entail that it will occur frequently, though high frequency of occurrence can ordinarily be taken to imply regularity. This is because there are many cases in which one would consider a certain usage to be part of a form's regular functional range and yet find that it occurs with less frequency than other uses regularly available to that form. For instance, the inceptive use of the Imperfect is certainly of rarer occurrence than, say, its habitual or characterizing uses, simply because the kinds of discourse contexts that elicit the inceptive reading tend to be more specific than for the other uses, typically requiring that something has just occurred in the immediate discourse which leads to the initiation of a related action in the Imperfect (cf. Rijksbaron 2002: 17-18). Yet, if the inceptive use occurs less frequently than the habitual, still it is met with on nearly every page of, say, Herodotus or Thucydides, and good examples of it are, in my experience, much easier to come by than truly solid examples of the Imperfect's progressive use, which most assume to be fundamental to the 
meaning of the Imperfect (e.g., Smyth 1956: 423). Therefore, ordering readings on a sliding scale of frequency of occurrence is problematic at best, and it is futile to attempt to determine at what critical threshold one should consider a usage "legitimate" or "illegitimate."

Partly to avoid the problems brought on by notions of relative frequency, I have instead attempted only to determine what usage is regular for a form at any given stage. By "regularity of usage" I mean something similar to the notion of regularity met with in other areas of linguistics, such as regularity of sound change. This has two properties of interest to us here: (i) A regular sound law may or may not actually apply to very many forms, so long as (ii) it applies everywhere it can apply. Any historical linguist will be familiar with regular sound laws that are used to explain only a handful of data (or sometimes even a single form, so long as no counterexamples exist). So with regularity of usage, a form may be regular without being frequent. There are a number of factors that contribute to relative frequencies, such as the kinds of discourse contexts that give rise to particular readings (just mentioned) and, most tellingly, categorical or partial blocking. Just as a regular sound law applies wherever it can but may be blocked (or "bled") from applying by some other rule that precedes it, so, analogously, a regular synchronic usage of a form will apply in every context that it can, though its application may meet with interference due to competition with another form in the same function. Given this assumption, it follows that, when two forms compete for the same semantic space, the semantically stronger form will apply in those cases where its particular functional range is most appropriate, not because the other form cannot express that nuance, but because the more specific form must apply in all instances that it can. Since the more specific form applies in a subset of the contexts that the less specific form does, it will block the application of the less specific form in exactly those contexts.

Whether this blocking is partial or categorical depends on numerous other factors of the particular verbal system, but either variety can be overridden by lexical or other considerations. For example, the English Preterite cannot have past progressive interpretations. Yet it would be rash to conclude on this basis that the Preterite is semantically incapable of expressing these shades of meaning. On the contrary, the English Preterite is generally regarded as a simple past gram (e.g., Bybee et al. 1994: 85; Denison 1998: 133), neutral in aspect, which we know in earlier forms of the language - when the Progressive construction was not fully grammaticalized - was used to characterize states of affairs as complete or incomplete in the past (Fischer 1992: 245-246; Rissanen 1999: 226). Further, even in Present-day English the simple Preterite is regular and even required for certain state predicates characterized as ongoing in 
the past, where the Progressive is impossible, as in Mary knew (" was knowing) the answer. It is thus inaccurate to say that the English Preterite does not regularly characterize states of affairs as incomplete or ongoing in the past. Rather, the event-in-progress readings that could apply to the Preterite (and used to do so) are categorically blocked in Present-day English by the Progressive construction (cf. Deo 2015b: 5), which applies in all contexts where it can apply, namely to charatcerize events as being in progress, in preference to the semantically more general Preterite (simple past gram). Such is the effect of blocking that readings which are well within the semantic scope of a form are not actually realized with complete freedom, since another form in the verbal system that is more highly specified for use in those contexts blocks the application of the more general form. Still, such readings may be realized by the more general form in a restricted domain, applying wherever the more specific form cannot, as in the case of state predicates in English that do not readily build Progressives, such as KnOw, where the Preterite is used instead. Thus, all regular uses of a functional category will apply in all contexts that they can apply in, though these contexts of application are often restricted by interaction with other forms in the same verbal system.

And so, I understand a reading or set of readings to be regular when it is compatible with the denotation of a particular morphological category at a given linguistic stage. Empirically, a usage of a form is taken to be regular if: (a) it is very common and virtually unrestricted lexically, syntactically, or pragmatically; or (b) it is not very common or is even uncommon and of restricted occurrence, but the restrictions on its application are definable and predictable, whether in terms of lexicon (predicate types), syntax, discourse context, or blocking relations with other functional categories in the verbal system (pragmatics). When there is no good reason to suppose that a usage that is marginal or completely lacking in secure attestation for a verb form at a given stage comes by its scarcity due to regular pragmatic or other restrictions along the lines of $(b)$, then the usage is considered not to be regular for that form at that stage.

It is possible for a usage to meet this definition of regularity but never actually be attested for a particular form, but crucially only if its lack of occurrence is regular and definable as the result of a blocking relation with another form in the verbal system. Such is very nearly the case of the resultative-perfect use of the Imperfect in Homer, which has only a few plausible attestations. One way of analyzing its near absence could be to include a stipulation in its semantic denotation against applying this form in a resultative function. But since the Aorist is systematically applied in resultative contexts, the more economic approach is to view the lack of resultative uses of the Imperfect as due to blocking on the part of the Aorist in the appropriate contexts, rather than as an 
entailment inherent in the meaning of the Imperfect itself (cf. the categorical blocking of event-in-progress readings of the Preterite in English by the Progressive, discussed just above). This allows us to suppose that the Imperfect denoted "neutral aspect," which can explain its extremely wide functional range, without stipulating more than is necessary or appropriate, since taking blocking into account gets this restriction, as it were, "for free," while also rendering the few possible instances of resultative Imperfects in Homer semantically unproblematic.

By contrast, sporadic, unsystematic, and unpredictable uses are considered not to be regular. In such cases, no particular lexical restriction on the usage can be identified, no predictable syntactic or discursive environment can be pointed to as eliciting the reading across occurrences, and no regular blocking relation with another form in the verbal system can be observed. There are some cases where an especially marginal or dubious reading of a form is found in a particular syntactic environment or discourse context, but, crucially, these environments or contexts cannot be generalized in order to predict where the form will occur when one looks at similar contexts in other utterances, because other forms are found there instead. Such cases must not be regarded as "regular" under the definition put forth here. An example of this is the English Perfect, which is ordinarily banned in contexts of definite past time deixis (the so-called "present perfect puzzle"; cf. Klein 1994: 208), as in *I have seen him at three o'clock yesterday. Nonetheless, there are occasions in which one will hear or produce the Perfect in contexts of this kind, as I once did when writing an email to a professor, saying, "I have already taken Ling $200 \mathrm{~A}$ last fall." Clearly the use of the Perfect with definite time reference to the previous fall, added at the end, was triggered by a special set of circumstances at the discourse level: I wanted to make clear that I already had the prerequisite filled for the upcoming course (hence the experiential perfect) but also wished to specify when that prerequisite had been completed (hence the definite time adverbial). Yet we cannot use this one-off example to make reliable predictions about where the Perfect can and cannot occur in English, or even in my own idiolect of English. In fact, when we look at similar contexts in other utterances, we find the simple Preterite almost invariably (of the type I took it last fall). So it would be unreasonable to suppose that the denotation of the English Perfect is such that it regularly permits co-occurrence with adverbials of definite past deixis.

Still, such sporadic occurrences can, over time, lead to changes in regularity. In fact, it is thought that one of the mechanisms driving the grammaticalization of a perfect gram to a perfective or simple past is its over-application, extending into contexts where it could not previously be applied (cf. Deo 2015a: 193). Eventually, this usage becomes part of the form's denotation (i.e., semantically regu- 
lar). Thus, sporadic, contextually or pragmatically motivated over-extension in usage can lead to systematic, regular usage at a later stage. It is therefore important to keep the two notions distinct to the extent possible. This concept will be relevant in what follows, as (e.g.) I deem the complexive uses of the Aorist in Archaic Greek to be irregular, even though they are attested a few times at this stage, since their occurrence is in no way predictable on the basis of their attestations or on regular interactions of the Aorist with the verbal system at large (similarly, cf. the marginal concentrative use of the Perfect at this stage). At the same time, however, I take these sporadic early occurrences as evidence of the type of over-extension of usage just described, which I assume led to the regularity of such uses in the later stages of the language: The complexive use of the Aorist and the concentrative use of the Perfect are clearly regular at the Classical and post-Classical stages, so it is unsurprising that we should find an occurrence or two at an earlier stage (Archaic Greek), when these uses were first emerging.

\subsection{Presentation of the data}

In the tables that follow in Section 5, I summarize the functional ranges of the three "past tense" categories (Aorist, Imperfect, and Perfect/Pluperfect) at each of the three stages of Ancient Greek defined above (Archaic, Classical, and postClassical). In each cell of a table a functional label (i.e., a "reading") may or may not be found. If a functional label appears in a cell and is unadorned, without further marking, it means that I take that reading to be part of the regular functional range of the category to which it is assigned (i.e., in the corresponding column). If, instead, the symbol " $\times$ " appears (without further adornment), it means that that particular functional slot finds no attestation in the data for that category at that stage of the language. As discussed above, lack of attestation may or may not correspond to a semantic entailment against that particular usage. In the case of the Imperfect, for instance, lack (or near lack) of attestation can in several cases be straightforwardly attributed not to limitations entailed by its semantic denotation but to restrictions imposed on it by pragmatic interaction with the Aorist, called categorical blocking. In the case of the Aorist, on the other hand, pragmatic conditions preventing certain uses that it could hypothetically have cannot readily be established, so a semantic account is more reasonable, wherein the denotation of the Aorist is taken to be such that it entails that the Aorist's application in certain contexts is not regularly admissible. The lack of regular attestation of the Aorist in such contexts is thus explained, in general, as a limitation imposed under its particular functional range, rather than by interaction with another form in the verbal system (via blocking). In any case, the symbol " $x$ " in the tables that follow is meant to 
be silent about this distinction, with the matter of whether a certain absence of attested usage is to be attributed to semantics or pragmatics taken up in the following section $(\S 6)$.

The rows of each table group readings according to functional similarity (if not absolute identity) across morphological categories (columns). Thus, if the symbol " $\times$ " appears in a particular cell, the reader must look to its right or left to see what the overall character of that row is like, in order to understand what sort of reading is unattested for the form in question. For example, the first " $x$ " in the Aorist column of Table 8 falls in a row including the progressive-conative use of the Imperfect and the intensive-frequentative use of the Perfect/Pluperfect. This row thus groups readings that refer to an event in progress at evaluation time. Therefore, the " $x$ " in the Aorist cell can be understood to mean that the Aorist does not attest any secure examples of a progressive use (or occur in progressive-like contexts) at the Archaic stage.

When a row would otherwise consist entirely of " $x$ " symbols, thereby rendering the row's intended functional parameter opaque, but its inclusion in the table is relevant with respect to diachrony, the intended funtional label is enclosed in square brackets. This notation is identical in meaning to the " $x$ " symbol, except that it additionally indicates information about what functional parameter is meant to be reflected in the whole row (the rest of which will contain " $\times$ " symbols), as seen in row 11 of Table 8 .

In addition to this basic contrast between a usage that is regularly attested (indicated by an unadorned usage label in the relevant cell) and one that is entirely unattested (indicated by " $\times$ " or a usage label enclosed in square brackets), there are several other notational strategies that I have adopted, in order to indicate various degrees of attestation, as this can often be quite complicated when one looks closely at the data and the grammatical literature written about it. Some of these are practical, such as the use of square brackets to indicate the functional parameter of a row (no different in meaning from " $x$ "), while others have distinctive meanings. I summarize all of these notations in the following list.

Unadorned usage label (e.g., "stative"): The stated reading is regularly attested for the form in question at the linguistic stage indicated. Boldface type (e.g., "universal") indicates an innovation of usage from the immediately preceding stage (i.e., an addition to the form's functional range). Boldface type also applies for uses that have become regular or ceased to be rare or questionable (see below) since the time of the immediately preceding stage (e.g., the universal and complexive uses of the Aorist and the resultative use of the Perfect in Table 9). 
$\times$ (unadorned): The reading proper to this cell of the table (as indicated by the row to which it belongs) is unattested for the form in question at the linguistic stage indicated, without an indication of whether this lack of attestation is semantically or pragmatically motivated (clarified in $\S 6$ ). The boldface equivalent is " $\boldsymbol{X}$," which indicates a loss in attestation compared with the immediately preceding stage.

Usage label enclosed in square brackets (e.g., "[performative/reportive]"):

The stated reading is unattested for the form in question at the linguistic stage indicated, without an indication of whether this lack of attestation is semantically or pragmatically motivated (clarified in $\S 6$ ). The " $\times$ " is avoided because the row in question would otherwise consist only of "x" symbols, in which case it would not be clear what manner of usage was being referred to. A row of null attestation is included for its interest to diachrony. Labels of this kind may be put in boldface to indicate an innovation from an immediately preceding stage (e.g., "[performative/reportive]").

Usage label with question mark (e.g., "resultative?"): The reading is of uncertain regularity, productivity, or legitimacy. In the face of doubt, the reading is considered to belong to the regular functional range of the form in question at the linguistic stage indicated. In all such cases, the available evidence, its treatment in the handbooks, and reasons to doubt its legitimacy are discussed in the relevant portions of the appendix. The question mark may be put in boldface to indicate a change in security of attestation or certainty of regularity from the immediately preceding stage (e.g., "stative?").

Usage label enclosed in square brackets with question mark (e.g., "[complexive]?"): The stated reading is deemed not to belong to the regular functional range of the form in question at the linguistic stage indicated. Such readings may be attested, however, whether dubiously or securely, but not regularly. That is, no rule can be established governing or predicting the reading's occurrence-whether semantic (entailed by denotation), lexical (predicate types it combines with), syntactic (adverbial or clausal environment), contextual (discourse), or pragmatic (blocking). Discussion of readings so labeled is always included in the appendix, where the motivations leading to the adoption of this label are explained, and the evidence and its treatment in the grammatical literature are carefully assessed. This label may be put in boldface (e.g., "[sequential?]") to indicate an innovation (loss) from an immediately preceding stage.

Usage label in boldface with strike-through line (e.g., "eomplexive"): Indicates that the stated usage has become restricted in its occurrence, though 
it is securely attested, for the relevant form in comparison with the immediately preceding stage of the language. This is to be attributed (in §6) to pragmatic interference (partial blocking) on the part of another form in the verbal system. Motivations for such a notation in any given case are discussed in the body of the text in Sections $5^{-6}$ and in greater detail with citations in the relevant portions of the appendix.

"(rare)" after an otherwise unadorned usage label (e.g., "resultative (rare)"): Indicates that the use in question, while regular, is not of frequent occurrence for the relevant form at the stage indicated. This label may be put in boldface to indicate an innovation in scarcity of occurrence from an immediately preceding stage (e.g., "futurate? (rare)"). Various other stipulations or qualifications may be added to it (e.g., "(rare unless prefixed))".

"(drama)" after a usage label (e.g., "stative? (drama)"): Indicates that possible examples of the use are only found in Attic drama, so far as I am aware or have been able to determine from the grammatical treatments and my own investigation of the data (see Appendix ad loc.).

Predicate type label in curly braces following one of the above labels (e.g., "\{states\}"): Indicates the predicate type(s) (cf. n. 18 above) for which the reading in question is available for the relevant form at a given stage, as discerned from its attestation. So, for example, the Aorist attests stative uses in Archaic Greek only when it is built to state predicates. When the restrictions on predicate type change from one stage to the next, the predicate type label is put in boldface in the table of the later stage (e.g., "\{nonachiev.\}"). Where the predicate type restrictions remain unchanged from a prior stage, however, I omit its label from subsequent tables. Events is the cover term used to pick out all non-state situation types (viz. achievements, accomplishments, and activities). Transformative (= achievements and accomplishments) is abbreviated "transfm."; non-transformative (= states and activities) is abbreviated "non-transfm." (cf. n. 8 above). When all but one situation type is available for a reading but does not form an established natural class, I simply put "non-" in front of the excluded situation type (e.g., "non-activities" picks out states, accomplishments, and achievements). Accomplishments is abbreviated "accomp."; achievements is abbreviated "achiev."

(Plpf.): Designates readings not available to the Perfect but only to the Pluperfect at the stage indicated. Note that the Pluperfect matches the Imperfect almost entirely in its functional range, particularly at the Archaic stage (cf. Appendix § A.1.6). 
Various other qualifiers (e.g., "'attained state' only") will be sufficiently transparent to the reader in consideration with the discussion accompanying each table, supplemented by the relevant portions of the appendix. "CF" stands for counterfactual.

Data

5.1 Archaic/Homeric Greek (c. 700-500 BCE)

In overview, the readings available to the three "past tenses" in Archaic Greek are presented in Table 8. For an explanation of the notation, see Section 4.5just above. For philological and theoretical details motivating the readings assumed in this and subsequent tables see the appendix.

In the appendix (online supplement, see p. 141) the reader will find discussion of every reading in Tables 8-10 except the generic, gnomic, habitual, and pluractional uses (iterative and distributive). The decision to exclude these readings from the appendix was made late in the drafting of this paper and solely for considerations of space, since these groups of readings do not significantly affect the findings here presented and, though interesting in many ways, do not vary much from stage to stage in ways relevant to the current investigation. The denotations in Section 6 have been made with these readings in mind, however, such that the habitual reading of the Imperfect, for instance, is fully compatible with the semantics assigned to the Imperfect at all stages (i.e., either $t_{E} \circ t_{A} \circ t_{E} \supset t_{A}$ ). In other words, these readings are assumed to be part of the functional ranges of their respective morphological categories (as shown in the tables), even though they are not explicitly discussed.

The rows of Table 8 correspond to groups of similar "readings" or interpretation types (i.e., uses) across morphological categories. So, for example, row 2 column 3 reflects the traditional label for the use of the Perfect designating an event (not a state) ongoing at speech/evaluation time, namely intensivefrequentative. This is qualitatively not very far from the progressive-conative uses of the Imperfect (row 2 column 2), though the former has present reference and the latter has past reference, and so I place them in the same row of the table. The progressive and conative are grouped together because I take the conative reading to be a special case of the progressive (e.g., 'was persuading' but had not yet accomplished the persuasion, and hence 'was trying to persuade'), though nothing depends on this assumption.

To take another example of a natural class of readings from Table 8, row 1 has to do with states that are ongoing at or before speech time (or local evaluation time, cf. $n .42$ below), a use which outside the perfect and perfective aspects 


\begin{tabular}{|c|c|c|c|}
\hline & AORIst & IMPERFECT & Perfect/Pluperfect \\
\hline 1. & stative $\{$ states $\}$ & continuous state $\{$ states $\}$ & stative $\{$ non-activities $\}$ \\
\hline 2. & $x$ & progressive-conative $\{$ events $\}$ & intensive-frequentative \{events\} \\
\hline 3 . & resultative/“hot news" \{transfm.\} & resultative? (rare) \{transfm.\} & resultative (rare) \{transfm. $\}$ \\
\hline 4. & experiential $\{$ any $\}$ & experiential? (rare) $\{$ any $\}$ & experiential \{any\} \\
\hline 5 . & present universal? \{any\} & (present/past) universal \{any\} & universal \{any\} \\
\hline 6. & concentrative-sequential \{events\} & concentrative-sequential $\{$ events\} & [concentrative]? \{events\} \\
\hline 7 . & counter-sequential \{events\} & counter-sequential \{events\} & (Plpf.) \\
\hline 8. & inceptive $\{$ states $\}$ & inceptive \{non-achiev. $\}$ & (Plpf.) \\
\hline 9 . & [complexive]?\{states\} & complexive \{non-transfm.\} & (Plpf.) \\
\hline 10. & past $\mathrm{CF}\{$ any $\}$ & past $\mathrm{CF}\{$ any $\}$ & (Plpf.: past CF) \\
\hline 11. & [performative/reportive] & $x$ & $x$ \\
\hline 12. & futurate? $\{$ transfm. $\}$ & $\times$ & $x$ \\
\hline 13. & egressive (rare) \{accomp.\} & $x$ & $x$ \\
\hline 14. & pluractional $\{$ any\} & pluractional $\{$ any $\}$ & $x$ \\
\hline 15. & gnomic $\{$ any $\}$ & past habitual \{any\} & generic uses $\{$ any $\}$ \\
\hline
\end{tabular}

is called "continuous state" (vel sim.) in the semantic literature (cf., e.g., Deo 2015b: 4, of the type was standing). I maintain this distinction to differentiate the use of the Imperfect from that of the Perfect. In this use, the Imperfect designates states that are ongoing in the past and does not imply an event preceding the state that resulted in the state's holding true. This is what I call

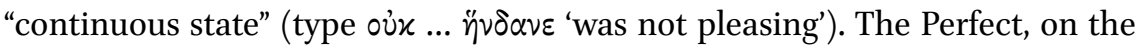
other hand, can designate both "attained states" (to transformative predicates, type $\tau \dot{\varepsilon} \theta \nu \eta \varkappa \varepsilon$ 'is dead') and continuous states (to state predicates, type हैo $\lambda \pi \alpha$ 'I hope'). Attained states differ from continuous states in that they imply a preceding event that has resulted in the state holding true at speech time (or time of local evaluation). Hence, I use the broader term "stative" to refer to this reading of the Perfect. ${ }^{20}$

The Aorist can also, though in a much more limited way, combine with state predicates to refer to a state ongoing either in the past (e.g., Il. 9.481, Od. 8.63) or, unlike the Imperfect, at speech time (cf. (6) below). I refer to this use of the

20 Of course, many lexical states may inherently imply an earlier event that led to that state (e.g., given the truth of a verb like sleep I can logically infer that some event of falling asleep has taken place). States of this kind may be built to the Imperfect, but the inference of a preceding event is simply a product of the world knowledge that many kinds of states are not eternal but have to have begun at some point in the past. In contrast to the Perfect, such inferences are inherent to the states built to the Imperfect (or Aorist) and do not arise from the notional content of the verbal morphology itself (cf. Appendix § A.1.1). 
Aorist as "stative" as well, but for a different reason than that of the Perfect. Whereas the label is used of the Perfect to account for its vagueness as to what kind of stative is meant (attained or continuous), the corresponding use of the Aorist is called "stative" here due to a lack of complete understanding (given the limited data available) about its nature and function (whether attained or continuous or neither), such that the unmarked term seems best (see the appendix $\S$ A.1.1 for a full discussion). Moreover, while the Aorist in its stative function can refer to present or past time, the Imperfect refers only to the past, so it is desirable that the two usage labels not be identical. Of course, the Aorist to state predicates may have other readings as well, such as inceptive (see below).

In most other rows, the usage labels are identical or nearly identical across morphological categories. This reflects a functional similarity of these readings across categories, though again distributional details and restriction according to predicate type may vary. Again, the reader is referred to the appendix for a full account of what is meant by each reading label, references to discussion in the grammatical and linguistic literature, and citations from the Greek texts. Note that the readings here presented are not necessarily mutually exclusive. For instance, an experiential perfect reading may at the same time be iterative (e.g., I have read that book many times), and so forth.

Though accounts of aspectual usage inevitably focus on the differences between functional categories, there is in Greek, from the Archaic period on, a remarkable amount of overlap in terms of usage across categories. I have everywhere sought not to suppress functional overlap of this kind, which I take to reflect semantic overlap (i.e., similarity in the denotations of different morphological categories), but to let the data speak for itself. I have thus drawn my conclusions about the functional range of each category solely on the basis of its attested usage (rather than, say, received wisdom about what that category "should" or "should not" be capable of doing).

We return to the sets of readings in Table 8 when we come to the Classical period in Section 5.2, in order to compare the two and observe any diachronic changes. For now, it is enough to emphasize two uses particularly characteristic of the Homeric stage. The first of these is the stative use of the Aorist. Though the Aorist is typically interpreted as having eventuality time $\left(t_{\mathrm{E}}\right)$ precede speech time $\left(\mathrm{t}_{0 / \mathrm{s}}\right),(6)$ shows that, in Homeric at least, the Aorist could also be interpreted as having eventuality time overlap with the time of speech (or evaluation), such that it can be felicitously used to refer to states that are ongoing in the present (or past, where $t_{0}$ is "past shifted"). In (6), where Aphrodite is addressing Helen, the Aorist must be read simply as 'I love' and cannot be interpreted otherwise in such contexts without violence to the text (cf. Chantraine 1953 [2015]: 214). 
(6) Stative use of the Aorist indicative in Homer

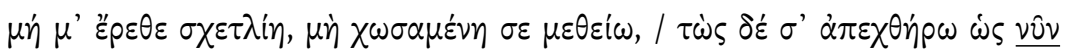
हैं $\pi \alpha \gamma \lambda \lambda^{\prime} \varepsilon \varphi$ iं $\lambda \eta \sigma \alpha_{[\text {AоR.] }}($ Il. $3.414-415) .{ }^{21}$

'Don't provoke me, stubborn woman, lest having been angered I cut you loose, and I come to despise you so terribly as I currently love $\mathbf{e}_{[\mathrm{AOR} .]}$ you'.

[NB: \#'have come to love/been loving']

Another use of particular prominence in Homer is the concentrative-sequential Imperfect (Goodwin 1889: 7-8, 25), referring to an Imperfect used to characterize events as complete in the past, such that eventuality time is fully contained in assertion time $\left(t_{\mathrm{E}} \subset \mathrm{t}_{\mathrm{A}}\right)$, which is often employed to sequence events chronologically in past narration, relative to other Imperfects or Aorists in the local discourse. Examples of the Imperfect used concentratively in sequential narration have been given in (1) above (cf. Appendix §A.1.6 for further discussion), where they are coordinated with likewise concentrative-sequential Aorists (cf. Wackernagel 1926-1928 [2009]: 235). Another example is (24a) in Section 6.3.1 below.

As shown above in (4), the Imperfect is also regular in the complexive function in Homer, rather than the Aorist (cf. Appendix § A.1.9), which is quite rare in this use (and lexically restricted) until the later stages of Greek (Purdie 1898). This is an important point to which we return in the next section.

Thus, the Imperfect of Homer shows a very wide range of aspectual uses, some of which are not typically considered to belong properly to the notion of "imperfective aspect," particularly the concentrative-sequential and complexive uses, both of which involve the imposition of "boundaries" (i.e., the upper and lower limits of the assertion time interval) on whatever predicate they are built to (respectively transformative/telic and non-transformative/atelic), such that $\mathrm{t}_{\mathrm{E}} \subseteq \mathrm{t}_{\mathrm{A}}$. For this reason, I have identified the Imperfect not as a past imperfective gram (which would entail $t_{\mathrm{E}} \supseteq \mathrm{t}_{\mathrm{A}}$ ) but as a simple past, which is neutral in aspect $\left(\mathrm{t}_{\mathrm{E}} \circ \mathrm{t}_{\mathrm{A}}\right)$ and therefore compatible with $\mathrm{t}_{\mathrm{E}} \subseteq \mathrm{t}_{\mathrm{A}}$ as well as $\mathrm{t}_{\mathrm{E}} \supseteq \mathrm{t}_{\mathrm{A}}$.

The Aorist, meanwhile, is rather more restricted in its use and is found regularly in a number of "perfect-like" functions, such as resultative, experiential, and stative (cf. Kiparsky 2002: 113 on the association of these readings with the perfect aspect). While some of these uses remain available to the Aorist in the later language, their frequency of occurrence in Homer sets them apart from later usage (cf. $§ 5.4$ ), and the stative use in (6) is virtually restricted to the

21 See Appendix $§$ A.1.1 for further examples and discussion of this use. 
Archaic period (with some exceptions in Attic drama). Moreover, the Aorist does not regularly have complexive as a use at this stage, suggesting that it does not yet permit the coextension relation, which would impose an upper and lower "boundary" on a state predicate (of the type 'reigned for twelve years'), so it must not denote the relation $t_{E} \subseteq t_{A}$, but rather $t_{E} \subset t_{A}{ }^{22}$ This predicts that when combined with a state predicate ${ }^{23}$ the Aorist will not yield a complexive reading but will instead coerce an event of entry into the state in question (inceptive reading), such that $t_{\mathrm{E}} \subset \mathrm{t}_{\mathrm{A}}$ can be true. Putting these facts together has led me to conclude that the Aorist was at the Archaic stage an "emergent perfective," showing a high degree of "perfect-like" behavior and lacking, as yet, a full range of "perfective-like" uses (e.g., the complexive reading or serving as the default tense of sequential past narration). Its full denotation is given in Section 6.1.1 (17) below.

The Perfect is a stative-resultative gram at this stage, showing a strong preference for stative usage (type $\tau \dot{\varepsilon} \theta \nu \eta \chi \varepsilon$ 'is dead'), as well as the "intensive-

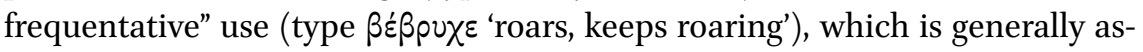
sumed to be archaic. Still, it shows some early signs of a shift along the grammaticalization pathway of ( 3 a) above, moving toward being a full-fledged perfect gram, as it is not uncommonly found in the experiential use, as well as in a few cases of resultative and universal uses (cf. Appendix §§ A.1.3-A.1.5).

\subsection{Classical Greek (c. 500-300 BCE)}

In overview, the readings available to the three "past tenses" in Classical Greek are presented in Table 9. See Section 4.5 above for an explanation of the notation; cf. the appendix ( $\$$ A.2) for details about individual readings.

Beginning with the AORIST column, we see that the stative use of the Aorist is only marginally attested in the Classical language, occurring only in a few isolated examples in Attic drama (cf. Appendix § A.2.1). Universal perfect usage of the Aorist is attested at this stage (type 'have been (in some state) since some time ago and continuing up to or into the moment of utterance'), and the complexive use of the Aorist to state predicates has become regular (see below). In

22 For possible exceptions within the Archaic period see Appendix Section A.1.9 (cf. also $\S$ A.1.5 on the universal Aorist).

23 At least individual-level states (cf. n. 18). Stage-level states, such as $\delta \varepsilon i \delta \omega$ 'be afraid' or $\ddot{\alpha} \omega$ ( $\left.i \alpha v^{\prime} \omega\right)$ 'sleep', act at once like states and events, such that in the Aorist they often have inceptive interpretations (e.g., Il. 1.33) but can sometimes be used concentratively (e.g.,

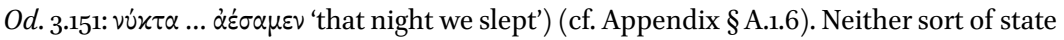
is used complexively in the Aorist at the Archaic stage, however. 


\begin{tabular}{|c|c|c|c|}
\hline & AOrist & IMPERFECT & Perfect/Pluperfect \\
\hline 1. & stative? (drama) & continuous state & stative \\
\hline 2. & [conative]? \{transfm. $\}$ & progressive-conative & intensive-frequentative? (drama) \\
\hline 3 . & resultative/"hot news" & resultative? (rare) & resultative/“hot news" \\
\hline 4. & experiential & (present) experiential $\{$ any $\}$ & experiential \\
\hline 5 . & present universal (rare) & (present/past) universal & universal \\
\hline 6. & concentrative-sequential & concentrative-sequential & concentrative[-sequential?] \{events\} \\
\hline 7. & counter-sequential & counter-sequential & counter-sequential $\{$ events\} \\
\hline 8. & inceptive & inceptive & inceptive $\{$ any $\}$ \\
\hline 9 . & complexive $\{$ states $\}$ & complexive \{non-achiev.\} & (Plpf.) \\
\hline 10. & $\operatorname{past}(/$ present $) \mathrm{CF}$ & present/past CF & (Plpf.: present/past CF) \\
\hline 11. & performative/reportive $\{$ events\} & $x$ & $x$ \\
\hline 12. & futurate $\{$ transfm. $\}$ & $x$ & futurate $\{$ events $\}$ \\
\hline 13. & egressive $\{$ accomp. $\}$ & $x$ & $x$ \\
\hline 14. & pluractional & pluractional & (Plpf.) \\
\hline 15 . & gnomic & past habitual & generic uses \\
\hline
\end{tabular}

addition, we now find clear performative/reportive usage of the Aorist (Bary 2012), which is especially common in (but not restricted to) Attic drama, as shown in (7).

\section{(7) Performative Aorist in Classical Greek

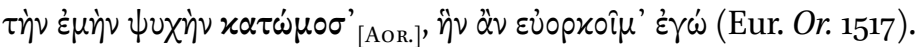 'I swear ${ }_{[\text {AоR.] }}$ by my soul, for which I would keep my oath'.}

There is also (very dubiously) said to be a "conative" Aorist usage (see Appendix $\S$ A.2.2). This is probably better classed with the well attested "futurate" use of the Aorist indicative (Appendix § A.1.12), which is typically used where English or Latin would have a Future or Future Perfect (Wackernagel 1926-1928 [2009]: 228), as shown in (8). In this example, the 'accomplishment' in question has yet to occur and so is located in the future, but it must logically precede its being 'ascribed' to Xerxes and so is construed in the Aorist (rather than the Present or Future), thus yielding a "future perfect" sort of value.

(8) Futurate ( $\approx$ "future perfect") use of the Aorist in Classical Greek

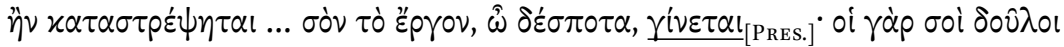

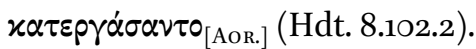
'If he (Mardonius) subdues (all that he says he will), then the achievement will be ascribed ${ }_{[\text {PREs.] }}$ to you, Sire; for your slaves will have accom- 
plished $_{[\text {AOR.] }}$ it [i.e., it will be your slaves who have wrought it]' (ex. and tr. Wackernagel 1926-1928 [2009]: 228).

The egressive interpretation of the Aorist is of clear regularity at this stage. It arises when only the culmination of an action is focused on, rather than its preparatory phase(s), which are typically expressed by the Imperfect (Gildersleeve \& Miller 1900: 94). We return to the egressive use later on (§6.3.2), with an example in (26) below. Lastly, the Aorist's use in sequential narration has expanded (Delbrück 1879: 114; Purdie 1898: 68), while its use in "perfect-like" contexts has diminished (see $§ 5.4$ ). Given this functional range, the Aorist must minimally express the relation $t_{E} \subseteq t_{A}$, representing the a fully grammaticalized (Type 1) perfective gram (to be treated more fully below, §6.1.1).

In the IMPERFECT column, we see most notably that the Imperfect is now regularly used for the expression of counterfactuality referring to the present time (though it may occasionally still have past reference under certain circumstances, particularly when the hypothetical event is imagined as ongoing in the past, on which see Smyth 1956: 518). Present counterfactuality is, according to Iatridou (2000: 239, 244-245), a characteristic function of imperfective aspect. Thus, the Imperfect of the Classical period, in terms of usage, better aligns with cross-linguistically paralleled uses of imperfective aspect than does the Homeric Imperfect. Though its denotation cannot have changed fundamentally from the Archaic period, as shown by its continued use in sequential narrative contexts (see below), it can be said to be losing functional "ground" to the Aorist (Delbrück 1879: 114), which is now preferred in a number of contexts previously favored by the Imperfect, such as complexive and inceptive to state predicates and concentrative-sequential (to all types of predicates). This pragmatic restriction favoring certain usages over others, without rendering any readings outright ungrammatical (and so not yet reflecting a change in the domain of semantics per se), shows early signs of what must have led to the eventual reinterpretation of the Imperfect as a grammaticalized imperfective gram within (or at least by the end of) the post-Classical stage.

Finally, the Perfect/Pluperfect column shows evidence of a now fully grammaticalized perfect gram, regularly expressing not only stative-resultative but also universal and experiential readings (see full discussion and analysis in Gerö \& von Stechow 2003). In addition, it is occasionally found in the concentrative use, though not yet in clear sequential narrative contexts. The Perfect (in addition to the Pluperfect) may now also be used in anterior/countersequential contexts (Rijksbaron 2002: 77; Smyth 1956:435), in competition with the Aorist, and it is on occasion found in inceptive and futurate uses as well (see Appendix ad loc.). 
Despite the fact that the Classical Greek Imperfect and Aorist share several of the same uses, there is partial complementary distribution according to situation type, at least for some of these functions. In general, the Aorist has inceptive uses only to state predicates (Smyth 1956: 430; Rijksbaron 2002: 2O21). The same appears to be true of the complexive use of the Aorist (cf. Basset 2009: 214), as shown in (9).

(9) Complexive Aorist in Classical Greek: $\beta \alpha \sigma i \lambda \varepsilon v$ u 'be king'

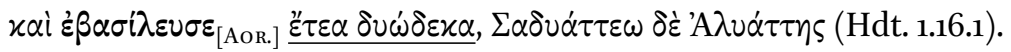
'And he (Sadyattes) reigned $_{[\mathrm{AoR} .]}$ for twelve years; then from Sadyattes Alyattes (received the kingship)'.

By contrast, the inceptive use of the Imperfect may occur with any situation type (with the possible exception of achievements, for practical rather than grammatical reasons, since achievements refer only to a culmination without its preparatory phase) (Hollenbaugh 202ob). The same is true of the Imperfect's complexive uses, as shown in (10), which has an activity predicate (or possibly an accomplishment, if $x \circ \mu i \zeta \omega$ is understood to mean basically 'bring home'). Here one may contrast the Aorist to the same verb in the concentrative function. ${ }^{24}$

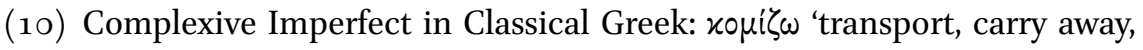
bring home'

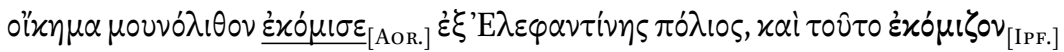

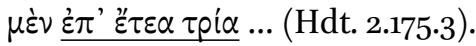

'He (Amasis) transported ${ }_{[\text {Aor. }]}$ from Elephantine a house made of a single stone, and they transported ${ }_{[I P F]}$ it for three years ...' (ex. and tr. Wackernagel 1926-1928 [2009]: 234: "i.e. they were occupied with its transport for three years").

The two complexive constructions can be seen side by side in (5) above, which shows a complexive Aorist to a state predicate beside a complexive Imperfect to an activity predicate.

The Imperfect in terminative uses (viz. concentrative and complexive) remains common until the end of the Classical period. The use of the Imperfect in sequential narration is, in fact, preferred to the Aorist in history (Rijksbaron

24 Citations from Herodotus of complexive uses of the Imperfect according to situation type are as follows: activity $(2.175 .3,5.68 .2)$, accomplishment (7.20.1), and state (1.18.1-3, 1.46.1, 1.106.1, 1.166.1, 2.140.2, 4.95.4, 4.158.1, 5.55.1). 
2019). ${ }^{25}$ Examples are given in (11) and (12), the latter of which shows coordination with the Aorist in the same function (just as in Homer; cf. (1) above).

(11) Sequential (and counter-sequential) Imperfect in Classical Greek

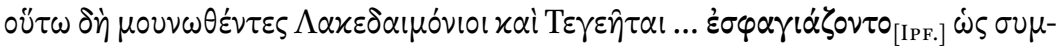

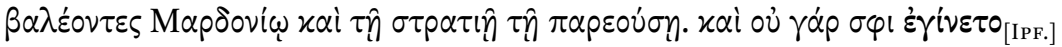

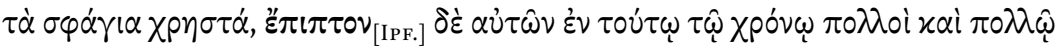

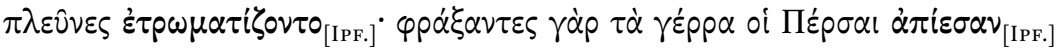
$\tau \hat{\omega} \nu \tau 0 \xi \varepsilon u \mu \dot{\alpha} \tau \omega \nu \pi 0 \lambda \lambda \dot{\alpha} \dot{\alpha} \varphi \varepsilon เ \delta \varepsilon \omega \varsigma$... (Hdt. 9.61.2-3).

'In just this way, having been left alone, the Lacedaemonians and the Tegeans ... offered sacrifice ${ }_{[\text {IPF. }}$ for the benefit of their joint attack on Mardonius and the army that was with (him). For their sacrifices did not turn out $_{[\text {[IF.] }}$ favorable, and in this time many of them fell(-dead)/died [IPF.] $_{\text {and }}$ and by far more got/were wounded [IP.] $_{\text {] }}$ for the Persians, having barricaded with their shields, (had) shot out ${ }_{[I P F]}$ an abundance of arrows unsparingly'.

(12) Sequential Imperfect (and Aorist) in Classical Greek

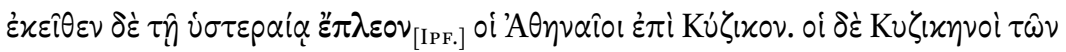

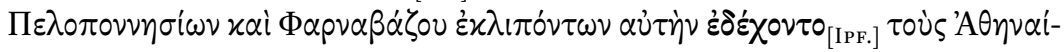

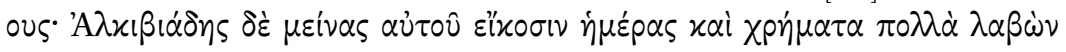

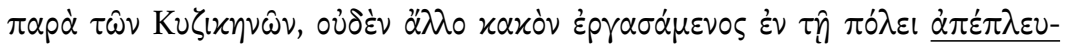

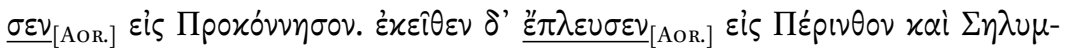
Bpíav (Xen. Hell. 1.1.19-20).

'From there (Proconnesus) the Athenians (with Alcibiades) sailed $_{\text {[IP.] }}$ on the next day against Cyzicus. The Cyzicenes, now that the Peloponnesians and Pharnabazus had evacuated the city, admitted ${ }_{[\mathrm{IPF}]}$ them. There Alcibiades stayed for twenty days, and obtained a great deal of money from the Cyzicenes, but without doing any further harm in the city, he sailed $\underline{\text { back }}_{[\text {Aor. }]}$ to Proconnesus. And from there he $\underline{\text { sailed }}_{[\text {Aor. }]}$ to Perinthus and Selymbria' (ex. and tr. Emde Boas et al. 2019: 429).

25 Delbrück (1879: 103) even asserts that "ist der Aorist der Griechen nie ein Tempus der Erzählung gewesen" ('the Greek Aorist has never been a tense of narration'; cf. also Wackernagel 1926-1928 [2009]: 235), though in fact the Aorist is not uncommonly used in sequential narration at all stages of Greek (Rijksbaron 2002: 13; Hollenbaugh 2018: 3031, 33, 44; BDF: 166). 
Attested readings of the Post-Classical Greek Aorist, Imperfect, and Perfect/Pluperfect ind.

\begin{tabular}{|c|c|c|c|}
\hline & AOrist & IMPERFECT & Perfect/Pluperfect \\
\hline 1. & [stative]? & continuous state & stative ("attained state" only) \\
\hline 2. & $x$ & progressive-conative & $x$ \\
\hline 3 . & resultative/"hot news" & $x$ & resultative/“hot news" \\
\hline 4. & experiential & $x$ & experiential \\
\hline 5 . & universal & past (only) universal & universal \\
\hline 6. & concentrative-sequential & concentrative-sequential & concentrative-sequential \\
\hline 7 . & counter-sequential & counter-sequential & counter-sequential \\
\hline 8. & inceptive (rare unless prefixed) & inceptive & inceptive \\
\hline 9 . & complexive $\{$ any $\}$ & complexive $\{$ states\} & (Plpf.) \\
\hline 10. & past CF & present/past CF & (Plpf.: past/present CF) \\
\hline 11. & [performative/reportive] & $\times$ & $\times$ \\
\hline 12. & futurate & $x$ & futurate? (rare) \\
\hline 13. & [egressive]? (prefixed only) & $x$ & $x$ \\
\hline 14. & pluractional & pluractional & $x$ \\
\hline 15. & gnomic & habitual & generic uses \\
\hline
\end{tabular}

\section{$5 \cdot 3$}

\section{Post-Classical Greek (Hellenistic Koine and Roman-Greek)} (c. 300 BCE-40oCE)

In overview, the readings available to the three "past tenses" in post-Classical Greek are presented in Table 10. See Section 4.5 above for an explanation of the notation; cf. the appendix ( $\$$ A.3) for details about individual readings.

By the time of post-Classical Greek, the experiential and resultative readings of the Imperfect are no longer found, which suggests categorical blocking on the part of the Aorist and Perfect in these contexts and a further push of the Imperfect toward imperfectivity. ${ }^{26}$

Also by the post-Classical period (and perhaps even beginning in the late Classical), the Imperfect in concentrative use is virtually restricted to verbs of communication, above all ह $2 \lambda \varepsilon \gamma \varepsilon v /-o v$ 'said' (BDF: 169-170; Wallace 1996: 541542; Robertson 1923: 882-884), as still in Modern Greek (Hedin 2000: 256-258). However, there are some occasional occurrences that seem genuinely sequential, as in (13). ${ }^{27}$

26 Particularly of Type $1\left(t_{E} \supset t_{A}\right)$, since Type 2 imperfects and simple past grams (Type 3 ) are known to permit experiential readings (cf. Appendix § A.2.4).

27 This differs from the even more restricted (lexically and syntactically speaking) "narrative" use of the Imperfects found in Modern Greek and Romance (cf. Hedin 200o: 255-256, 262-263). 
(13) Sequential Imperfect in post-Classical Greek (rare)

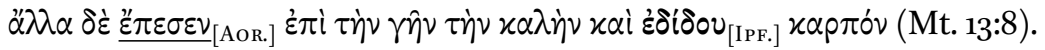
'But other (seed) $\underline{\text { fell }}_{[\text {AOR.] }}$ onto good soil and produced ${ }_{[\text {IPF. }]}$ a crop'.

Yet examples of this kind are quite rare, such that we may observe a far more limited application of the concentrative interpretation of the Imperfect at this stage than at the Classical and Archaic stages, seeing as it is restricted to a high degree by lexical item (mostly to verbs of communication) and syntactic/discursive environment (strongly dispreferred in sequential narration).

The complexive use of the Imperfect has also essentially disappeared by this period, having been taken over by the Aorist (Purdie 1898), except to verbs lack-

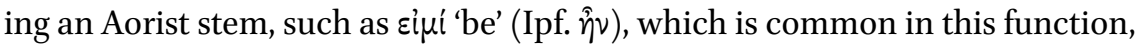
as in (14a). A possible exception is (14b), where a non-copular state predicate shows complexive function in the Imperfect.

(14) Complexive Imperfect in post-Classical Greek (very rare apart from $\hat{\eta} v$ 'was')

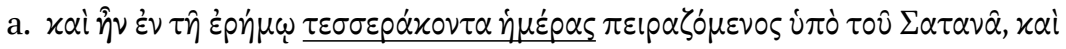

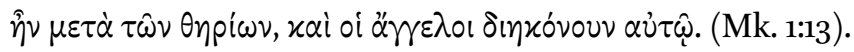

'And he was in the desert for a forty days being tempted by Satan, and he was among the beasts, and the angels attended/were attending him'.

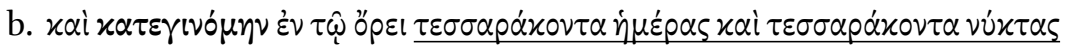
(Deu. 9:9).

'And I stayed on the mountain for forty days and forty nights'.

With these two near losses_-admitting regular exceptions, as in the case of $\hat{\eta} v$ 'was', and sporadic others - the Imperfect effectively loses its terminative functions (viz. concentrative and complexive), becoming practically restricted to use in "canonical" imperfective (i.e., non-terminative) contexts, namely those uses compatible with the relation $t_{\mathrm{B}} \supset \mathrm{t}_{\mathrm{A}^{*}}$. Still, given the existence of the attested concentrative and complexive uses of the Imperfect at this stage, it seems best to view this restriction as pragmatic in nature, rather than semantic, such that the denotation of the Imperfect remains that of an aspectually neutral simple past gram $\left(t_{\mathrm{E}} \circ \mathrm{t}_{\mathrm{A}}\right)$, thus predicting the grammaticality of sentences like those in (13) and (14) above, while admitting that such sentences have come to be dispreferred in favor of alternative constructions involving the Aorist or Perfect. Due to the pragmatic limitations on the use of the Imperfect in terminative contexts at the post-Classical stage, I suggest that its denotation as aspectually neutral became unrecoverable to learners at a later stage, and so the Imperfect 
was ultimately reinterpreted as semantically imperfective $\left(t_{E} \supset t_{A}\right)$, as it remains in the Modern language.

As for the Aorist, it now seems to be freely used in the universal-perfect function, whether past or present, as shown in (15) (cf. Appendix § A.3.5 for further discussion). I take this innovation of usage to be due to the fact that the Perfect is no longer functionally a perfect gram and so no longer takes precedence over the Aorist in universal contexts (cf. discussion in $\$$ 6.1.1 below).

(15) Universal Aor. in post-Classical Greek: present (a-b) or past (c) reference

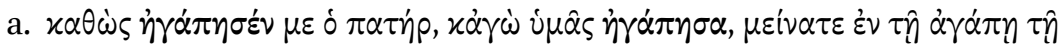

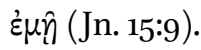

'As the Father has loved me, so have I loved you. Remain in my love'.

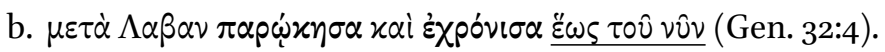
'I have been residing with Laban and have been spending time (there) until now'.

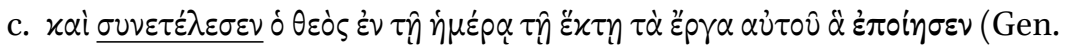
2:2).

'And on the seventh day god finished the work that He had been doing'.

In addition, the Aorist has taken over the complexive use to all predicate types (cf. Appendix § A.3.9), rather than just states as it had in Classical Greek. Examples are given in (16), which shows the Aorist built to state predicates (16a) and event predicates $((16 \mathrm{~b})-(16 \mathrm{~d}))$ in complexive value. The event predicates range from activities (16b) to accomplishments (16c) and even achievements (16d).

(16) Complexive Aor. in post-Classical Greek: states (a) and events (b-d)

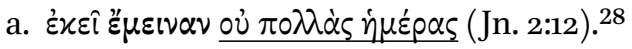

'They stayed there for a few [lit. 'not many'] days'.

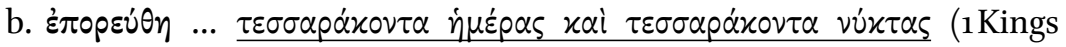
$19: 8) .^{29}$

'He traveled for forty days and forty nights'.

28 Other complexive Aorists built to state predicates at this stage include: Acts 2o:6, Job 2:13, Ezk. 3:15, Jdg. 3:11, Ps. 95:10, Heb. 3:9-10, 3:17.

29 Other complexive Aorists to activity predicates at this stage include: Neh. 9:21, Deu. 9:9, 18,25 . 
TABLE 11 Development of the regular means of expressing the complexive reading in Greek

\section{STATE PREDICATES ELSEWHERE}

\begin{tabular}{lll} 
I. Archaic & Imperfect(/Aorist) & Imperfect \\
II. Classical & Aorist $(/$ Imperfect) & Imperfect \\
III. post-Classical & Aorist(/Imperfect) & Aorist \\
\hline
\end{tabular}

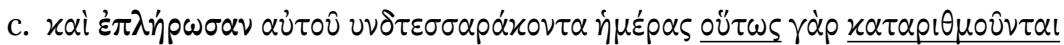

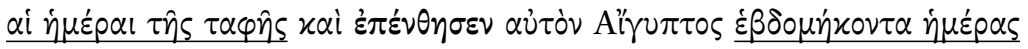
(Gen. 50:3). ${ }^{30}$

'And (the physicians) embalmed him for forty days, for thus were the days allotted for burial. And Egypt mourned him for seventy days'.

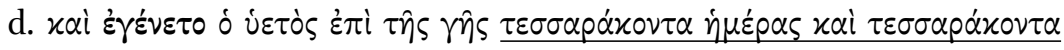

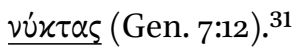

'And the rain occurred/came about on the earth for forty days and forty nights'.

This change completes a fundamental shift in the means by which Greek expresses the complexive reading: from Homer's regular use of the Imperfect and exceptional use of the Aorist in complexive contexts to Classical Greek's use of the Aorist for state predicates and the Imperfect elsewhere to the postClassical Greek situation, wherein the Aorist is regularly complexive for all predicate types and the Imperfect is exceptional. This development is summarized in Table 11, with parentheses enclosing forms used marginally at a given stage (see Appendix for details).

Meanwhile, according to Purdie (1898), what had been the inceptive and egressive functions ("perfective" in Purdie's (1898) terms) of the simplex Aorist have been largely taken over by the Aorist with various prefixes, while the simplex Aorist is practically restricted to the complexive and concentrative readings (Purdie's (1898) term is "constative," a category which overlaps partly with

30 Other complexive Aorists to accomplishment predicates at this stage include: Ezr. 6:22, Neh. 8:18, and cf. especially ह̇ं 35:17.

31 Other complexive Aorists to achievement predicates at this stage include: Jdg. 6:1, 13:1. 
my complexive and partly with my concentrative; cf. n. 65 in Appendix § A.1.9). Accordingly, the Aorist is at this stage used in sequential narration to the near exclusion of the Imperfect (Delbrück 1879: 114; Purdie 1898: 68). Thus, as the Aorist comes to be more and more "perfective-like" in terms of its functional range (conforming to the cross-linguistic grammaticalization pathway in ( $3 \mathrm{a})$ above) the Imperfect comes to be increasingly "imperfective-like" in its usage, in what appears to be a sort of "push-chain" effect.

\section{4 "Aoristic drift"}

The diachronic change in usage of the Imperfect, I claim, depends crucially on interaction with the Aorist (and to some extent with the Perfect). Due to its semantic change along the lines of the grammaticalization path in (3a) above (so-called "aoristic drift"), the Aorist comes to be preferred to the Imperfect in contexts where it had not been previously (such as complexive) or to be predominant in contexts that had previously admitted of a high degree of variability between the Aorist and Imperfect (such as concentrative-sequential). Thus, to explain the observed changes of the Imperfect, it is necessary first to explain the changes observed for the Aorist. This section explains how the grammaticalization path in (3a) above applies to the Greek Aorist and provides some further evidence for its taking place within the historical stages under investigation here. I will then suggest how these changes interact with the Imperfect to bring about its own functional changes observed in the data.

As seen above, in the course of Ancient Greek the Aorist loses its stative function, ${ }^{32}$ while the complexive and futurate readings become more common over time. The conclusions of Hollenbaugh 2018 suggest that the Aorist in Homer expresses perfect aspect more readily, at least, than in later Greek. ${ }^{33}$ This is why the Homeric Aorist has been identified here as an "emergent per-

32 On the stative reading as a function of the perfect aspect, see Kiparsky 2002: 113. Importantly, the stative use found in the oldest Greek literature differs from superficially similar uses found later on, in that the Archaic Greek stative Aorist is built only to state predicates, which are characterized as ongoing in the present without presupposing a change-of-state event from which that state has resulted (type $\dot{\varepsilon} \varphi$ ' $\lambda \lambda_{\eta} \sigma \alpha$ 'I love'). This is a fundamentally "perfect-like" reading (compare the similar use of the Archaic Greek Perfect built to state predicates, discussed in Appendix § A.1.1). Later (cf. Appendix § A.3.1), the Aorist built to change-of-state (i.e., transformative) predicates can yield an "attained state" reading (type 'I have come' and so 'am here'), which is a reading typically expressed by perfect or perfective grams across languages (including the Perfect in Ancient Greek and the Perfectives, e.g., in Arabic and Russian).

That this "perfect-like" function of the Aorist is inherited is confirmed by comparison to Indo-Iranian and Old Russian, among others (see Schwyzer-Debrunner: 277, 281-282). 
fective" gram, which is a cross-linguistically motivated category (gram type) that expresses perfect aspect (showing readings typically expressed by perfect grams) that also has uses properly belonging to the perfective aspect (typically expressed by perfective grams) (cf. §6.1.1). The respective functional ranges of the Aorist summarized in Tables 8 and 9-10 above suggest a diachronic change from the Homeric Aorist as an emergent perfective gram-expressing perfect aspect but regularly compatible with "perfective-like" uses- to the Classical and post-Classical Greek Aorist as a perfective gram-expressing perfective aspect, which is compatible with some "perfect-like" uses. ${ }^{34}$

One way to check this claim and track its validity over the history of Greek is to search for Aorist forms in contexts that are especially conducive to "perfectlike" interpretations, including especially the resultative and experiential readings. The most reliable adverb that evokes such readings is vôv 'now', since it is practically restricted to present time reference, such that $t_{A} \supset t_{0 / s}$ (accordingly, it is almost never found scoping over the Imperfect; cf. Hollenbaugh 2018: 45). This differs from other Greek adverbs meaning 'now', such as ทैס 'already, (by) now', that allow use in past narration (such that $\mathrm{t}_{\mathrm{A}}<\mathrm{t}_{0 / \mathrm{s}}$ ), not uncommonly cooccurring with the Imperfect in the sense 'was already/by now doing X'. vชิv is also favorable in that its use in the meaning 'now' spans the whole of documented literary Greek (to the present day), unlike other adverbs of currency, which are confined to one period or another, such as $\pi \omega$ 'yet' (Homeric, cf. Hol-

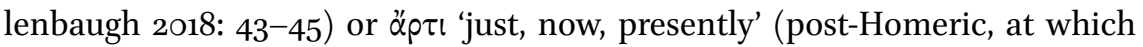
time it occurs only rarely with the Aorist, as expected under the analysis put forth here).

Figure 4 shows the occurrence of vôv followed within 5 words by an Aorist indicative, per 10,000 words (to account for differing corpus sizes), in rough chronological order by author (or text in the case of the Homeric works, their "authorship" being uncertain). ${ }^{35}$ Though this method necessarily includes a

34 Recall that, cross-linguistically, the functional range available to the perfect aspect is a strict subset of the functional range available to the perfective aspect, so perfectives can typically apply in a wider range of contexts than perfects, including in contexts where perfects characteristically occur, such as resultative contexts. Still, there is a difference between a perfect gram that admits of perfective uses, which I call an "emergent perfective" gram (cf. §6.1.1), and a fully grammaticalized perfective gram, which definitionally entails at least some "perfect-like" uses (resultative and often experiential, and sometimes universal and/or stative for "attained states"). This difference is made explicit in Section 6 below and is meant to capture and account for the difference in the functional ranges available to the Aorist at the Archaic stage vs. the Classical stage, as reflected in Tables 8 and 9 .

Data retrieved from Perseus under PhiloLogic November 2, 2019. 


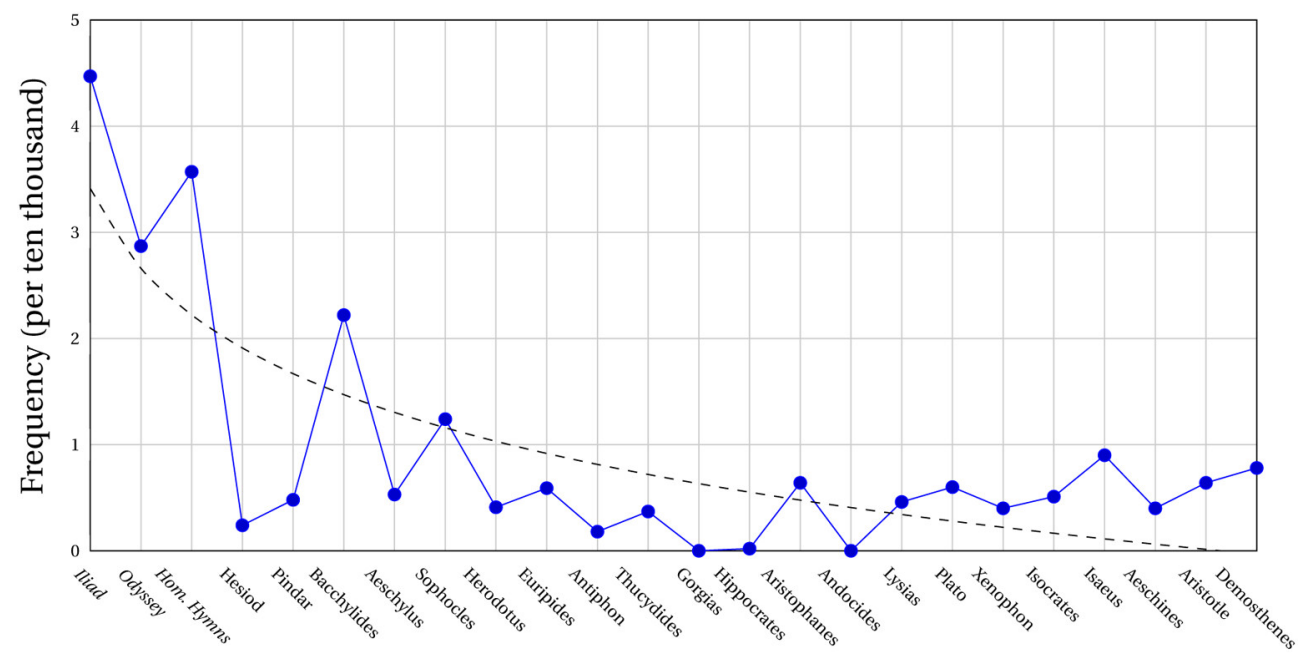

Authors/Works (ordered chronologically, earliest to latest)

$$
r(22)=-0.776395689, p<.001
$$

FIGURE 4 ขิv 'now' within 5 words preceding the Aorist indicative

considerable amount of data in which vôv does not actually scope over the Aorist (i.e., they just so happen to be within 5 words of one another), in the vast majority of cases the data points do represent genuine examples of an Aorist under the scope of vôv. In Homer, where the occurrences are by far the most frequent, I have checked the data returned by Perseus under PhiloLogic against my data collected "by hand" for Hollenbaugh 2018 and have found that nearly all of them not only represent genuine examples of an Aorist under the scope of $v 0 \hat{v}$ but also have a clearly resultative (or sometimes experiential) value.

As can be seen in Figure 4, there is a general downward trend in the frequency of the Aorist indicative under the scope of vôv 'now', which has resultative (or experiential) perfect readings 'have (as of) now done/been X'. This is shown plainly by the logarithmic regression line (i.e., the curving dashed line) trending downwards from Homer to Demosthenes (chosen as an arbitrary cutoff within the Classical period, the trend line leveling off by this point). Authors/texts are ranked by time from most ancient to least ancient. The statistical hypothesis tests - namely the probability value ( $p$-value) and the Pearson correlation coefficient ( $r$-value) - given below the chart indicate a strong correlation between the two variables, viz. time ( $x$-axis) and frequency of the co-occurrence of the Aorist with vôv (y-axis): As time goes on, the collocation $v \hat{v} v+$ Aorist becomes less frequent. This trend is expected if the Aorist is indeed becoming more "perfective-like" over time, such that its resultative and experiential uses become less central to its functional range. 
A similar trend can be observed for the Aorist in anterior/counter-sequential contexts (also called "relative past," of the type "had done X'; cf. Appendix $\S$ A.1.7), which are characteristic of perfect aspect and essentially equivalent to the resultative or experiential readings shifted into the past (cf., e.g., I have tried sushi $\rightarrow$ Once I had tried sushi, I realized I loved it). To verify this, I have conducted searches, using Perseus under PhiloLogic, for the Aorist within 5 words following the conjunctions ö $\tau \varepsilon$ and $\dot{\varepsilon} \pi \varepsilon i(\delta$ '), both meaning 'when', in the same Greek authors as above. The results of these two searches are summarized in Figures 5 and 6. The same sort of downward trend line seen in Figure 4 is seen in each of these figures as well, again shown to be statistically significant by the results of the hypothesis tests ( $r$-and $p$-values) below each figure, indicating a strong correlation between variables.

The data suggests that the Aorist is used less and less in characteristically "perfect-like" contexts over time (though it never becomes incompatible with such contexts). This is, no doubt, in part due to the fact that the morphological Perfect is also moving along the same "perfect(ive) cline" seen in (3a) above (as demonstrated already by Gerö \& von Stechow (2003)), grammaticalizing into a perfect gram by the Classical period and so partially blocking the application of a number of uses formerly expressed more typically by the Aorist, particularly its resultative and counter-sequential/relative past functions. This seems to have contributed to limiting the Aorist's application largely to terminative contexts, namely concentrative-sequential ${ }^{36}$ and complexive (cf. Purdie's (1898) "constative"). This, in turn, puts pressure on the Imperfect not to be used in sequential narration or complexive contexts. ${ }^{37}$ Thus, the Aorist becomes more and more the default tense for complexive use and for sequencing events in past narration (concentrative), in preference to the Imperfect. ${ }^{38}$ This distribution, beginning already in Homer, is categorical by the time of post-Classical Greek (cf. Browning 1983: 29, 34) - a diachronic development explicitly observed by Delbrück (1879:114): "Es ist ... gezeigt, dass das Imperfectum das altüberlieferte Tempus der Erzählung ist, dass aber im Griechischen

36 "The perfect was dropped in later Greek ... after it had earlier competed in vain with the aorist as a narrative tense" (BDF: 176).

37 That the concentrative-sequential Imperfect is inherited into Greek is strongly supported by comparison to Indo-Iranian, Anatolian, Slavic, and other IE languages (see, e.g., Wackernagel 1926-1928 [2009]: 235; Schwyzer-Debrunner: 276-277; Hollenbaugh 2018; cf. Kühner-Gerth: 144). Rijksbaron (2019), Basset (2009: 218-219), and Delbrück (1897: 103106) view the Imperfect as the (unmarked) tense of sequential narration in Classical Greek, while the Aorist always contributes some other nuance (cf. nn. 25, 53, and 57).

38 On the sequential-narrative use of the Aorist as a secondary development of Greek, see Purdie 1898: 68. 


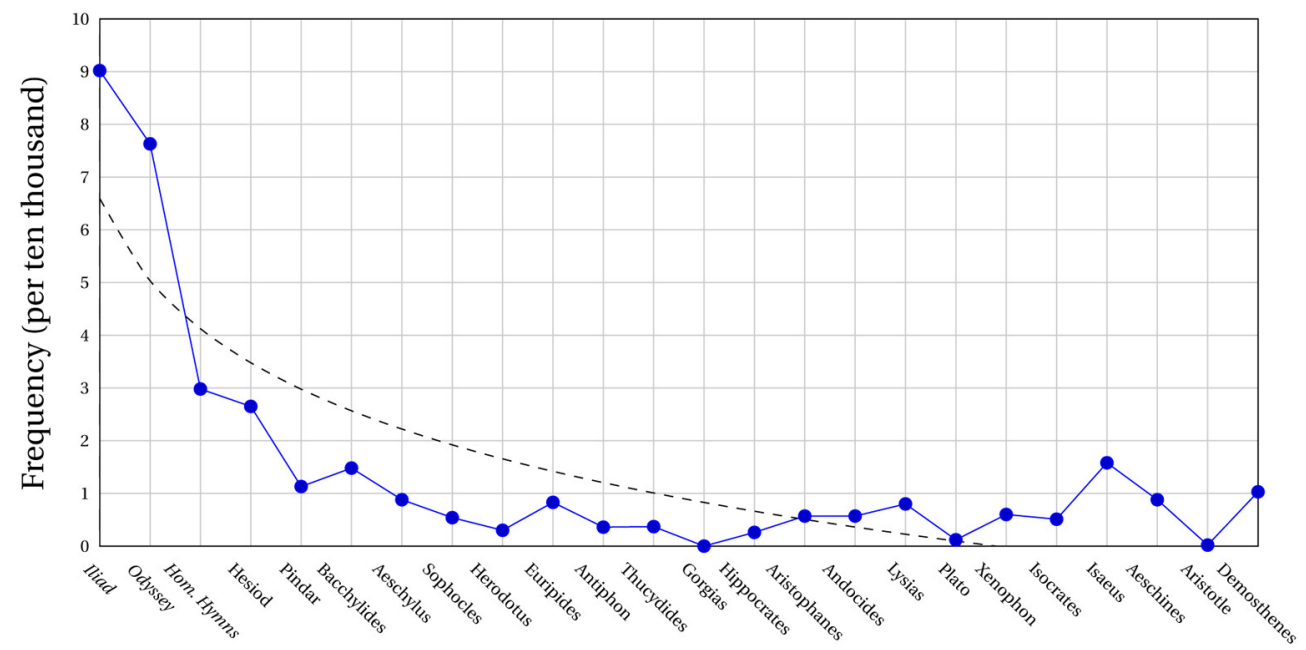

Authors/Works (ordered chronologically, earliest to latest)

$$
r(22)=-0.831374552, p<.001
$$

FIGURE 5 ö $\tau$ 'when' within 5 words preceding the Aorist indicative

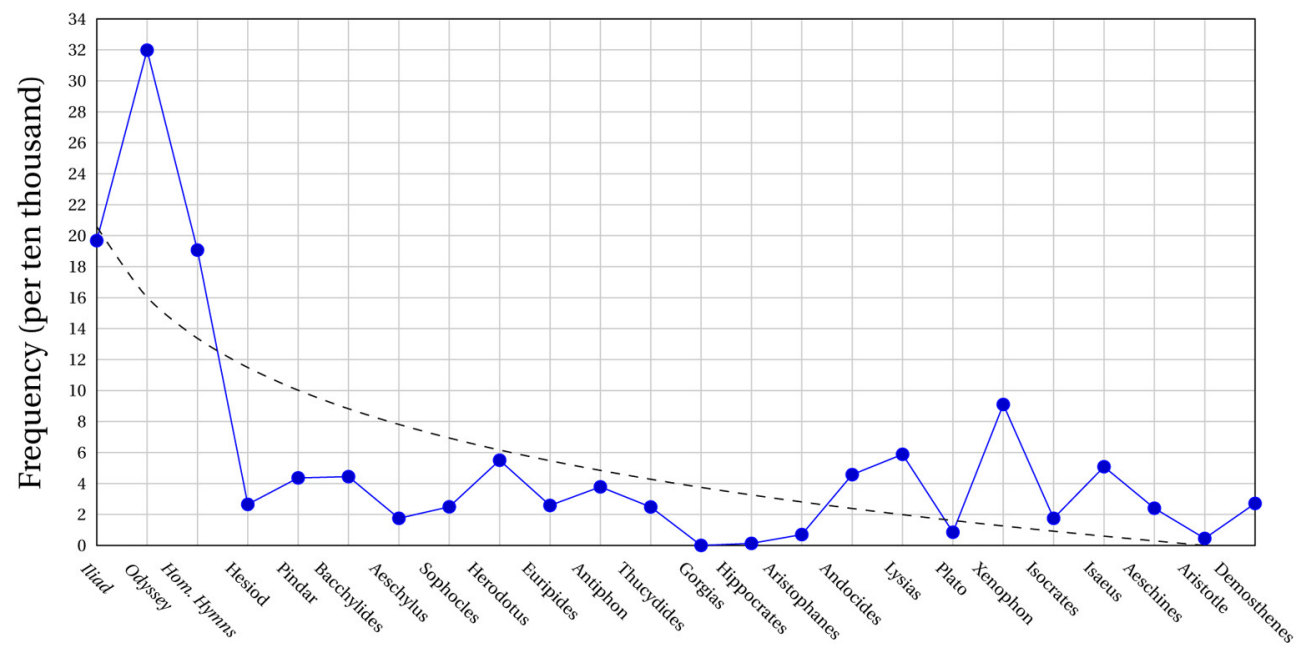

Authors/Works (ordered chronologically, earliest to latest)

$$
r(22)=-0.721238917, p<.001
$$

FIGURE $6 \quad \dot{\varepsilon} \pi \varepsilon i(\delta \dot{\eta})$ 'when' within 5 words preceding the Aorist indicative 
der Aorist demselben immer mehr Terrain ab hat" ("It is shown that the Imperfect is the ancient tense of narration, but that in Greek the Aorist gains more and more ground from it').

\subsection{Local summary: trends conspiring to bring about the simple past to imperfective shift}

To summarize, the inceptive Aorist and Imperfect become increasingly common in the Classical stage (Hollenbaugh 202ob; Friedrich 1974: 10; Wallace 2006; Jacobsohn 1933: 308-309),39 as does the complexive Aorist (Jacobsohn 1933: 305-310; Schwyzer-Debrunner: 281), even being built to event predicates in the post-Classical stage. ${ }^{40}$ In other words, the Aorist indicative is built to state predicates - which is the only predicate type that regularly gives rise to inceptive and complexive readings of the Aorist in Classical Greek-with increasing frequency after Homer.

The Imperfect, meanwhile, is not used for present counterfactual conditions until after the Archaic stage, when it becomes the regular means of expressing present counterfactuality. As mentioned above, this is in line with a crosslinguistic observation of Iatridou's (2000: 239, 244-245) that past-tense imperfectives tend to express counterfactuality only for the present time (type 'if she were doing $X$...'). That the Homeric Imperfect lacks this use is therefore unsurprising only if it was not yet an imperfective (semantically or pragmatically) (cf. Hollenbaugh 2018: 2, 32). The post-Homeric Imperfect is thus more in line with a canonical imperfective (Type 1 or 2) than was its ancestor in Archaic Greek.

By the post-Classical stage the complexive use of the Imperfect virtually disappears $^{41}$ (which may be related to the loss of its experiential use at the same

39 For instance, to $\beta \alpha \sigma i \lambda \varepsilon \dot{\omega} \omega$ 'reign' I find only one inceptive in Homer, which is Imperfect $(\mathrm{Od}$.

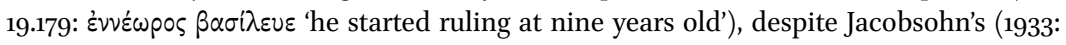
309) denial of such an example. The Aorist $\dot{\varepsilon} \beta \alpha \sigma i \lambda \varepsilon v \sigma \varepsilon$ in a complexive function becomes common only later. Further, of the pair ${ }^{\circ} \sigma \chi v \sigma \alpha \nu$ (Aor.) and $i \sigma \chi v 0 v$ (Ipf.), respectively meaning, according to Jacobsohn (1933: 308), 'they gained power' and 'they came to power', the earliest inceptive example is the Aorist at Dem. 9.23 ('gained some authority'). Its Imperfect does not occur in clearly inceptive meaning, as far as I can see, until Septuagint (Ex. 1:12, 20) and the New Testament (Acts 19:20).

40 Purdie (1898: 152-153) concludes that the complexive use (which she calls "constative") is rare in Homer but becomes "the main one pertaining to the Aorist in later Greek," beginning already in Classical and categorical by the time of Polybius (post-Classical). She comes to this conclusion despite having a more permissive definition of complexive (her "constative") than the one I have adopted here, thus leading her to adduce a greater number of possible examples of complexive Aorists in Homer (cf. n. 65 in Appendix §A.1.9).

Despite Jacobsohn 1933: 305, the Imperfect of $\beta \alpha \sigma \lambda \lambda \varepsilon v ं \omega$ 'reign' never occurs with हैंท 'years' 
stage), and the concentrative-sequential function has fallen almost entirely to the Aorist. In this way, there come to be fewer and fewer contexts in which the Imperfect is favored outside of its "backgrounding" functions in a discourse (such as its progressive and habitual readings), as the Aorist and Perfect emerge as the forms for characterizing events as complete or "bounded" in the past, whether complexive, inceptive, or concentrative-sequential.

Nonetheless, although the terminative uses (i.e., concentrative-sequential and complexive) of the Imperfect become more and more restricted both lexically and in frequency of use, at no period from Homer to the Hellenistic Koine is the Imperfect incompatible with terminative contexts (i.e., canonical "perfective" contexts), as Wackernagel (1926-1928 [2009]: 235) is careful to observe, and as is evident from their sustained attestation into the post-Classical stage (however infrequent). Therefore, a sufficient analysis must account for the grammaticality of terminative uses of the Imperfect at the post-Classical stage, while simultaneously explaining their restricted application in terminative contexts at this stage.

I accomplish this in the next section (§6) by supposing that the semantic denotation of the post-Classical Imperfect permits terminative readings (since it remains aspectually neutral) but that the realization of the Imperfect in contexts that would elicit terminative readings is partially blocked (pragmatically) by interaction with the Aorist and Perfect, whose perfective denotations make them preferred in terminative contexts. I further include in my analysis an account of how the post-Classical situation must have emerged out of the earlier two stages, in which the Imperfect was not averse to (and was even favored in) terminative functions. Finally, I suggest that the blocking of the Imperfect's application in terminative contexts by the Aorist eventually became categori$c a l$, such that its semantic compatibility with terminative uses would no longer have been recoverable to learners. As a result, the Imperfect must have at last undergone genuine semantic change by the beginning of the Medieval period, being reanalyzed as denoting imperfective aspect $\left(t_{\mathrm{E}} \supset \mathrm{t}_{\mathrm{A}}\right)$, rather than simply being compatible with it, as it had been in the Ancient stages (I-III) under its "neutral" denotation $\left(t_{\mathrm{E}} \circ \mathrm{t}_{\mathrm{A}}\right)$.

(confirmed by a TLG search), though its Present infinitive does (see (23) below and cf. Basset 2009: 215, 217). 


\section{Analysis}

\subsection{Semantic denotations: specifying the stages}

The denotations at the various stages of development outlined in Section 3 above are in need of some refinement in order to adequately account for exactly those readings regularly available to each functional category at each stage of development as presented in Section 5 .

\subsubsection{Semantics of the Aorist}

As shown in Table 8 above, in Archaic Greek the Aorist must be compatible with readings typical of perfect aspect, including the stative use, while also being compatible with the concentrative use but not the complexive use. The affinity of the Archaic Aorist for readings more typical of stative-resultative or perfect grams suggests that it is not yet fully grammaticalized as a perfective gram, but neither does it fit the profile of a perfect gram, since perfect grams typically lack concentrative as a use. Technically speaking, then, the Homeric/Archaic Aorist is best understood as an emergent perfective (for details and comparative evidence, see Hollenbaugh 2018). The term "emergent perfective" is my (hopefully more intuitive) relabeling of a category with a variety of confusing names in the typological literature on aspect ("bad perfect" in Laca 2010: 6-7, "old anterior" in Bybee et al. 1994: 78-81). By this label I simply refer to a gram type that exists in the synchronic grammars of some languages (including the language of Homer) and has properties of both the perfect and the perfective gram types but cannot be adequately characterized as either one. From a diachronic perspective, this represents an intermediate stage between a perfect and perfective gram on the grammaticalization pathway shown in (3a) above. Yet it has real, synchronic status as a grammatical category, which can be defined semantically, as shown in (17) below.

In concrete terms, I take the difference between the perfect gram type and the emergent perfective gram type to be that the perfect requires that assertion time $\left(t_{A}\right)$ include speech time $\left(t_{s}\right)$ or local evaluation time $\left(t_{0}\right),{ }^{42}$ while the emergent perfective does not. ${ }^{43}$ The difference between the emergent perfective and

42 For "local evaluation time" ( $\left.\mathrm{t}_{0}\right)$ see von Stechow 1995: 369 and E. Dahl 2010: 56, also called "perspective time" (cf. Kiparsky 1998: 38; 2002: 115). Unless "past shifted" (e.g., narrative present) or "future shifted" (e.g., present for future), $t_{0}$ coincides with speech time $\left(t_{s}\right)$. Evaluation time is used in the formal semantic denotations of this paper rather than simply speech time, since it is technically a more precise term in that it allows denotations to be more readily generalizable to all contexts than does a system which operates with speech time alone.

43 So, to be precise, the denotation of perfect aspect is: $\left[\lambda P . \lambda \mathrm{t}_{\mathrm{A}} \cdot \exists e\left(\mathrm{t}_{e} \subset \mathrm{t}_{\mathrm{A}} \wedge \mathrm{t}_{e} \leq \mathrm{t}_{0} \wedge \mathrm{t}_{\mathrm{A}} \supseteq\right.\right.$ $\left.\left.\mathrm{t}_{0} \wedge P(e)=1\right)\right]$. Contrast this with the emergent perfective denotation in (17), which is 
fully grammaticalized perfective gram types is that the former requires that eventuality time at least partially precede speech/evaluation time $\left(t_{\mathrm{E}} \leq t_{0 / \mathrm{s}}\right)$, while the latter does not (cf. (18) below). The simple past gram type (neutral aspect) requires only an overlap relation between eventuality time and assertion time $\left(t_{\mathrm{E}} \circ \mathrm{t}_{\mathrm{A}}\right)$ and that assertion time at least partially precede speech/evaluation time $\left(t_{A} \leq t_{0 / s}\right)$, which is to say that it is past in tense. The change from perfect to emergent perfective to perfective or simple past over time is what is meant by "aoristic drift" (cf. Willi 2018: 411-412), which corresponds to the grammaticalization pathway (or "cline") in (3a) above. Each subsequent stage on this cline shows a "weakening" (or broadening) of the semantics associated with the form in question (in this case the Aorist), as is clear from the denotations here presented.

\section{Archaic Greek Aorist:}

Based on the data summarized in Table 8 in Section 5.1 at the earliest attested stage the Greek Aorist can be identified as an emergent perfective gram, whose denotation is in (17). Here and below, for ease of comparison, I put in boldface the parts of the denotation that are most important with respect to the diachronic developments of interest to this analysis (such as those most relevant to the grammaticalization path of (3a) above). Note that " $\mathrm{e}$ " denotes the runtime or temporal correlate of the eventuality instantiating the eventuality description $P$. That is, it corresponds to what I have been notating as " $\mathrm{t}_{\mathrm{E}}$ " so far. The lambda operator $(\lambda)$ may be taken to abstract over the variables $\left(\mathrm{P}, \mathrm{t}_{\mathrm{A}}\right)$ and to ensure that they pick out exactly the right set of referents.

(17) Emergent-perfective denotation of the Aorist in Archaic Greek $\left[\lambda \mathrm{P} . \lambda \mathrm{t}_{\mathrm{A}} \cdot \exists e\left(\mathbf{t}_{e} \subset \mathbf{t}_{\mathbf{A}} \wedge \mathbf{t}_{e} \leq \mathbf{t}_{\mathbf{0}} \wedge P(e)=1\right)\right]$

For some eventuality $e$, eventuality time $t_{e}$ is properly included in assertion time $t_{A}$, and the eventuality time at least partially precedes the local evaluation time $\mathbf{t}_{\mathbf{0}}$ (by default equals speech time), and the eventuality description $P$ applied to the eventuality $e$ is true (1).

Since nothing is said in (17) about the relation between assertion time $\left(t_{A}\right)$ and speech/evaluation time $\left(\mathrm{t}_{0 / \mathrm{s}}\right)$, assertion time is free to precede the evalua-

slightly "weaker" in that it lacks the requirement that $t_{A} \supseteq t_{0}$. My formulation of perfect aspect amounts, in a manner of speaking, to a sort of Neo-Reichenbachian version of the Extended Now (XN) framework (McCoard 1978; Dowty 1979), with $t_{\mathrm{A}}$ representing the XN interval. Yet my framework allows for this interval $\left(t_{A}\right)$ to be used consistently across the denotations of all aspect types, rather than being something peculiar to the perfect aspect alone. 


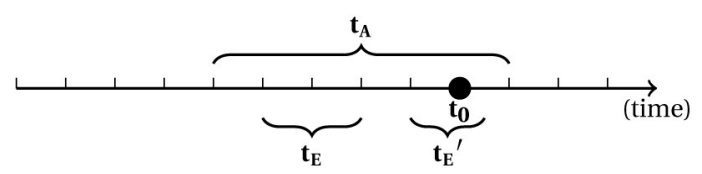

FIGURE 7 PERFECT aspect: resultative/experiential

$\left(t_{\mathrm{E}}\right)$ and stative $\left(\mathrm{t}_{\mathrm{E}}{ }^{\prime}\right)$ readings

tion time (i.e., $\mathrm{t}_{\mathrm{A}}<\mathrm{t}_{0}$ ), which corresponds to past tense (following Klein 1994: 124). This, coupled with the fact that (17) requires eventuality time to be fully included in assertion time, is what permits the various "preterital" uses associated with the Aorist, as enumerated in Table 8, above all the concentrativesequential reading (represented in Figure 3 above). ${ }^{44}$ This is also what sets the Archaic Greek Aorist apart from plain perfect grams, which typically are not compatible with the temporal relation $\mathrm{t}_{\mathrm{A}}<\mathrm{t}_{0}$ ( $\mathrm{cf}$. $\mathrm{n} .43$ above), and distinguishes it as an emergent perfective (permitting but not requiring that $t_{A} \supseteq t_{0}$ ).

However, the denotation in (17) is also compatible with the relation $t_{A} \supseteq t_{0}$, which yields the present perfect readings of the Aorist (resultative, experiential, and stative), as represented in Figure 7. The perfect aspect readings, in general, come in four different varieties, for which the reader is referred to the appendix for full discussion. By way of example, the resultative reading is of the type Look how far we've come (result state still holds at $\mathrm{t}_{0 / \mathrm{s}}$ ), the experiential reading is of the type I have been to Paris (consequent state still holds at $\mathrm{t}_{0 / \mathrm{s}}$ ), the stative reading is of the type I've got something to tell you (the eventuality is itself a state that holds at $\left.\mathrm{t}_{0 / \mathrm{s}}\right)$, and the universal reading is of the type I've lived in LA for six years now (i.e., the eventuality proceeds from some point in the past and continues up to the present of $\mathrm{t}_{0 / \mathrm{s}}$. A consequent state is one that follows necessarily from the mere fact of an event's having taken place. It is a property of a time such that it is preceded by a time which contains an eventuality of a particular sort, such as GO TO PARIS. A result state is the target state of a change-of-state predicate. Given that the target state of come is BE HERE, the result state implied by We've come is WE ARE HERE.

44 On the inceptive reading, see now Hollenbaugh $202 \mathrm{Ob}$ and cf. § A.1.8 in the appendix to this paper. This paper does not attempt to solve the perennial problem of the gnomic Aorist, which I have addressed elsewhere (Hollenbaugh 2020a). I will say here only that the denotations presented in this section are no less compatible with the gnomic reading of the Aorist than any other proposals that have (to my knowledge) been put forth. Various other readings of the Aorist at this and subsequent stages, such as the "pluractional" uses or the "past counterfactual" pose no problem for the denotations presented here but are also not of particular interest for the aims of this section and are accordingly passed by in silence (cf. Appendix § A.1.10). 
Where the assertion time $\left(t_{A}\right)$ includes the speech/evaluation time $\left(t_{0 / s}\right)($ as admitted by (17)), if the eventuality time $\left(t_{\mathrm{E}}\right)$ fully precedes $\mathrm{t}_{0 / \mathrm{s}}$ (as also admitted by (17)) but is also included in $t_{A}$ (as required by (17)), this gives the sense of the "continued relevance" of that eventuality at speech/evaluation time. This configuration, represented by $t_{\mathrm{E}}$ in Figure 7 , may be interpreted as implying either that the result state of the eventuality continues to hold at speech/evaluation time (resultative perfect reading) or that its consequent state does (experiential perfect reading), the choice between the two being based on various factors, including pragmatic ones, whose details do not concern us here (factors such as context, predicate type, usage conventions in competition with other forms, and so on).

The relation $t_{E} \leq t_{0}$ in (17) requires only that $t_{E}$ at least partially precede $t_{0}$. Because this precedence needs only to be partial, (17) permits a relation such that $t_{\mathrm{E}}$ properly includes $\mathrm{t}_{0}$. I take cases of this sort to give rise to the stative perfect use of the Aorist of the type seen in (6) above (i.e., $t_{e} \supset t_{0}$, where the eventuality $e$ is a state predicate), which is represented by $\mathrm{t}_{\mathrm{E}}{ }^{\prime}$ in Figure 7 . In this use, the state expressed by the Aorist is "ongoing" at speech/evaluation time in that its runtime includes that of the speech time or some contextually salient "past-shifted" evaluation time (cf. Appendix § A.1.1). On this reading of perfect aspect cf. Kiparsky 2002: 120-121. ${ }^{45}$

Crucially, (17) excludes the complexive reading, such that eventuality time and assertion time must not be coextensive $\left(t_{E} \neq t_{A}\right)$. Like the complexive reading, the universal perfect reading is also practically ruled out at this stage by the requirement of $(17)$ that eventuality time $\left(t_{\mathrm{E}}\right)$ be properly included in assertion time $\left(t_{A}\right)$, since the two intervals must be coextensive (or nearly so) in order to give rise to the universal perfect reading (i.e., $\left.t_{E}=t_{A} \wedge t_{A} \supset t_{0}\right) \cdot{ }^{46}$ As noted above

45 Condoravdi \& Deo's (2014: 28o-281) treatment of Sanskrit -tá- as not only an aspectual operator but also a lexical operator accounts nicely for its "purely stative" use (type 'The cave is hidden by foliage'). However, it is not clear to me how such an analysis might apply to other languages whose perfect(ive) morphology has no obvious origin as a "lexical stativizer," as we find in Greek (Aorist and Perfect) or Russian (cf. Comrie 1976: 58). I set aside the intriguing details (and mysteries) of this "purely stative" reading for future research, content here simply to allow for its possibility, such that the eventuality time interval is permitted to overlap with the speech time. Note that the speaker does not necessarily commit to the state ending even though it is included in $t_{A}$, since nothing actually requires that $t_{A}$ have an upper limit, and so $t_{A}$ can in principle extend indefinitely into the future, which in the case of the present stative interpretation is reasonable, since a speaker has no definite knowledge about the future from the perspective of the present.

46 Of course, the universal reading of the Present indicative (cf. Smyth 1956: 422-423) is available at all stages of Greek (and is consistently the most common strategy for its expression), since the Present not only allows $t_{E}$ and $t_{A}$ to be coextensive but also for $t_{E}$ 
and discussed in the appendix (§ A.1.5 and § A.1.9), both of these readings are found extremely marginally in Archaic Greek. I formulate the denotation of the Aorist in (17) so as to regularly exclude these readings (but, with a somewhat different treatment of the universal reading, see now Hollenbaugh 2021: § 4.5). However, under certain syntactic or pragmatic conditions, it seems that these readings (or, at least, readings resembling these ones) could occasionally arise even at this early stage. This is unproblematic, given that a basic assumption of grammaticalization adopted in this analysis is that an interpretation that is irregularly associated with some morphological category (such as the Aorist) only when triggered by an especially salient context (syntactic and/or discursive) at one stage of a language is often reinterpreted as part of the notional content expressed by that morphological category at a later stage of the same language. So, if we find that the Aorist at the Classical stage regularly attests complexive uses (as we do), it is assumed that its association with such interpretations must have come from somewhere, in order to have been available for reinterpretation as part of the notional content of the Aorist in the first place. In this way, I take grammatical "leakage" at one stage (i.e., contextually driven exceptional interpretations of a form) to give rise to grammaticality at a later stage (cf. Deo 2015a for discussion of how grammaticalization may proceed).

The futurate use of the Aorist is restricted by the requirement in (17) that $t_{\mathrm{F}}$ $\leq t_{0}$, such that $t_{A}$ (which includes $t_{E}$ ) cannot follow the evaluation time (future tense being typically defined as $\left.t_{0}<t_{A}\right)$. This is desirable, since examples of futurate Aorists at the Archaic stage are few and isolated (Wackernagel 19261928 [2009]: 228-229; cf. Appendix § A.1.12, (A24) and (A25)). However, the few occurrences of futurate Aorists that we do find in Homer may be explained as "future shifted", whereby $t_{0}$ is located not at speech time but at some point after speech time, and thus, under particular pragmatic conditions, $\mathrm{t}_{\mathrm{A}}$ (which includes $\mathrm{t}_{\mathrm{E}}$ ) may be located in the future with respect to speech time (cf. discussion in Appendix § A.1.12). Because the futurate reading is licensed only under special circumstances, all of the Homeric examples occur in a context of some salient future reference point, expressed by a verb in the Future tense.

The relation $\mathrm{t}_{\mathrm{E}} \leq \mathrm{t}_{0}$ additionally rules out the performative/reportive reading for the Aorist at this stage. Following Bary (2012) and Lloyd (1999), I take the performative/reportive reading of a perfective gram to arise when eventuality time is coextensive with speech time (i.e., $t_{\mathrm{E}}=\mathrm{t}_{0 / \mathrm{s}}$ ). Since the relation $\mathrm{t}_{\mathrm{E}} \leq \mathrm{t}_{0}$ excludes the possibility that the two intervals be coextensive (i.e., $\mathrm{t}_{\mathrm{E}}$ must at least partially precede $\mathrm{t}_{0}$ ), the performative/reportive reading is not available. In these

to include $t_{A}\left(t_{B} \supset t_{A}\right)$, thus allowing the eventuality to begin in the past and extend up through speech time $\left(t_{0}\right)$, provided the right syntactic environment or discourse context. 
ways, (17) captures exactly those readings observed to be regularly available to the Aorist in Archaic Greek, while predicting the absence (or near absence) of those readings which are not regularly available to it at this stage.

\section{Classical Greek Aorist:}

Moving now to Classical Greek, we observe, based on the data summarized in Table 9 in Section 5.2, that the Aorist has acquired complexive as a regular use $\left(t_{\mathrm{E}}=\mathrm{t}_{\mathrm{A}}\right)$ when combined with a state predicate $(e)$. The Aorist is also now regularly compatible with the futurate interpretation $\left(t_{0}<t_{A}\right)$, which is thus of less restricted occurrence at the Classical stage than it had been in Homeric (cf. Wackernagel 1926-1928 [2009]: 228-229). A maximally permissive perfective denotation is accordingly assigned to the Aorist in (18) for the Classical stage, in order to regularly permit these additional uses.

(18) Perfective (Type 1) denotation of the Aorist in Classical Greek $\left[\lambda \mathrm{P} . \lambda \mathrm{t}_{\mathrm{A}} \cdot \exists e\left(\mathbf{t}_{e} \subseteq \mathbf{t}_{\mathrm{A}} \wedge P(e)=1\right)\right]$

For some eventuality $e$, eventuality time $t_{e}$ is included in assertion time $\mathbf{t}_{\boldsymbol{A}}$, and the eventuality description $P$ applied to the eventuality $e$ is true (1).

This constitutes a weakening of the semantics of the Aorist and a shift along the grammaticalization path of (3a) from an "emergent perfective" to a fully grammaticalized perfective (of Type 1 in Table 2 above). In accordance with the grammaticalization path of (3a) being "uniformly generalizing," all readings available to the Aorist at the previous stage remain available to it in Classical Greek. However, the loss of the entailment that eventuality time be properly included in assertion time $\left(t_{\mathrm{E}} \subset \mathrm{t}_{\mathrm{A}}\right)$ means that the two intervals may now be coextensive, thereby permitting the complexive reading of the Aorist (i.e., $t_{\mathrm{E}}=$ $\left.\mathrm{t}_{\mathrm{A}} \wedge \mathrm{t}_{\mathrm{A}}<\mathrm{t}_{0}\right)$.

Admitting the coextension of $t_{\mathrm{E}}$ and $\mathrm{t}_{\mathrm{A}}$ also technically renders the universal perfect reading available to the Aorist ${ }^{47}$ which had not previously been the case, or at least not clearly so. The structural configuration for the universal reading is one in which the eventuality time $\left(t_{\mathrm{E}}\right)$ begins some way back in the past (relative to $t_{0}$ ) and extends all the way up to (or through) speech/evaluation time $\left(t_{0 / s}\right)$, partially overlapping with or including it (i.e., $t_{E} \supseteq t_{0}$ ). This is captured by assuming that, in the universal reading of the Aorist, assertion time and eventuality time are coextensive (or nearly so) and that assertion time

47 On the relationship between universal and complexive readings cross-linguistically, cf. Iatridou et al. 2003: 171. 
includes the speech/evaluation time (i.e., $t_{E}=t_{A} \wedge t_{A} \supset t_{0}$ ). However, in actual usage the universal reading of the Aorist is extremely marginal. This I take to be a blocking effect brought on by its competition with the Perfect (now a fully grammaticalized perfect gram) and the Present indicative, which are strongly preferred to the Aorist in universal contexts (cf. Gerö \& von Stechow 2003: 273274), conforming to a robust cross-linguistic tendency wherein the universal perfect is expressed by means of present or perfect grams rather than perfective ones (cf. Laca 2010), even though perfectives strictly allow (i.e., are not semantically incompatible with) the universal interpretation (cf. Condoravdi \& Deo 2014: 266). Further support for this view comes from the fact that later, at the post-Classical stage, when the Perfect has also grammaticalized to a perfective gram (see §6.1.2), the Aorist is more commonly met with in universal contexts than it had been at the Classical stage (cf. (15) above), being now on roughly equal footing with its nearest semantic competitor, the Perfect.

Further, the loss of the relation $t_{E} \leq t_{0}$ in the denotation of the Aorist means that the eventuality time interval is no longer obliged to be located at least partially before the time of speech or local evaluation, thus allowing the Aorist to have uses that regularly refer to future time. The loss of this relation also allows the $t_{\mathrm{E}}$ and $\mathrm{t}_{0}$ to be coextensive, thereby permitting the performative/reportive use of the Aorist, which had not been available to it at the Archaic stage (cf. above), such that $t_{E}=t_{0 / s} \wedge t_{A} \supseteq t_{0 / s}$. It should be noted, however, that despite the regularity of these non-past uses at this stage, the Aorist continues to be most strongly associated with past tense. This preference for past time reference can be attributed to its perfective aspect, since cross-linguistically perfective aspect is known to correlate with past time reference (Ö. Dahl 1985: 81-84), even if the perfective gram is unmarked for tense (e.g., in Arabic, on which see Comrie 1976: 78-81), due to the fact that, under normal circumstances, the representation of an eventuality as complete will imply that it is completed, insofar as events that are complete are most typically located in the past relative to speech time. Yet past reference is, crucially, only an implicature or correlate of perfective aspect and not an entailment.

Hence, the change in denotation (and corresponding gram type) from Archaic to Classical Greek reflects exactly the changes in usage observed in Section 5.2.

\section{Post-Classical Greek Aorist:}

At the post-Classical stage, we observe, based on the data summarized in Table 10 in Section 5.3, that the stative and performative/reportive uses of the Aorist are no longer attested. The former is likely due to categorical blocking on the part of the Perfect, which continues to allow stative as a use (for "attained 
states"), rather than genuine semantic change (i.e., "strengthening"). ${ }^{48}$ The denotation capturing this is in (19), which is the same as (18) except that it disfavors the inclusion of speech/evaluation time in the eventuality time. Since this probably represents a pragmatic restriction rather than a semantic one, I enclose it in curly braces in (19) to indicate that it is likely not to be part of the truth conditional content of the form. I include it in the denotation of (19) in order to make clear the difference from Classical Greek, though it should be noted that the Aorist has not fundamentally changed in terms of its gram type from the Classical to the post-Classical period (viz. a Type 1 perfective).

(19) Perfective denotation of the Aorist in post-Classical Greek $\left[\lambda\right.$ P. $\left.\lambda \mathrm{t}_{\mathrm{A}} \cdot \exists e\left(\mathbf{t}_{e} \subseteq \mathbf{t}_{\mathrm{A}}\left\{\wedge \mathbf{t}_{e} \nsupseteq \mathbf{t}_{\mathbf{0}}\right\} \wedge P(e)=1\right)\right]$

For some eventuality $e$, eventuality time $t_{e}$ is included in assertion time $t_{A}$, (and the eventuality time does not include the local evaluation time $\mathbf{t}_{\mathbf{0}}$,) and the eventuality description $P$ applied to the eventuality $e$ is true (1).

The universal reading of the Aorist regularly available at this stage is conceived of as a special case of the same relation that gives rise to the resultative and experiential perfect readings $\left(t_{E} \subseteq t_{A} \wedge t_{E} \leq t_{0} \wedge t_{A} \supseteq t_{0}\right)$, with a sufficiently long span of the eventuality time interval. Of course, since $t_{E} \nsupseteq t_{0}$ is not an entailment of (19), the possibility of $t_{\mathrm{E}}$ continuing up through and including $\mathrm{t}_{0}$ is not excluded outright, such that the universal reading is still permitted, as seen in (15) above. As noted earlier, the reason the universal reading of the Aorist is more frequent in post-Classical Greek than Classical is probably because the Perfect has by the post-Classical stage grammaticalized to a perfective gram, meaning that the Aorist and Perfect are on roughly equal footing as candidates for use in universal function.

48 Some support for this view (i.e., usage restricted by blocking rather than semantic change) comes from the fact that Modern Greek has the stative use of the Aorist to certain predicates (for "attained states") (Thumb 1912: 123; Schwyzer-Debrunner: 282). In addition, post-Classical Greek seems to have regular universal perfect uses (cf. (15) above and Appendix § A.3.5), which may involve overlap between $t_{\mathrm{E}}$ and $t_{0}$, so a sufficient denotation of the Aorist at this stage should probably not exclude that possibility. Further, according to Joseph (2000: 324), after the loss of the synthetic Perfect in Medieval Greek until the Early Modern period (early 17 th century CE) the Aorist indicative was re-recruited for use as a present perfect (see also CGMG: 1936-1937, with examples). This implies that the denotation of the Aorist was at no stage incompatible with perfect readings, though its actual use in such contexts fluctuated over time, depending on the state of the rest of the verbal system at any given stage. In Modern Greek, where an analytic Perfect is firmly in place, the Aorist nevertheless remains preferred for conveying the resultative perfect reading, with either past or present reference (Thumb 1912: 125-126, 162-163). 


\section{Modern (and Medieval) Greek Aorist:}

In Modern Greek, the Aorist is described by some as an "unmarked" past tense, neutral in aspect (Hedin 2000: 227-228). If true, this would constitute an even further semantic "weakening" from a perfective to a simple past gram - a typological development hypothesized by Bybee et al. (1994: 92-94) and seen, perhaps, in Modern Hebrew (whose Past tense form corresponds to the Perfective of Biblical Hebrew). However, the fact that the Aorist indicative in Modern Greek can still be used to refer to future time (Thumb 1912: 123) and in the gnomic function (Seiler 1952: 65) is problematic for the view that it is a past tense, as (to a lesser extent) are its persistent stative uses for "attained states" (Thumb 1912). Yet all such readings are entirely expected for a perfective gram (cf. Bybee et al. 1994: 95), ${ }^{49}$ which strongly suggests that the Modern Greek Aorist does not represent a simple past tense but remains a perfective aspect gram (of Type $1, t_{E} \subseteq t_{A}$, seeing as it continues to have complexive as a use (Seiler 1952: 75)). Further support for this view is that, as far as I can determine, the Modern Greek Aorist lacks continuous-state, past habitual, and progressive uses (i.e., canonical "imperfective-like" readings), which might be expected to occur, at least in certain environments, for an aspectually neutral simple past tense (cf. the English Preterite). Therefore, I tentatively assume that the denotation of the Aorist in Medieval and Modern Greek is essentially unchanged from that of the (post-)Classical period, in (18)/(19). As noted in n. 48 above, the increase in the "perfect-like" uses of the Aorist after the post-Classical stage is to be attributed to the loss of the Perfect in Medieval Greek, which could thus no longer block these readings of the Aorist (cf. Joseph 2000: 324).

\subsubsection{Semantics of the Perfect}

By the time of Hellenistic Greek, the Perfect was used "with indicative Aorist meaning” (Schwyzer-Debrunner: 287-288). Gerö \& von Stechow (2003) show that the Perfect follows the typical grammaticalization pathway (cf. (3a) above) from stative-resultative in Homer to perfect in Classical Greek (cf. n. 43 above) to perfective in Hellenistic Greek, discussing its semantics at each stage in detail, which I will not repeat here.

\subsubsection{Semantics of the Imperfect}

As for the Imperfect, I assume that its denotation remains, for the duration of Ancient Greek, that of a simple past, as defined in (20). This constitutes the "neutral aspect," which is maximally permissive in that it allows any relation to

49 Cf. the futurate and performative/reportive interpretations of the Perfective in Slavic (Fortuin 2019: 15, 18-20), among others, such as present stative (Comrie 1976: 58). 
hold between the two temporal parameters, $t_{E}$ and $t_{A}$, so long as one overlaps with (i.e., intersects with or includes) the other.

(20) Simple past denotation of the Imperfect in Ancient Greek (stages I-III) $\left[\lambda\right.$ P. $\left.\lambda \mathrm{t}_{\mathrm{A}} \cdot \exists e\left(\mathbf{t}_{\boldsymbol{e}} \circ \mathbf{t}_{\mathbf{A}} \wedge \mathbf{t}_{\mathbf{A}} \leq \mathbf{t}_{\mathbf{0}} \wedge P(e)=1\right)\right]$

For some eventuality $e$, eventuality time $t_{e}$ overlaps with assertion time $t_{A}$, and the assertion time at least partially precedes the local evaluation time $\mathbf{t}_{0},{ }^{50}$ and the eventuality description $P$ applied to the eventuality $e$ is true (1).

Such a denotation allows for concentrative-sequential and complexive uses, both found abundantly in Homer. Though these uses survive into the Classical period, they become increasingly restricted in the ways described above until by the post-Classical period the Imperfect is dispreferred in these functions. In post-Classical Greek, the Imperfect comes to apply almost exclusively in "canonical" imperfective contexts $\left(t_{\mathrm{B}} \supset \mathrm{t}_{\mathrm{A}}\right)$, only occasionally found in concentrative or complexive uses. That its denotation has not changed, however, is shown by the exceptions to the foregoing generalizations at every stage, which, while increasingly infrequent, are there nonetheless (viz. terminative uses, requiring that $\mathrm{t}_{\mathrm{E}} \subseteq \mathrm{t}_{\mathrm{A}}$ ).

This denotation also permits all the other readings observed for the Imperfect in Section 5 above, including its occasional "perfect-like" readings, such as experiential (cf. n. $5^{\circ}$ above). Futurate uses of the Imperfect are of course ruled out by the requirement that the Imperfect be past in tense $\left(t_{A} \leq t_{0}\right)$. Any other readings not typically expressed by the Imperfect, such as performative/reportive or resultative, are assumed to be categorically blocked by one of the other functional categories, whose denotations are more specific (i.e., "stronger"), namely the Aorist and Perfect (cf. §6.2.1 below). Evidence for this blocking relationship can be seen, for example, from the fact that the Imperfect is generally dispreferred in complexive contexts in the post-Classical period wherever the Aorist can apply. However, verbs that only build Present stems,

$5^{\circ}$ The relation " $\mathrm{t}_{\mathrm{A}}<\mathrm{t}_{0}$ " ('assertion time fully precedes evaluation time') is how past tense is defined, e.g., by E. Dahl (2010: 57-58, 67) and Klein (1994: 124). However, such a denotation would exclude the possibility of present reference, which is commonly available to past tense grams across languages in "perfect-like" readings of the simple past (cf. American English Help, I've fallen and I can't get up! beside the equally felicitous Help, I fell and I can't get up!). I therefore borrow E. Dahl's (2010: 57 ) "partial precedence" relation (s). This allows for $t_{A}$ to overlap with or even include $t_{0}$, as required in present perfect contexts (the present tense being defined as $t_{A} \supseteq t_{0}$ by E. Dahl (2010: 58$)$ and Klein (1994: 124)), so long as $t_{\mathrm{A}}$ at least partially precedes $\mathrm{t}_{0}$. 
such as sixi 'be', regularly use their Imperfect in this function (cf. (14) above). Since the converse is not true-i.e., the Aorist and Perfect do not occur in "imperfective-like" functions no matter what-the denotation of the Imperfect must permit a wider functional range than do the other categories, even though not all of the readings that it is compatible with are realized in actual usage except under special circumstances of type just described.

\subsubsection{Semantic change: Medieval and Modern Greek Imperfect}

Eventually, however, the association of the Imperfect with imperfectivity does appear to become conventionalized as part of its truth-conditional content. At a certain stage, the "neutral aspect" of the Imperfect may not have been recoverable to learners, because the form would have applied almost exclusively in canonical imperfective contexts, being categorically blocked in terminative contexts by the Aorist. Hence, learners could understand its denotation to be that of a Type 1 imperfective gram $\left(t_{E} \supset t_{A}\right)$, based on the available input data. Thus, the Medieval and Modern Greek Imperfect seems to express "canonical" imperfective aspect (cf. CGMG: 1934-1935; Johanson 2000: 95, 98-99), comparable in most respects to the imperfective grams found in the Romance languages (Hedin 2000: 262-263). This development appears to have taken place by the end of what I have been calling the post-Classical period, since no traces of terminative uses (i.e., concentrative or complexive) of the Imperfect are reported for Medieval and Modern Greek. The past imperfective denotation of the Medieval/Modern Greek Imperfect is given in (21).

(21) Imperfective denotation of the Imperfect in Medieval/Modern Greek $\left[\lambda\right.$ P. $\left.\lambda \mathrm{t}_{\mathrm{A}} \cdot \exists e\left(\mathbf{t}_{e} \supset \mathbf{t}_{\mathbf{A}} \wedge \mathbf{t}_{\mathbf{A}} \leq \mathbf{t}_{\mathbf{0}} \wedge P(e)=\mathbf{1}\right)\right]$

For some eventuality $e$, eventuality time $t_{e}$ properly includes assertion time $t_{A}$, and the assertion time at least partially precedes the local evaluation time $\mathbf{t}_{\mathbf{0}}$, and the eventuality description $P$ applied to the eventuality $e$ is true (1).

\subsection{Pragmatics of the Imperfect}

6.2.1 Blocking, partial blocking, and deblocking

The blocking of the non-imperfective readings of the Imperfect by the Aorist in Ancient Greek may be captured in a theoretically rigorous way by applying the methods of Grønn (2007, 2008b) (following Blutner 2000). He adapts a framework known in neo-Gricean paragmatics as a "Horn strategy" (Horn 1984) to the aspectual system of Russian, in order to explain how speakers decide when to use the Perfective and Imperfective as a partial blocking process. When two morphological forms compete for the same semantic space (due to partial over- 


$$
m_{1}: \text { direct } m_{2}: \text { indirect }
$$

\begin{tabular}{cccc}
\hline & $\mathbf{m}_{\mathbf{1}}$ : count & & $\mathbf{m}_{\mathbf{2}}$ : mass \\
\hline $\mathrm{f}_{1}$ : cow & $\checkmark$ & $\leftarrow$ & $x$ \\
& $\uparrow$ & & $\uparrow$ \\
$\mathrm{f}_{2}$ : beef & $x$ & $\leftarrow$ & $\checkmark$ \\
\hline
\end{tabular}

lap in meaning), the more specific form may block the application of the less specific form wherever it can apply (cf. $\S 4.4$ above). This is because the more specific form (in our case the Aorist) is "weakly optimal" in some specialized meaning (here, perfect(ive) aspect).

Recall that the Ancient Greek Imperfect does not entail perfect(ive) aspect, though it is compatible with it, whereas the Aorist does entail perfect(ive) aspect. ${ }^{51}$ We know this because the Imperfect regularly attests readings other than perfect(ive) ones, such as habitual or progressive, while the Aorist does not. Thus, the Imperfect can be said to permit but not guarantee perfect(ive) meaning, while the Aorist entails it. So, when the Imperfect is used, the addressee may infer that, if the speaker had meant to express perfect(ive) aspect, they would have done so with the form that entails the expression of that aspect (viz. the Aorist) rather than merely implicating it with the Imperfect. The Aorist thus comes to block to the application of the Imperfect in contexts that are not canonically imperfective. Because of this blocking, the Imperfect becomes associated with imperfective aspect, inasmuch as its denotation allows for its use in "imperfective-like" contexts while the denotations of the other members of the Greek "past-tense" system do not.

The (partial) blocking process is represented as a $2 \times 2$ game between the speaker's preference for "short, unmarked forms" and the addressee's preference for "stereotypical, unmarked meanings" (Grønn 2007). This can be visualized as in Tables 12 and 13, where vertical arrows represent the speaker's preferences and the horizontal arrows represent the addressee's preferences. To help conceptualize this framework, I give English examples of lexical blocking first, in Tables 12 and 13.

$5^{1}$ The parenthesis on "perfect(ive)" here is meant to capture the various stages of the Aorist, since its denotation changes from more "perfect-like" to more "perfective-like" over time, though it is always compatible with use in both "perfect-like" and "perfective-like" contexts, and tends to block the application of the Imperfect in both- the more so in perfective contexts as it undergoes "aoristic drift" along the lines of ( $3 \mathrm{a})$. 
TABLE 14 Deblocking of cow in a special meaning

\section{$\mathrm{m}_{1}$ : canonical mass $\quad \mathrm{m}_{2}$ : non-canonical mass}

\begin{tabular}{llll}
\hline $\mathrm{f}_{1}$ : beef & $\checkmark$ & $\leftarrow$ & $x$ \\
& $\uparrow$ & & $\uparrow$ \\
$\mathrm{f}_{2}$ : cow & $x$ & $\leftarrow$ & $\checkmark$ \\
\hline
\end{tabular}

In Table 12, the speaker prefers the minimally marked form (viz. kill $\left.\left(\mathrm{f}_{1}\right)\right)$ and the addressee assumes its most stereotypical meaning (viz. direct killing $\left(\mathrm{m}_{1}\right)$ ). When a speaker makes the discourse move to say cause to die instead $\left(\mathrm{f}_{2}\right)$, some less stereotypical meaning (viz. indirect killing $\left(\mathrm{m}_{2}\right)$ ) is assumed because, if the speaker had meant $\mathrm{m}_{1}$, there was a better form available (viz. kill). Applying the algorithm of weakly bidirectional OT (Jäger 2002), the preferences of speaker and addressee conspire to prefer the pair $\left\langle\mathrm{f}_{1}, \mathrm{~m}_{1}\right\rangle$ over the pairs $\left\langle\mathrm{f}_{1}, \mathrm{~m}_{2}\right\rangle$ and $\left\langle\mathrm{f}_{2}, \mathrm{~m}_{1}\right\rangle$. The two losing pairs are removed from the table $(\boldsymbol{x})$ and the optimal pair remains $(\boldsymbol{V})$. Thus, kill is the preferred form with the preferred meaning of direct killing. The remaining pair $\left\langle\mathrm{f}_{2}, \mathrm{~m}_{2}\right\rangle$ survives despite the existence of the optimal pair $\left\langle\mathrm{f}_{1}, \mathrm{~m}_{1}\right\rangle$. This is said to be the "weakly optimal" candidate: "True, there is a better form $\left(f_{1}\right)$, but not given meaning $m_{2}$. Similarly, there is a better meaning $\left(\mathrm{m}_{1}\right)$, but not given form $\mathrm{f}_{2}$ " (Grønn 2007, emphasis original).

Table 13 works similarly - the mass noun beef blocking the application of cow in $\mathrm{m}_{2}$ - except that there are certain contexts in which one might wish to use cow as a mass noun $\left(\mathrm{m}_{2}\right)$, as in (22).

(22) Deblocking: Non-canonical mass noun

Hindus are not allowed to eat cow (ex. Grønn 2008b).

This is called "deblocking" (Grønn 2007, 2008b), whereby the mapping $\left\langle\mathrm{f}_{1}, \mathrm{~m}_{2}\right\rangle$ can arise only if $\mathrm{m}_{2}$ is understood in some unusual sense. Deblocking is captured by assuming a second round of blocking (Grønn 2008b), such that beef is $\mathrm{f}_{1}$, mapped to an $\mathrm{m}_{1}$ "canonical mass noun" while cow $\left(\right.$ now $\mathrm{f}_{2}$ ) is mapped to an $\mathrm{m}_{2}$ "non-canonical mass noun," shown in Table 14.

This framework can be readily extended to tense-aspect systems, being ideally suited to explaining why one form blocks another (synchronically) and, as a consequence, why each form grammaticalizes in the way that it does (diachronically). I represent the pragmatic interactions of the Greek Aorist, Imperfect, and Perfect at various stages of development in the following tables. 
TABLE 15 Blocking of the perfect readings of the Imperfect by the Aorist in Ancient Greek (all stages)

$\mathrm{m}_{1}$ : non-perfect $\quad \mathrm{m}_{2}$ : perfect

\begin{tabular}{llll}
\hline $\mathrm{f}_{1}$ : Imperfect & $\checkmark$ & $\leftarrow$ & $x$ \\
$\mathrm{f}_{2}$ : Aorist & $\uparrow$ & & $\uparrow$ \\
& $x$ & $\leftarrow$ & $\checkmark$ \\
\hline
\end{tabular}

A word about markedness: I have shown that the Imperfect is categorically "unmarked" in terms of its meaning (aspectually neutral) and hence occupies the $\mathrm{m}_{1}$ slot in Table 15. The matter of formal markedness, however, is more complicated. I take the Aorist to be the "marked" form $\left(\mathrm{f}_{2}\right)$ because building an Aorist stem seems to require an extra derivational "step." In the synchronic grammar of Greek (at any given stage), an Aorist stem can be straightforwardly derived from a Present stem by applying productive morphology (most regularly the suffix /-s-/), but the converse is not true: There are no synchronic morphological processes in Greek that will reliably generate a Present stem on the basis of an Aorist. I therefore assume that the Present stem is the unmarked form and the Aorist stem is derived from it by adding morphology to the base (viz. the suffix /-s-/ or sometimes reduplication), thus making the Aorist the more marked member of the pair (but cf. Garrett 2008 for a different view). ${ }^{52}$ The Perfect, in its turn, is transparently a derived stem, employing reduplication in all cases (except oi $\delta \alpha$ ' $k n o w ')$, and is accordingly regarded here as formally marked.

Thus, in Table 15, the Aorist is shown to categorically block the application of the Imperfect in "perfect-like" functions (especially the resultative, a reading that belongs most straightforwardly to the Aorist).

Similarly, Table 16 can be assumed to account for the partial blocking of the perfect readings of the Aorist by the Perfect, under normal circumstances, at the Classical stage (recall that the universal perfect reading is practically excluded by the Aorist's denotation at the Archaic stage). This is because the Perfect has a more specific denotation than the Aorist, being a perfect gram in

$5^{2}$ In the case of root Aorists, thematic Aorists, and suppletive paradigms, neither the Aorist nor the Present stem is straightforwardly derivable from the other, such that taking either form as the "base" would come at the same derivational "cost." Such cases would have to be learned individually, just as English speakers must acquire the exceptional "strong" preterites separately from the forms marked with the productive -ed suffix. 
TABLE 16 Partial blocking of the Aorist by the Perfect in Classical Greek

$m_{1}$ : non-perfect $\quad m_{2}$ : perfect

\begin{tabular}{llll}
\hline $\mathrm{f}_{1}$ : Aorist & $\checkmark$ & $\leftarrow$ & $x$ \\
& $\uparrow$ & & $\uparrow$ \\
$\mathrm{f}_{2}$ : Perfect & $x$ & $\leftarrow$ & $\checkmark$ \\
\hline
\end{tabular}

the Classical period, while the Aorist is more grammaticalized along the path of "aoristic drift" in (3a) above and therefore has a more generalized denotation.

When we find, as we occasionally do, the Imperfect in "perfect-like" contexts - namely resultative, experiential, and universal (cf. §5) — we may understand this in terms of deblocking, along the lines of Table 14 above: A form whose denotation is compatible with a particular function that is blocked under normal circumstances by a more specific form that competes with it may occasionally meet with contexts or lexical items that permit (or force) this ordinarily blocked usage to surface nonetheless. For example, verbs like siri 'be' that only build a Present stem, must of course use their Imperfect even in "perfect-" and "perfective-like" contexts, since there is no better alternative (cf. respectively Il. 13.228-229 and (14a) above).

A somewhat different explanation must be given for why we find sometimes the Aorist and sometimes the Perfect in the experiential, stative-resultative, and (mostly after Homer) universal perfect functions. Though we may appeal to blocking to some extent, and most reliably at the Classical stage (per Table 16), it seems that we still must admit a higher degree of variability or "division of labor" of readings among these morphological categories than blocking alone might predict, especially at the Archaic stage. Descriptively, then, it can be said that when two forms with similar (but non-identical) denotations compete for the same semantic space, all readings are not necessarily divided among the separate forms stably across all utterances, at least not immediately so, and sometimes one form is preferred for one kind of reading while the other is preferred for another kind of reading, in such a way that blocking alone cannot predict. This can be seen at the Archaic stage, where the Aorist is preferred in resultative contexts while the Perfect is preferred in experiential contexts (though not uniformly so). Since both represent varieties of perfect grams (one "late-stage" and one "early-stage"), it seems they have each become specialized for particular readings within the perfect domain. It is not easy to see how blocking or deblocking alone can account for such specialization of 
usage, since this would predict the Perfect to be preferred in all perfect-like uses, given its more specific denotation. The denotations of these two functional categories seem to drift apart somewhat at the Classical stage-now grammaticalized respectively to a perfective and a perfect gram-such that a rather firmer blocking relationship holds between the two (though the Aorist is never uncommon in the resultative function). Yet they converge again at the post-Classical stage, when both forms represent kinds of perfective grams (the Perfect having also undergone "aoristic drift" per (3a)), and they accordingly compete almost equally in all sorts of "perfect-" and "perfective-like" uses, showing a near functional merger, which is matched by the beginnings of a formal merger as well (cf. Browning 1983: 30). The notion of gradation and of gradual regularization of blocking processes is expanded upon in the next subsection (§6.2.2), and variability is discussed further in Section 6.3.1 below.

In a similar way, the Imperfect and Aorist show alternation in sequential narrative contexts at the Archaic stage. Since neither form specifically encodes perfective aspect per se - the Imperfect being neutral in aspect and the Aorist being still an "emergent" perfective (i.e., a late-stage perfect) — neither form is definitively favored in this most characteristic of perfective contexts (cf. n. 10 above). Still, the Aorist is already somewhat preferred to the Imperfect in the concentrative use at the Archaic stage (as shown in Hollenbaugh 2018: 46-47), its denotation at this time being only slightly stronger than that of the perfective gram to which it will later develop. Once this happens, the Aorist comes to be more strongly preferred in the concentrative use, to the near total exclusion of the Imperfect by the post-Classical stage. However, deblocking may apply in cases where the Imperfect surfaces in concentrative contexts at the postClassical stage, often motivated by lexical item (such as siji 'be') or other factors enumerated below ( $\$ 6.2 .2)$.

As for the complexive use, the Imperfect is the favored form at the Archaic stage because it is the only one whose denotation is compatible with such contexts. When the Aorist "weakens" later on, thereby permitting the coextension relation to hold between eventuality time and assertion time, it then has the most specific denotation that is compatible with the complexive reading, and accordingly comes to be preferred in complexive contexts, to the near total exclusion of the Imperfect by the post-Classical stage. Again, deblocking may apply in some cases, such that the Imperfect in the complexive function surfaces even at the post-Classical stage.

The partial blocking of the Imperfect by the Aorist in "perfective-like" or terminative contexts (i.e., concentrative, complexive, etc.) at the post-Classical stage is shown in Table 17. At this stage, the Imperfect is still compatible with 
TABLE 17 Partial blocking of the Imperfect by the Aorist in post-Classical Greek

\begin{tabular}{lccc}
\hline & m $_{\mathbf{1}}$ : non-perfective & & $\mathbf{m}_{\mathbf{2}}$ : perfective \\
\hline $\mathrm{f}_{1}$ : Imperfect & $\checkmark$ & $\leftarrow$ & $\boldsymbol{x}$ \\
& $\uparrow$ & & $\uparrow$ \\
$\mathrm{f}_{2}$ : Aorist & $x$ & $\leftarrow$ & $\checkmark$ \\
\hline
\end{tabular}

terminative uses, as evinced by its attestation in such contexts (which I regard as a deblocking process), but its application in these uses is restricted by the Aorist, which is now more specially suited to terminative contexts, due to its specifically perfective denotation (cf. (19) above), which it did not have at the Archaic stage (cf. (17) above).

Once this blocking process became categorical, it seems that it was eventually no longer recoverable to learners as a synchronic process. It would then have simply been learned that the Imperfect is used for imperfective aspect and the Aorist is used for perfective aspect, without any need for recourse to these kinds of reasoning processes. This assumption of semantic change is confirmed by the general lack of "perfective-like" uses of the Imperfect at the Medieval and Modern stages of Greek.

The observed blocking processes thus adhere to the generalization, adopted at the outset (cf. §4.4), that the form with the more specific denotation tends to block the application of a form with a more general denotation in contexts where either form could, in principle, apply based on the functional range permitted under its semantic denotation alone. In this way, the Imperfect comes be restricted over time to specifically imperfective contexts, due not to its expression of "imperfective-like" readings in particular, but rather its mere compatibility with such contexts, where the other "past tense" forms were not permissible (as entailed by their semantics). Even so were the "perfectivelike" uses of the Imperfect—so robust at the Archaic stage — gradually taken over by the Aorist, whose specifically perfective denotation at the Classical and post-Classical stages made it ideally suited to use in terminative functions, in preference to the Imperfect. The gradual nature of this process is the subject of the next subsection, where I also take account of the various factors that seem to have contributed to the use of the Imperfect in terminative contexts even after the Archaic period - frequently so at the Classical stage, and occasionally at the post-Classical stage. 
6.2.2 Development of blocking over time: from partial to categorical Since the partial blocking described above is a reasoning process that applies synchronically, the blocking does not necessarily become categorical right away. The specific imperfective uses associated with the Imperfect do not become conventionalized and associated with its truth-conditional content immediately. Rather, the association builds gradually over a long period of time. This lag in grammaticalization is due to various factors that favor or require the use of the Imperfect in contexts where one might ordinarily expect a perfective, even after the Archaic stage. As discussed above, the surfacing of the less specific form in a context that ordinarily calls for the more specific form is typically attributed to deblocking (Grønn 2008b). Aside from lexical factors discussed in Section 6.3.1 below, some factors contributing to the use of the Imperfect in terminative functions are listed as follows. The first two have to do with deblocking $((\mathrm{A})-(\mathrm{B}))$; the third with the notion of partial blocking as being sensitive to predicate type (C). I expand on the notion of non-culmination (B) in Section 6.3.2 below.

(A) Avoidance of potential ambiguity brought on by the Aorist: The Imperfect is preferred in concentrative contexts in order to avoid potential ambiguity that would arise from using the Aorist, since the Aorist is commonly associated with resultative and counter-sequential interpretations, while the Imperfect is not (cf. Altshuler 2014: 765-770 and n. 57 below) ${ }^{53}$ Wherever a speaker wishes to rule out a resultative or countersequential interpretation that could arise from use of the Aorist, the Imperfect is available for use instead, thereby clarifying that a plain concentrative reading is intended (assuming the context is not conducive to progressive, habitual, or other "imperfective-like" interpretations).

(B) Non-culmination: The Imperfect surfaces in sequential narration when the event ceases to develop but does not necessarily culminate (preferred under certain QUD s, ${ }^{54} \mathrm{cf}$. $\S 6.3 .2$ and $\left.\S 5.5\right)$.

(C) Distribution by situation type: In Classical Greek, the use of the Imperfect in the complexive and inceptive functions is only partially blocked

53 Delbrück (1879: 103-104) compares the situation to North German (followed in Hollen-

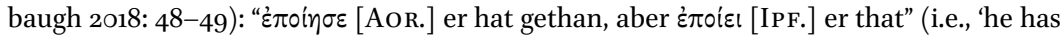
done' vs. 'he did'). This also resembles the have-Perfect and simple Preterite distinction in English (has done vs. did). The Greek Aorist thus often leaves open the possibility of a resultative meaning undesirable in plain narration, whereas the Imperfect lacks this ambiguity.

54 QUD is a term in pragmatics that refers to the "question under discussion" in a given discourse. Different QUDs, whether implied or stated, will elicit different kinds of responses from speakers. 
TABLE 18 Partial blocking of the complexive/inceptive uses of the Ipf. by the Aor. in Classical Greek

$\mathrm{m}_{1}$ : complexive non-state $\quad \mathrm{m}_{2}$ : complexive state

$\begin{array}{llll}\mathrm{f}_{1} \text { : Imperfect } & \checkmark & \leftarrow & x \\ \mathrm{f}_{2} \text { : Aorist } & \uparrow & \uparrow \\ \end{array}$

by the Aorist, which has these readings only when built to state predicates (cf. Hollenbaugh 202ob), while the Imperfect has them elsewhere. Although we do find the Imperfect used for some state predicates in these functions (being the "elsewhere" case), the Aorist is strongly preferred for state predicates in this usage, and there is little overlap in the set of lexical items that belong to the Aorist in this use vs. those of the Imperfect (cf. §5.2). This partial blocking relationship is represented in Table 18.

\subsection{Exploring variability: paradigms and the role of partitive operators}

6.3.1 Variation and paradigmatic limitations: Present vs. Aorist stems As Wackernagel (1926-1928 [2009]: 222) observes, "we are absolutely not entitled to expect that every Greek verb is, in schoolbook terms, fully conjugated." Langslow (id.) in his footnote to this remark points out that "standard, predictable conjugation" is emergent within the history of Greek, arising between Homer and Attic (Classical). Still, there are several verbs that do not conjugate

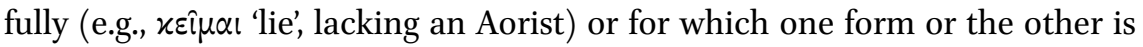
unexpectedly rare (e.g., frequent Ipf. $\varepsilon^{\prime} \varepsilon^{\prime} \lambda \varepsilon v \varepsilon$ beside rare Aorist $\dot{\varepsilon} \chi \dot{\varepsilon} \lambda \varepsilon v \sigma \varepsilon$, both concentrative 'ordered'). 55

Besides paradigmatic and lexical restrictions, there does appear to be some degree of just plain alternation, which could be called "free" variation (cf. Wackernagel quote above in §1.1). Consider (23), which has two infinitives (inf.) to the same verb in the same kind of context, both having a complexive interpretation, the first being Aorist, the second being Present. ${ }^{56}$

55 For examples and discussion see Wackernagel 1926-1928 [2009]: 222-224, 235-236.

56 Cf. (5) above for a similar example with the Aorist and Imperfect. Jacobsohn's (1933: 305) example of the Imperfect $\dot{\varepsilon} \beta \alpha \sigma i \lambda \varepsilon v \varepsilon$ with हैं $\eta$ 'reigned for X years' is in fact never attested (confirmed by a $T L G$ search), though the Aorist indicative is common in this meaning after Homer (cf. (9) above). For an example with the (present-referring) Aorist and Present 
(23) Aorist and Present infinitives in the complexive use

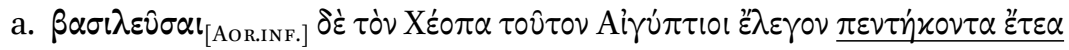
(Hdt. 2.127.1).

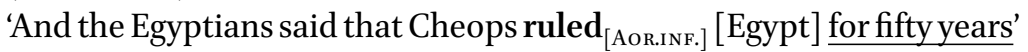
(ex. Basset 2009: 215).

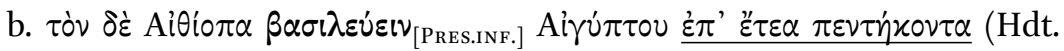
2.137.2).

'And [they said that] the Ethiopian $\operatorname{ruled}_{[\mathrm{PrES.INF}]}$ Egypt for fifty years (ex. Basset 2009: 217').

(24) shows Homeric examples of single, momentary events of 'placing' (concentrative use). The first employs the Imperfect, the second the Aorist. As (24a) demonstrates, coordination of an Imperfect with an Aorist is not uncommon.

(24) Imperfect and Aorist of $\tau i \theta \eta \mu$ 'put, place' in the concentrative use

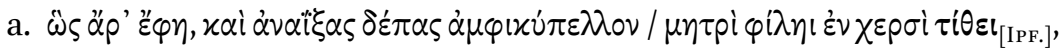

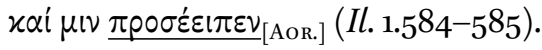

'Thus he spoke, and having sprung up he put [IPF.] $_{\text {. }}$ the double-sided cup in his dear mother's hands, and he said ${ }_{[\text {AOR.] }}$ to her' (cf. similarly Il. 1.446-447).

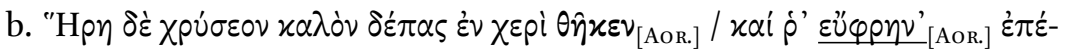
$\varepsilon \sigma \sigma \mathrm{l}($ Il. 24.101-102).

'And Hera put ${ }_{[\mathrm{AOR} .]}$ in her hand a fair golden cup, and spoke words of cheer $_{[\text {Aов. }]}{ }^{57}$

indicative (viz. Soph. Aj. 270), see Wackernagel 1926-1928 [2009]: 226. In (23) the Aorist infinitive marks culmination (the story continues with his death and succession by his brother), while the Present infinitive might not (the story continues with his deeds as ruler). However, this is not true of all such examples (cf. (24) below), and Basset (2009: 213, 217-219) concludes that the exact opposite is true generally (i.e., the Aorist establishes a frame in which other events fall, while the Imperfect/Present list individual events; with a similar point see Wackernagel 1926-1928 [2009]: 234).

57 Cf. similarly Il. 18.614-616, 21.145, 23.750. Most often, though, the Aorist to this root is reserved for one of the following uses: resultative (Il. 6.357, 23.333), counter-sequential (Il. 1.55, 8.324), pluractional (Il. 1.2, 9.547), factitive (Il. 2.482, 12.399, 23.263, 269, 24.538). By contrast, the Imperfect is typically used in sequential narration or plain concentrative use. On this pervasive distribution of Aorist and Imperfect to the same verb, see Delbrück 1879: 103-106 and cf. §1.1. 
There does not seem to be any difference between the two acts of placing in (24): Both seem to be characterized as complete in the past and both seem to have culminated.

Given two forms with overlapping semantics, it is entirely reasonable that there should be some degree of "speaker choice" or "interchangeability" of this sort, whereby two different forms are used in virtually identical contexts. The benefit of the analysis developed here is that it makes correct predictions about where we should expect to find such formal alternations and where we should not. In sequential narration, for instance, we expect alternation between the Aorist and Imperfect at the Archaic stage; under the scope of vôv 'now', however, we typically expect the Aorist. Still, the notion of culmination vs. nonculmination described in the next subsection (\$6.3.2) is invoked to account for many occurrences of the Imperfect in terminative contexts after Homer (e.g., (5) above). Examples like (24), where both the Aorist and the Imperfect seem to characterize events as culminated, may perhaps be understood in terms of entailment vs. implicature: The Aorist entails culmination, while the Imperfect merely implicates it.

\subsubsection{Partitive operators: culminating vs. ceasing to develop}

It remains to explain why, particularly in Classical Greek, when the Aorist had fully grammaticalized to a perfective gram, we still find the Imperfect used quite commonly in terminative contexts, such as sequential narration. Given what has been said so far about blocking, we might expect the Aorist to block the Imperfect in all such contexts after the Archaic stage. I have said above that indeed the Aorist does begin to block the Imperfect in terminative contexts at the Classical stage, but we still need some way to explain how the Imperfect can apply with such frequency in these kinds of contexts despite its blocking relationship with the Aorist (i.e., what licenses its frequent "deblocking"), until the blocking of its terminative readings by the Aorist approaches being categorical within the post-Classical period.

The answer, in my view, has to do with the notion of culmination of an eventuality vs. its merely ceasing to develop, as discussed by Altshuler (2014: 738, 747-750). Culmination seems to be entailed by the Aorist (cf. English ate the cookie up), whereas the Imperfect in terminative contexts only requires that an event ceased to develop any further but did not necessarily culminate (cf. ate some of the cookie). Wherever culmination is considered too strong an entailment for the speaker's intended meaning or the context in which the utterance occurs (i.e., under what QUD it occurs; cf. n. 54 above), the Imperfect is available for use instead. Thus, the Imperfect continues to be used in terminative contexts, to which it remains semantically just as well suited as the Aorist, and 
is favored when the speaker does not want to commit to the culmination of the eventuality in question. Still, the Aorist eventually comes to be the default form in such contexts (post-Classical), due to the blocking relationship it has with the Imperfect (described above in §6.2.1), which applies under normal circumstances and is strengthened as time goes on.

Wackernagel (1926-1928 [2009]: 233-234) notes that in archaic (and later

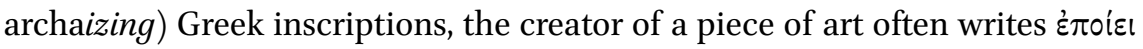

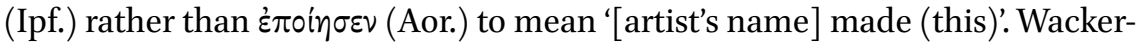
nagel claims that the former is used to mean 'so-and-so worked on/did work on this' (Imperfect, partitive) vs. 'so-and-so has produced/is the author of this' (Aorist, resultative). The Imperfect seems to assert that "at least some $\mathrm{X}$ happened." It could be that all $\mathrm{X}$ happened, or it could be that only some $\mathrm{X}$ happened, within the relevant assertion time interval. Just as the word some in English is ambiguous between "only some" and "not none," the Greek Imperfect is semantically ambiguous between the interpretation that some $(\exists)$ or all $(\forall)$ of a given eventuality takes place within a given assertion time. By contrast, a "canonical" general imperfective of the Romance or Semitic type (Type 1) entails that not all $(\neg \forall)$ of the eventuality falls within the salient assertion time (i.e., "only some"). When the Ancient Greek Imperfect receives the interpretation (as determined by context and predicate type) that all of $t_{\mathrm{F}}$ falls within $t_{A}$ (i.e., terminative), there is no evidence to suggest that it entails culmination of the eventuality. Therefore, I regard the Ancient Greek Imperfect as being compatible with interpretations that involve a cessation of development but not necessarily culmination (though it may, of course, implicate culmination).

The difference between "an event that culminated and an event that ceased to develop further" is discussed by Altshuler (2014: 738, 747-750) and is illustrated by an example like (25).

\section{(25) Mary ate the cookie, \#but she did not finish it.}

While (25) is illicit in English with the simple past, there are a number of languages whose perfective (or neutral) aspect grams allow such non-culmination of the event, even while allowing or requiring that the event has ceased to develop any further. In such languages (e.g., Hindi, Tunisian Arabic), a sentence like (25) with the perfective would mean that Mary has stopped eating the cookie, she's had enough, but not necessarily that the cookie is all gone. By contrast, languages like Russian or Modern Greek (or English), whose perfective (or neutral) aspect grams entail culmination, require that the cookie have been fully consumed (or else a different form of the verb would be used). 
It is difficult to establish definitively that the Aorist indicative in Ancient Greek entails culmination, though Wackernagel (1926-1928 [2009]: 235) certainly defines the Aorist in such terms (cf. §1.1): "The most that we can say, if we wish to draw a distinction between the [aorist and imperfect], is that occasionally the aorist denotes more the culmination of a series of actions or processes, while their actual performance is expressed in the imperfect" (emphasis added). ${ }^{58}$ Yet there is also no evidence to suppose that it represents a partitive operator. The egressive reading, peculiar to the Aorist (Gildersleeve \& Miller 1900: 94 "Aorist of attainment"), provides one strong piece of evidence to suggest that the Aorist entails culmination while the Imperfect does not. The Imperfect in (26) is plainly partitive, in the sense that it designates a VP-event stage (per Altshuler 2014: 738).

(26) Aorist egressive for $\alpha \gamma \omega v i \zeta o \mu \alpha \iota$ 'contend for a prize' (accomplishment predicate)

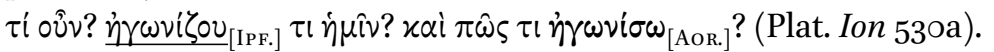

'So what (of it)? Pray tell, did you do some competing ${ }_{[\text {[PF. }}$ ? And how did you compete ${ }_{[\mathrm{AOR} .]}$ ?'

[i.e., 'Did you participate in the contest, and (if so) how did you finish up or place in it?']

The egressive use is also found in Russian, which Altshuler (2014: 766) concludes has a perfective gram that entails culmination (called Perfective (Pfv.)). The past Imperfective (Ipfv.) verbs in (27) are conative.

(27) Russian Perfective, egressive use (accomplishment predicates)

a. On mnogo delal ${ }_{[\mathrm{IPFv}]}$, no malo sdelal ${ }_{[\mathrm{PFv}]}$.

'He did (i.e., undertook) ${ }_{[\mathrm{IPFv} .]}$ a lot but did (i.e., accomplished) $\left.)_{[\mathrm{PFv} .]}\right]$ ittle' (ex. Comrie 1976: 113).

58 On the other hand, Purdie (1898: 67-68) maintains that the Greek Aorist cannot be equated with the Russian Perfective due to the latter's obligatory culmination effects and lack of complexive ("constative") use. The inceptive reading would seem to speak against regarding culmination as an entailment of the Greek Aorist, but this can be dealt with in ways that are not incompatible with such a semantics (see Bary \& Egg 2012 and Hollenbaugh 202ob). The stative use of the Aorist at the Archaic stage, in which a state is characterized as ongoing at evaluation time, may speak against assuming a culmination entailment for the Aorist until the Classical period, though it is difficult to be certain of this given the nature of the evidence. Some of the other readings of the Aorist (e.g., universal) may require further explanation to understand in what way they (can) fall out from a culmination entailment. 
b. On dolgo ugovariva $l_{[\mathrm{IPFv}]}$ menja, no ne ugovoril ${ }_{[\mathrm{PFv} .]}$.

'He was persuading ${ }_{[\mathrm{IPFv}]}$ me for a long time (i.e., he spent a long time trying to persuade $_{[\mathrm{IPFv}]} \mathrm{me}$ ) but didn't (successfully) persuade ${ }_{[\mathrm{PFv}]} \mathrm{me}^{\prime}$ (ex. Comrie 1976: 19).

Further, the Aorist in Modern Greek cannot be used to felicitously translate the sentence in (25), as shown by (28). Here, substituting the Ipf. ह่ $\tau \omega \omega \gamma \varepsilon$ 'was eating' for the Aor. $\varepsilon \varphi \propto \gamma \varepsilon$ 'ate' would render the sentence grammatical. ${ }^{59}$

(28) Culmination entailment of the Modern Greek Aorist

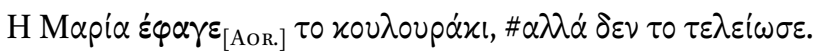

'Mary ate $_{[\mathrm{AOR} .]}$ the cookie, \#but she did not finish it'.

This strongly suggests that the Modern Greek Aorist entails culmination, which offers further support for the assumption that the Aorist in Ancient Greek did so as well. ${ }^{60}$

If this is correct, then the Greek Imperfect and Aorist can be analyzed similarly to how Altshuler (2014) analyzes the Hindi "SV" (simple) Perfective and Russian Imperfective (partitive, non-culminating) vs. the Hindi "CV" (complex) Perfective (non-partitive, culminating). The Classical Greek Aorist can thus be considered a genuine perfective gram, in that it "requires a maximal stage of an event[uality]" (id.: 771), but a perfective of a specific kind, namely one that entails culmination. The Classical Greek Imperfect, however, cannot be a perfective (unlike the Hindi SV Perfective), since it does not require a maximal stage of an eventuality but only requires a stage and hence must be regarded as an "imperfective" of some kind. It is not quite like the Russian Imperfective either, though, in that it is regularly used in sequential narration (at least until post-Classical Greek, cf. n. 37 above), a reading which seems to require the concentrative relation $t_{\mathrm{E}} \subset \mathrm{t}_{\mathrm{A}}$. Thus, while I find Altshuler's (2014) claims extremely attractive, I see no way to avoid falling back on Smith's (1997) and Grønn's (2004) notion of neutral aspect for the Ancient Greek Imperfect $\left(t_{\mathrm{E}} \circ t_{A}\right)$, partitive though it may be (i.e., it is a partitive operator) and "imperfective" in the sense that it does not require a maximal stage. ${ }^{61}$

59 Many thanks to my native-speaker consultants for this information.

6o I have been unable to document and unsuccessful at eliciting a Modern Greek example like the one in (26). Accordingly, we may tentatively conclude that egressive is not a (typical) use of the Modern Greek Aorist. Still, (28) provides sufficient evidence of its culmination entailment.

61 The Greek Imperfect would occupy the same spot in Altshuler's (2014: 765) typology as 
TABLE 19 Deblocking of the terminative uses of the Classical Greek Ipf. in terms of culmination

\section{$\mathrm{m}_{1}$ : canonical pfv. context $\quad \mathrm{m}_{2}$ : non-canonical $\mathrm{pfv}$. context (culminating) (non-culminating)}

$\begin{array}{llll}\mathrm{f}_{1} \text { : Aorist } & \checkmark & \leftarrow & x \\ & \uparrow & & \uparrow \\ \mathrm{f}_{2} \text { : Imperfect } & x & \leftarrow & \checkmark\end{array}$

In Grønn's (2007, 2008b) terms, the Classical Greek situation can be represented as in Table 19 (compare Table 14 above), where the Aorist, being a perfective gram, is preferred in what might be considered the most "canonical" perfective contexts, namely where the eventuality culminates, while the Imperfect is nevertheless "weakly optimal" in less "canonical" perfective contexts, where the eventuality merely ceases to develop. Note that, because Table 19 represents deblocking, the normal markedness ranking seen in Tables $15^{-18}$ is reversed, such that the Aorist is $\mathrm{f}_{1}$ and the Imperfect is $\mathrm{f}_{2}$ (just as cow and beef are reversed in Table 14 as compared to Table 13).

Typologically speaking, then, we may observe that an imperfective gram may permit interpretations under which an event ceases to develop (as emerges within post-Classical Greek), or it may not (as in Modern Greek). Likewise, neutral and perfective aspect-denoting grams may entail culmination or not. The Homeric and Classical Greek Imperfect represents a clear case of a form that denotes non-culminating neutral aspect, while the (post-Homeric) Greek Aorist is a form that denotes culminating perfective aspect. ${ }^{62}$

\section{7}

\section{Conclusion}

Wackernagel (1926-1928 [2009]: 243) says that part of the reason that "the understanding and proper evaluation of the Greek imperfect have been greatly hindered" is its "usual equation" with the Imperfect of Latin, which "is palpa-

the Russian Imperfective, yet it differs in at least one crucial respect: its use to sequence events in past narration. Therefore, the addition of a category to the typology is required, namely "neutral aspect."

62 To complete the typology, culminating neutral aspect is instantiated by the English Preterite, while non-culminating perfective aspect is instantiated by the Hindi "SV" Perfective. 
bly more constrained" (i.e., something like the general imperfectives of modern Romance). While we abandon this equation, at least until post-Classical Greek, it is important to keep in mind that the Greek Imperfect is a moving target. Any "proper evaluation" of it will accommodate this fact. I have therefore tried to treat the Imperfect with as little reverence for its name as possible, governed in my analysis of it only by attested usage. I hope thereby to have shown that:

- The Imperfect did not entail imperfective aspect (defined as $t_{E} \supseteq t_{A}$ ) at any stage of Ancient Greek.

- The trend towards imperfectivity has less to do with semantic change than it does with pragmatic restriction by means of various pressures from other functional categories within the verbal system, eventually resulting in categorical blocking of the terminative uses of the Imperfect by the Aorist (and to some extent the Perfect before its demise).

- In the Archaic period, there was a high degree of variability between the Aorist and Imperfect in the concentrative function, and the Imperfect was the preferred form in the complexive function.

- In the Classical period, the Imperfect continues to be used in terminative contexts, partly because it characterizes an event as ceasing to develop, while the Aorist entails its culmination, and it is often desirable not to have to commit to the culmination of an event in ordinary discourse. By the postClassical period, however, the Aorist is preferred in terminative uses generally.

- The Aorist undergoes semantic change along the "perfective cline" (3a) and consequently restricts the application of the Imperfect primarily to "imperfective-like" uses by the post-Classical stage due to categorical blocking. The Imperfect was then reinterpreted as imperfective in denotation, thereby accomplishing semantic change.

- The observed changes were by no means abrupt and were never entirely without exception (up to the present day), even allowing a certain degree of "free" variation and variation from author to author.

- In the face of alternation between different morphological categories found in nearly identical discourse contexts, the advantage of this analysis is that it correctly predicts where variability will and will not occur. The locus of formal alternations between the Aorist and Imperfect, for instance, is predicted on the basis of known areas of semantic overlap among the two forms. Hence, we regularly find both forms in sequential narration but only one or the other in various other contexts (such as counter-sequential or progressive).

With these conclusions in mind, we may now consider applying the same line of inquiry to other languages that have similar verbal systems (cf. Hol- 
lenbaugh 2021, 2018). The most instructive in this respect may be Sanskrit, which, despite having nearly exact formal matches for all the functional categories of the Greek verbal system here considered, nevertheless displays a completely different kind of diachronic development. Its (so-called) "Imperfect," in particular, never regularly expresses imperfective aspect, despite competing with an Aorist and a Perfect, which could, according to the very same principles observed for Greek, have imposed pragmatic restrictions on the Imperfect via categorical blocking. Why two languages with exact formal matches for each of these three verbal categories (Aorist, Imperfect, Perfect/Pluperfect) should be subject to such wildly different kinds of developments over time is an important outstanding question that must await future research on this topic.

\section{Supplementary material}

For reasons of space, supplementary material providing some of the empirical basis for this study is included as an appendix. This material was submitted by the author along with the original manuscript and can be found here: https:// doi.org/10.6o84/mg.figshare.14797866.

\section{Acknowledgments}

A version of this paper was delivered at Formal Diachronic Semantics 4 (FoDS4) at The Ohio State University on 16 November 2019. I wish to thank the organizers of that workshop and all present at my talk, who provided insightful feedback and encouraging remarks. I also wish to thank the editors of the Journal of Greek Linguistics and my two anonymous reviewers for their helpful suggestions that have added much to the clarity and thoroughness of this paper. Final responsibility is, of course, my own.

\section{Nomenclature and technical abbreviations}

$t_{A}$ assertion time: the interval about which some claim is made (i.e., asserted), with respect to which the runtime of the eventuality is said to hold and may be assessed as either true or false.

$t_{0} \quad$ evaluation time (or time of local evaluation): the point or interval of perspective from which a state of affairs is "evaluated" as to its truth or falsity 
and the location of its temporal parameters $\left(t_{E}, t_{A}\right.$, or $\left.t_{S}\right)$ in time relative to one another. These temporal parameters may be situated prior to, at, or after the contextually salient evaluation time. In the default case, speech time $\left(\mathrm{t}_{\mathrm{s}}\right)$ and evaluation time coincide, but the evaluation time may be past or future "shifted" in certain syntactic or discourse contexts (see n. 42).

$t_{B} \quad$ eventuality time: the interval at which the eventuality (state or event) expressed by a verb holds true.

$t_{s}$ speech time (or time of utterance): the point or interval at which the speech act takes place (typically the "now" of the present moment). This may be thought of as a special case of evaluation time $\left(\mathrm{t}_{0}\right)$. Where this term is used (rather than $t_{0}$ or $t_{0 / s}$ ) it is intended that evaluation times other than speech time not be considered.

$t_{0 / s}$ speech time or any other contextually salient evaluation time: This refers to the evaluation time $\left(t_{0}\right)$, whether it coincides with speech time $\left(t_{s}\right)$ or not. Technically speaking, it is not distinct from simple $t_{0}$. It is used in this paper only for the sake of clarity and ease of exposition, particularly in contexts where the default case of speech time is most intuitive but I do not wish to rule out the possibility of past or future shifting (as the term $t_{s}$ would do).

accomp. accomplishments, referring to an eventive situation or predicate type consisting of a preparatory phase and a culmination, such as come or paint a picture.

achiev. achievements, referring to an eventive situation or predicate type consisting of a culmination only, such as arrive or fall asleep.

Aor. Aorist (indicative unless otherwise stated): the name of a functional category in Greek

CF counterfactual or contrary-to-fact use

conc. concentrative reading: the eventuality is characterized as complete in the past with respect to an assertion time interval $\left(t_{A}\right)$ that fully contains (properly includes) the runtime of the eventuality $\left(t_{\mathrm{E}}\right)$, as determined by the local syntactic or discourse context.

cplxv. complexive reading: the eventuality is characterized as complete in the past with respect to an assertion time interval $\left(t_{A}\right)$ that is coextensive with the runtime of the eventuality $\left(t_{\mathrm{E}}\right)$, as determined by the local syntactic or discourse context.

ex. example from

frequ. frequent in occurrence: referring to a reading or set of readings that is commonly attested in association with a particular morphological category at a given linguistic stage. Frequency presupposes regularity and 
indicates that a form is relatively free of pragmatic interaction with other forms in the verbal system (blocking) in a particular usage.

ind. indicative mood (Greek)

inf. infinitive (Greek)

Ipf. Imperfect indicative: the name of a functional category in Greek

Ipfv. Imperfective: the common English name of the imperfective grams in Russian and Arabic (among others)

ipfv. imperfective (aspect, gram type, or gram)

non-transfm. non-transformative, referring to the natural class of "unbounded" situation types (i.e., those without an inherent endpoint), namely states and activities.

Pf. Perfect (indicative unless otherwise stated): the name of a functional category in Greek

pf. "perfect-like" uses - namely the resultative, experiential, stative, and (in some cases) universal readings - are available to a particular form at a given linguistic stage.

Pfv. Perfective: the common English name of the perfective grams in Russian and Arabic (among others)

pfv. perfective (aspect, gram type, or gram)

Plpf. Pluperfect indicative: the name of a functional category in Greek

Pres. Present indicative: the name of a functional category in Greek

reg. regular: referring to a reading or set of readings that is compatible with the denotation of a particular morphological category at a given linguistic stage. Regularity does not necessarily imply frequency of occurrence, as a form can be blocked by other forms in the verbal system preferred in certain contexts for a variety of reasons.

sequ. sequential function: states of affairs characterized as complete in the past are sequenced in narration relative to one or more other complete states of affairs within the local discourse context.

tr. translation by

transfm. transformative, referring to the natural class of "bounded" situation types (i.e., those with an inherent endpoint), namely achievements and accomplishments.

\section{Abbreviations of authors and texts}

Aj. Ajax of Soph.

Hell. Hellenica of Xen.

HH Homeric Hymns (Archaic) 
Il. Iliad of Hom.

Ion Ion of Plat.

Od. Odyssey of Hom.

Or. Orestes of Eur.

SH Shield of Heracles of Ps.-Hes.

Th. Theogony of Hes.

WD Works and Days of Hes.

1 Kings Book of 1 Kings in LXX

2 Chron. Book of 2 Chronicles in LXX

Acts Book of the Acts of the Apostles in NT

Dem. Demosthenes, Speeches (Classical)

Deu. Book of Deuteronomy in LXX

Eur. Euripides (Classical, drama)

Ex. Book of Exodus in LXX

Ezk. Book of Ezekiel in LXX

Ezr. Book of Ezra in LXX

Gen. Book of Genesis in LXX

Hdt. Herodotus, Histories (Classical)

Heb. Book of Hebrews in NT

Hes. Hesiod (Archaic)

Hom. Homer (Archaic)

Jdg. Book of Judges in LXX

Jn. Book of John in NT

Job Book of Job in LXX

LXX Septuagint (post-Classical Koine)

Mk. Book of Mark in NT

Mt. Book of Matthew in NT

Neh. Book of Nehemiah in LXX

NT Greek New Testament (post-Classical Koine)

Pind. Pindar, Odes (late Archaic)

Plat. Plato (Classical)

Plb. Polybius, Histories (post-Classical/Hellenistic)

Plut. Plutarch (post-Classical/Hellenistic)

Ps. Book of Psalms in LXX

Ps.-Hes. Pseudo-Hesiod (Archaic)

Soph. Sophocles (Classical, drama)

Thuc. Thucydides, The Peloponnesian War (Classical)

Xen. Xenophon (Classical) 


\section{Abbreviations of references}

BDF See Blass, Friedrich, Albert Debrunner, \& Robert W. Funk. 1961.

CGMG See Holton, David, Geoffrey Horrocks, Marjolijne Janssen, Io Manolessou, \& Notis Toufexis. 2019.

Kühner-Gerth See Kühner, Raphael \& Bernhard Gerth. 1898.

Perseus under PhiloLogic See Dik, Helma, ed. 2018.

Schwyzer-Debrunner See Schwyzer, Eduard \& Albert Debrunner. 195 o.

TLG See Pantelia, Maria C., ed. 2001-.

\section{References}

Altshuler, Daniel. 2014. A typology of partitive aspectual operators. Natural Language and Linguistic Theory 32: 735-775.

Arche, María J. 2006. Individuals in time: Tense, aspect and the individual/stage distinction. Amsterdam/Philadelphia: John Benjamins.

Arregui, Ana, María Luisa Rivero, \& Andrés Salanova. 2014. Cross-linguistic variation in imperfectivity. Natural Language and Linguistic Theory 32: 307-362.

Bach, Emmon. 1981. On time, tense, and aspect: An essay in English metaphysics. Radical Pragmatics, ed. by P. Cole, 63-81. New York: Academic Press.

Bach, Emmon. 1986. The algebra of events. Linguistics and Philosophy 9: 5-16.

Bary, Corien. 2012. The Ancient Greek tragic aorist revisited. Glotta 88 (4): 31-53.

Bary, Corien \& Markus Egg. 2012. Variety in Ancient Greek aspect interpretation. Linguistics and Philosophy 35: 111-134.

Basset, Louis. 2009. The use of the imperfect to express completed states of affairs: The imperfect as a marker of narrative cohesion. Discourse cohesion in Ancient Greek, ed. by Stéphanie Bakker \& Gerry Wakker, 205-219. Leiden: Brill.

Bianconi, Michele. 2019. The linguistic relationship between Greek and the Anatolian languages. Doctoral Dissertation, University of Oxford.

Blass, Friedrich, Albert Debrunner, \& Robert W. Funk. 1961. A Greek grammar of the New Testament and other early Christian literature. Chicago: University of Chicago Press.

Blutner, Reinhard. 2000. Some aspects of optimality in natural language interpretation. Journal of Semantics 17: 189-216.

Boneh, Nora \& Edit Doron. 2010. Modal and temporal aspects of habituality. Lexical semantics, syntax, and event structure, ed. by Malka Rappaport Hovav, Edit Doron, \& Ivy Sichel, $33^{8-363 . ~ N e w ~ Y o r k: ~ O x f o r d ~ U n i v e r s i t y ~ P r e s s . ~}$

Browning, Robert. 1983. Medieval and Modern Greek. Cambridge: Cambridge University Press. 
Bybee, Joan \& Östen Dahl. 1989. The creation of tense and aspect systems in the languages of the world. Studies in Language 13: 51-103.

Bybee, Joan, Revere Perkins, \& William Pagliuca. 1994. The evolution of grammar: Tense, aspect, and modality in the languages of the world. Chicago: University of Chicago Press.

Chantraine, Pierre. 1953 [2015]. Grammaire homérique, tome II: Syntaxe. 2nd edn. Ed. by Michel Casevitz. Paris: Klincksieck.

Comrie, Bernard. 1976. Aspect. Cambridge: Cambridge University Press.

Condoravdi, Cleo \& Ashwini Deo. 2014. Aspect shifts in Indo-Aryan and trajectories of semantic change. Language change at the syntax-semantics interface, ed. by Chiara Gianollo, Agnes Jäger, \& Doris Penka, 261-291. Berlin: de Gruyter.

Crespo, Emilio. 2014. A rule for the choice of aorist and imperfect. The Greek verb: Morphology, syntax, and semantics (Proceedings of the 8th international meeting on Greek linguistics, Agrigento, October 1-3, 2009), ed. by Annamaria Bartolotta, 71-82. Louvain-la-Neuve: Peeters.

Dahl, Eystein. 2010. Time, tense and aspect in early Vedic grammar. Leiden: Brill.

Dahl, Östen. 1985. Tense and aspect systems. Oxford: Blackwell.

Dahl, Östen. 200o. The tense-aspect systems of European languages in a typological perspective. Tense and aspect in the languages of Europe, ed. by Östen Dahl, 3-25. Berlin: Mouton de Gruyter.

Delbrück, Berthold. 1879. Die Grundlagen der griechischen Syntax. Halle: Verlag der Buchhandlung des Waisenhauses.

Delbrück, Berthold. 1897. Vergleichende Syntax der indogermanischen Sprachen. Vol. 2. Strassburg: Karl J. Trübner.

Demirdache, Hamida \& Myriam Uribe-Etxebarria. 20oo. The primitives of temporal relations. Step by step: Essays on minimalist syntax in honour of Howard Lasnik, ed. by Roger Martin, David Michaels, \& Juan Uriagereka, 157-186. Cambridge, MA: MIT Press.

Denison, David. 1998. Syntax. The Cambridge history of the English language, vol. IV: 1776-1997, ed. by Suzanne Romaine \& Richard M. Hogg, 92-329. Cambridge: Cambridge University Press.

Deo, Ashwini. 2015a. Diachronic semantics. Annual Review of Linguistics 1: 179-197.

Deo, Ashwini. 2015b. The semantic and pragmatic underpinnings of grammaticalization paths: The progressive to imperfective shift. Semantics \& Pragmatics 8 (14): $1-52$.

Dickey, Stephen M. 1997. Parameters of Slavic aspect. Doctoral Dissertation, Indiana University.

Dickey, Stephen M. 200o. Parameters of Slavic aspect: A cognitive approach. Stanford: CSLI Publications.

Dickey, Stephen M. 2015. Parameters of Slavic aspect reconsidered: The east-west aspect 
division from a diachronic perspective. Studies in accentology and Slavic linguistics in honor of Ronald F. Feldstein, ed. by Miriam Shrager, Edna Andrews, George Fowler, \& Steven Franks, 29-45. Bloomington, IN: Slavica Publishers.

Dik, Helma, ed. 2018. Perseus under PhiloLogic. University of Chicago http://perseus .uchicago.edu. Accessed November 2, 2019.

Dowty, David R. 1979. Word meaning and Montague grammar: The semantics of verbs and times in generative semantics and in Montague's PTQ. Dordrecht: Reidel.

Emde Boas, Evert van, Albert Rijksbaron, Luuk Huitink, \& Mathieu de Bakker. 2019. Cambridge grammar of Classical Greek. Cambridge: Cambridge University Press.

Fischer, Olga. 1992. Syntax. The Cambridge history of the English language, vol. II: 1066${ }_{1476}$, ed. by Norman Blake \& Richard M. Hogg, 207-408. Cambridge: Cambridge University Press.

Fortuin, Egbert. 2019. Universality and language-dependency of tense and aspect: Performatives from a crosslinguistic perspective. Linguistic Typology 23 (1):1-58.

Friedrich, Paul. 1974. On aspect theory and Homeric aspect. International Journal of American Linguistics 40: 1-44.

Garrett, Andrew. 2008. Paradigmatic uniformity and markedness. Linguistic universals and language change, ed. by Jeffrey Good, 125-143. Oxford: Oxford University Press.

Gerö, Eva-Carin \& Arnim von Stechow. 2003. Tense in time: The Greek perfect. Words in time: Diachronic semantics from different points of view, ed. by R. Eckardt, K. von Heusinger, \& C. Schwarze, 251-293. Berlin: de Gruyter.

Gildersleeve, Basil Lanneau \& Charles William Emil Miller. 19oo. Syntax of Classical Greek from Homer to Demosthenes. Vol. 1. New York: American Book Company.

Goodwin, William W. 1889. Syntax of the moods and tenses of the Greek verb. 3rd edn. London: Macmillan.

Grønn, Atle. 2004. The semantics and pragmatics of the Russian factual imperfective. Doctoral Dissertation, University of Oslo.

Grønn, Atle. 2007. Horn strategies and optimization in Russian aspect. Proceedings of language, games, and evolution, 1-8. Dublin: ESSLLI workshop.

Grønn, Atle. 2008a. Imperfectivity and complete events. Interdependence of diachronic and synchronic analyses, ed. by Folke Josephson \& Ingmar Söhrman, 149-165. Amsterdam: John Benjamins.

Grønn, Atle. 20o8b. Russian aspect as bidirectional optimization. Studies in formal slavic linguistics, ed. by F. Marusic \& R. Zaucer, 121-137. Linguistik International 19. Frankfurt: Peter Lang.

Haspelmath, Martin. 2010. Comparative concepts and descriptive categories in crosslinguistic studies. Language 86 (3): 663-687.

Hedin, Eva. 200o. The type-referring function of the imperfective. Tense and aspect in the languages of Europe, ed. by Östen Dahl, 227-264. Berlin: Mouton de Gruyter. 
Hermann, Eduard. 1927. Objektive und subjektive aktionsart. Indogermanische Forschungen 45 (1): 207-228.

Hollenbaugh, Ian. 2018. Aspects of the Indo-European Aorist and Imperfect: Re-evaluating the evidence of the Rgveda and Homer and its implications for PIE. IndoEuropean Linguistics 6: 1-68.

Hollenbaugh, Ian. 2020a. Augmented reality: A diachronic pragmatic approach to the development of the IE injunctive and augment. Paper presented at the 39th Annual East Coast Indo-European Conference, Blacksburg, VA. https://ihollenbaugh.files .wordpress.com/2020/12/augmented_reality_a_diachronic_pragmatic.pdf.

Hollenbaugh, Ian. 202ob. Inceptives in Ancient Greek. Proceedings of the 31st annual UCLA Indo-European conference (November 8th-gth, 2019), ed. by David M. Goldstein, Stephanie W. Jamison, \& Brent Vine, 139-159. Bremen: Hempen.

Hollenbaugh, Ian. 2021. Tense and aspect in Indo-European: A usage-based approach to the verbal systems of the Rgveda and Homer. Doctoral Dissertation, University of California, Los Angeles.

Holton, David, Geoffrey Horrocks, Marjolijne Janssen, Io Manolessou, \& Notis Toufexis. 2019. The Cambridge grammar of Medieval and Early Modern Greek, vol. 4: Syntax. Cambridge: Cambridge University Press.

Horn, Laurence R. 1984. Towards a new taxonomy of pragmatic inference: Q-based and R-based implicature. Meaning, form, and use in context: Linguistic applications, ed. by Deborah Schiffrin, 11-42. Washington, D.C.: Georgetown University Press.

Iatridou, Sabine. 200o. The grammatical ingredients of counterfactuality. Linguistic Inquiry 31.2: 231-270.

Iatridou, Sabine, Elena Anagnostopoulou, \& Roumania Izvorski. 2003. Observations about the form and meaning of the perfect. Perfect explorations, ed. by Artemis Alexiadou et al., 153-204. Berlin: Mouton de Gruyter.

Jacobsohn, Hermann. 1933. Aspektfragen. Indogermanische Forschungen $5^{1}$ (1): 292318.

Jäger, Gerhard. 2002. Some notes on the formal properties of bidirectional optimality theory. Journal of Logic, Language and Information 11 (4): 427-451.

Janda, Laura A. 2019. A metaphor in search of a source domain: The categories of Slavic aspect. Cognitive Linguistics 15 (4): 471-527.

Janda, Laura A. \& Antonio Fábregas. 2019. Seeing from without, seeing from within: Aspectual differences between Spanish and Russian. Cognitive Linguistics 30 (4): $687-718$.

Johanson, Lars. 2000. Viewpoint operators in European languages. Tense and aspect in the languages of Europe, ed. by Östen Dahl, 27-187. Berlin: Mouton de Gruyter.

Joseph, Brian D. 20oo. Textual authenticity: Evidence from Medieval Greek. Textual parameters in Ancient languages, ed. by S. Herring, P. van Reenen, \& L. Schoesler, 309-329. Amsterdam:John Benjamins. 
Kiparsky, Paul. 1998. Aspect and event structure in Vedic. Yearbook of South Asian Languages and Linguistics 1998 1: 29-62.

Kiparsky, Paul. 2002. Event structure and the perfect. The construction of meaning, ed. by David I. Beaver, Luis D. Casillas, Martínez, Brady Z. Clark, \& Stefan Kaufmann, 113-135. Stanford, CA: Center for the Study of Language and Information (CSLI).

Klein, Wolfgang. 1994. Time in language. New York: Routledge.

Kratzer, Angelika. 1995. Stage-level and individual-level predicates. The generic book, ed. by Gregory N. Carlson \& Francis Jeffry Pelletier, 125-175. Chicago: The University of Chicago Press.

Krüger, Karl Wilhelm. 1873. Griechische Sprachlehre für Schulen, zweites Heft: Syntax. Berlin: K.W. Krügers Verlagsbuchhandlung.

Kühner, Raphael \& Bernhard Gerth. 1898. Ausführliche Grammatik der griechischen Sprache, Teil 2: Satzlehre, Bd. I. Hannover: Hahnsche Buchhandlung.

Laca, Brenda. 2010. Perfect semantics: How universal are Ibero-American present perfects? Selected proceedings of the 12th hispanic linguistics symposium, ed. by Claudia Borgonovo, Manuel Español-Echevarría, \& Philippe Prévost, 1-16. Somerville, MA: Cascadilla Proceedings Project.

Lloyd, Michael. 1999. The tragic aorist. The Classical Quarterly 49 (1): 24-45.

McCoard, R.W. 1978. The English perfect: Tense choice and pragmatic inferences. Amsterdam: North Holland.

Moens, Marc \& Mark Steedman. 1988. Temporal ontology and temporal reference. Computational Linguistics 14: 15-28.

Napoli, Maria. 2006. Aspect and actionality in Homeric Greek: A contrastive analysis. Milan: Angeli.

Pantelia, Maria C., ed. 2001-. Thesaurus Linguae Graecae ${ }^{\circledR}$ digital library. University of California, Irvine http://stephanus.tlg.uci.edu. Accessed November 2, 2019.

Purdie, Eleanor. 1898. The perfective 'aktionsart' in Polybius. Indogermanische Forschungen 9: 62-153.

Ramchand, Gillian C. 2018. Situations and syntactic structures: Rethinking auxiliaries and order in English. Cambridge, MA: MIT Press.

Reichenbach, Hans. 1947. Elements of symbolic logic. New York: Collier-MacMillan.

Rijksbaron, Albert. 2002. The syntax and semantics of the verb in Classical Greek. Chicago: The University of Chicago Press.

Rijksbaron, Albert. 2019. The discourse function of the imperfect. Form and function in Greek grammar: Linguistic contributions to the study of Greek literature, ed. by Rutger J. Allan, Evert van Emde Boas, \& Luuk Huitink, 6o-79. Leiden: Brill.

Rissanen, Matti. 1999. Syntax. The Cambridge history of the English language, vol. III: 1476-1776, ed. by Roger Lass \& Richard M. Hogg, 187-331. Cambridge: Cambridge University Press. 
Robertson, Archibald Thomas. 1923. A grammar of the Greek New Testament in the light of historical research. New York: George H. Doran.

Ruipérez, Martín Sánchez. 1954. Estructura del sistema de aspectos y tiempos del verbo griego antiguo: Análisis funcional sincrónico. Salamanca: Colegio Trilingüe de la Univ.

Schwyzer, Eduard \& Albert Debrunner. 1950. Griechische Grammatik, Bd. II: Syntax und syntaktische Stilistik. München: C.H. Beck.

Seiler, Hansjakob. 1952. L'aspect et le temps dans le verbe néo-grec. Paris: Les Belles Lettres.

Smith, Carlota S. 1997. The parameter of aspect. 2nd edn. Dordrecht: Kluwer.

Smyth, Herbert Weir. 1956. Greek Grammar. 2nd edn. Cambridge, Mass.: Harvard University Press.

Thumb, Albert. 1912. Handbook of the Modern Greek vernacular: Grammar, texts, glossary. Transl. by S. Angus. Edinburgh: T. \& T. Clark.

Vendler, Zeno. 1957. Verbs and times. The Philosophical Review 66: 143-16o.

von Stechow, Arnim. 1995. On the proper treatment of tense. Proceedings of SALT 5, ed. by Teresa Galloway \& Mandy Simons, $362-386$. Ithaca: Cornell University.

Wackernagel, Jacob. 1926-1928 [20o9]. Lectures on syntax: With special reference to Greek, Latin, and Germanic. Ed. and transl. by David Langslow. Oxford: Oxford University Press.

Wallace, Daniel B. 1996. Greek grammar beyond the basics: An exegetical syntax of the New Testament. Grand Rapids, MI: Zondervan Academic.

Wallace, Daniel B. 2006. The validity of ingressive imperfects in the Greek of the New Testament. https://bible.org/article/validity-ingressive-imperfects-greek-new-testa ment.

Whitney, William Dwight. 1889. A Sanskrit grammar. Leipzig: Breitkoff \& Härtel.

Willi, Andreas. 2018. The origins of the Greek verb. Cambridge: Cambridge University Press. 